\title{
A Simple DGE Model for Inflation Targeting
}

Jaromir Benes, Marta Castello Branco, and David Vavra 



\title{
IMF Working Paper
}

\author{
Middle East and Central Asia Department \\ A Simple DGE Model for Inflation Targeting \\ Prepared by Jaromir Benes, Marta Castello Branco, David Vavra ${ }^{1}$ \\ Authorized for distribution by Marta Castello Branco
}

August 2007

\begin{abstract}
The paper presents a DGE model designed as a core projection tool to support monetary policy in inflation-targeting (IT) emerging market economies. The paper uses a particularly simple and flexible general equilibrium model structure that can be amended to account for various phenomena that often complicate policy analysis in emerging markets, such as persistent trends in relative prices. The model's calibration is intuitive and can draw on the vast experience many countries have with calibrating small 'gap' models of monetary policy transmission. Moreover, the definition of the model's steady state in terms of nominal expenditure ratios, rather than levels of real variables, allows for the easy use of the model in a regular forecast production cycle in an IT central bank. The paper tests the model's properties on recent Turkish data, demonstrating that the main stylized features relevant for monetary policy making are well captured by the model.
\end{abstract}

\section{This Working Paper should not be reported as representing the views of the IMF.}

The views expressed in this Working Paper are those of the authors and do not necessarily represent those of the IMF or IMF policy. Working Papers describe research in progress by the authors and are published to elicit comments and to further debate.

JEL Classification Numbers: E13, E17, E31, E37, E58, E52

Keywords: Inflation Targeting, Monetary Policy Transmission Mechanism, Macroeconomic Models

Author’s E-Mail Address: Jaromir.Benes@,rbnz.govt.nz; mcastellobranco@imf.org; dvavra@imf.org

\footnotetext{
${ }^{1}$ We would like to thank Ahmet Kipici, Hakan Kara, Zelal Kotan, Neslihan Kaya, Tayyar Buyukbasaran, and Fethi Öğünç for help, comments and encouragement.
} 


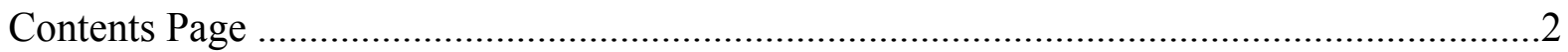

Glossary of Terms and Abbreviations Used in the Figures ...................................................5

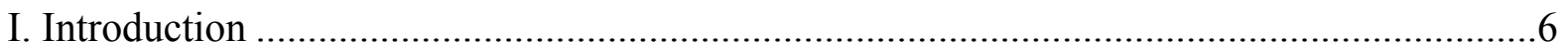

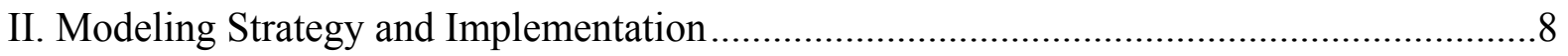

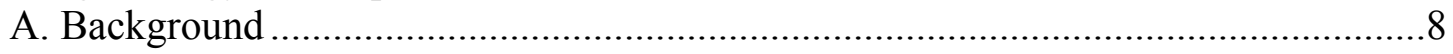

B. A Core Forecasting Model for IT Monetary Policy in an Emerging Market Environment .........................................................................

III. Turkey’s Recent Monetary Experience: Stylized Facts....................................................14

A. Stylized Facts on Long-term Trends ................................................................16

B. Stylized Facts on Business Cycle Fluctuations .......................................................20

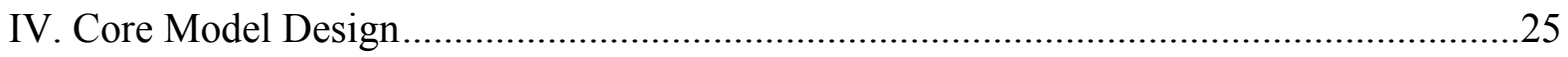

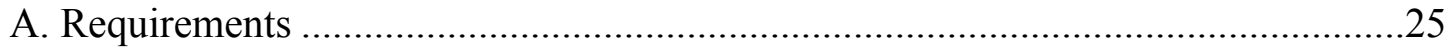

B. Main Model Features …………………………………...................................2

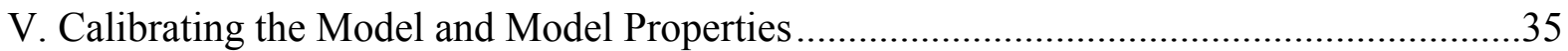

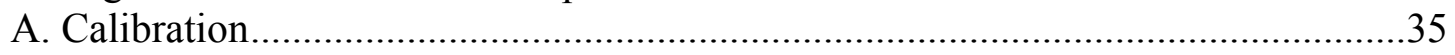

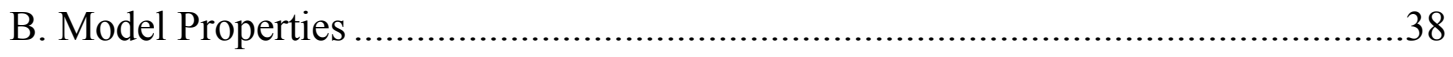

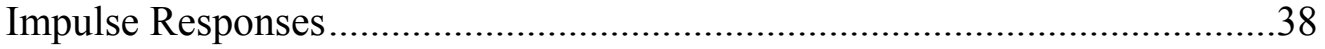

Forecast Error Variance Decomposition...........................................................53

VI. Learning From Recent Turkish Data Using The Model...................................................55

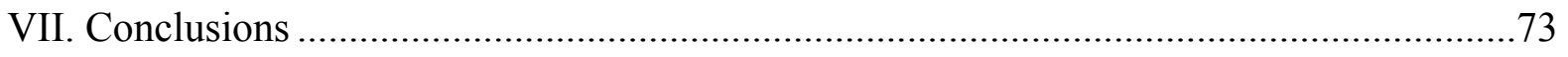

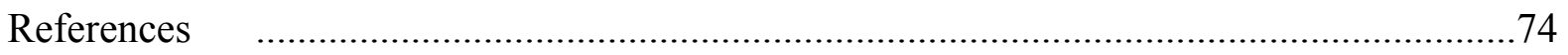

Tables

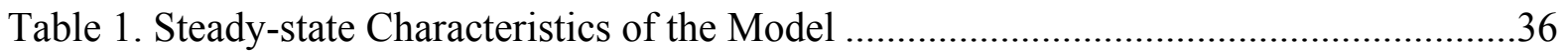

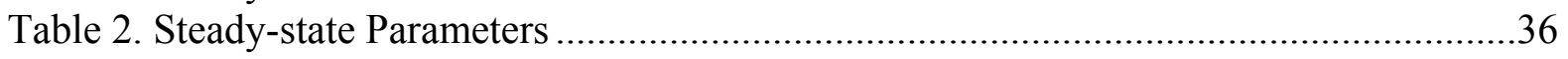

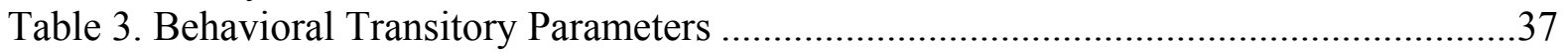

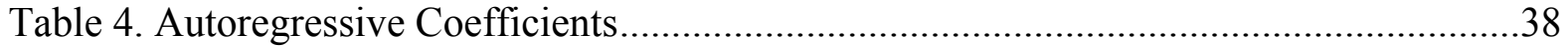

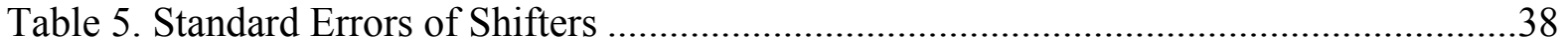

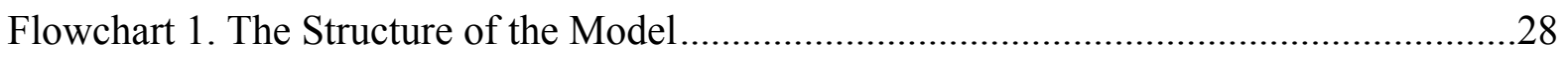


Figures

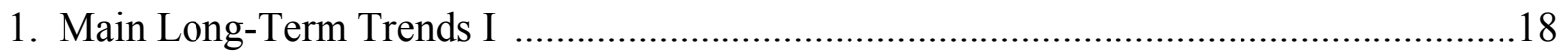

2. Main Long-Term Trends II ................................................................................... 19

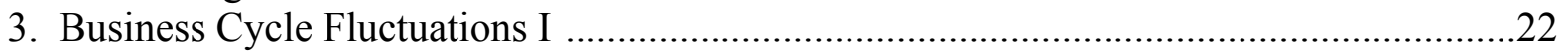

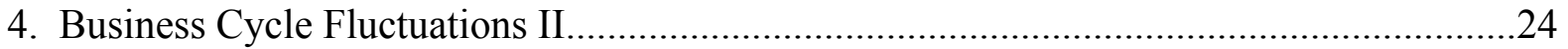

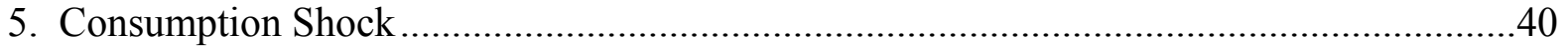

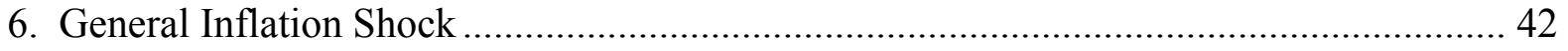

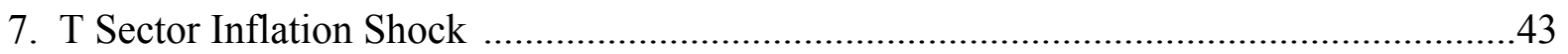

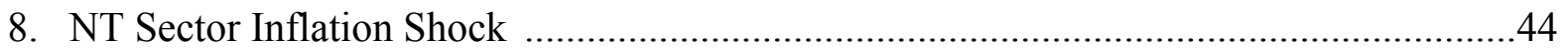

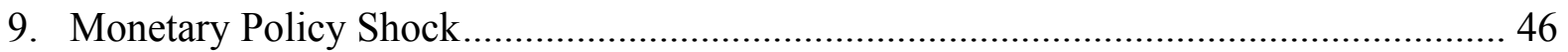

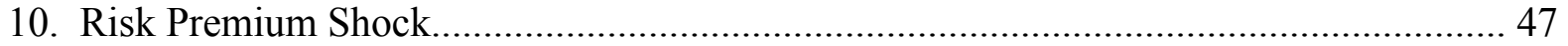

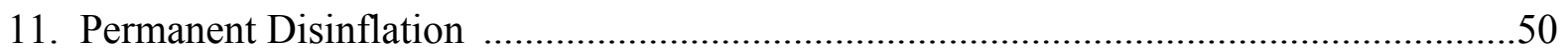

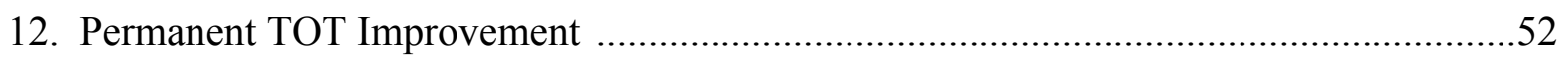

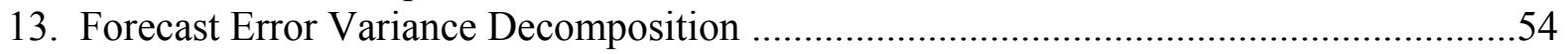

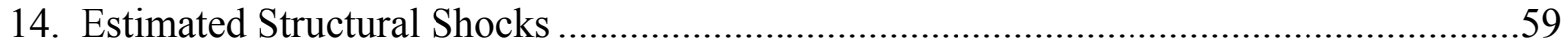

15a. Contributions of the Four Most Important Stochastic Shocks to Observed Data Before the Crisis......................................................................6

15b. Contributions of the Four Most Important Stochastic Shocks to

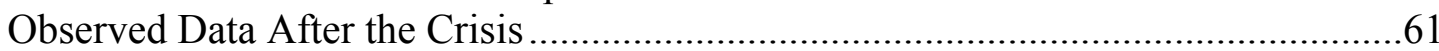

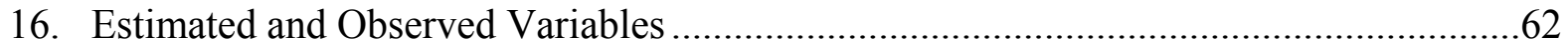

17. Population Standard Deviations.............................................................................64

18. Population Autocorrelation Coefficient ....................................................................66

19. Population Contemporaneous Cross-Correlation Coefficients ....................................67

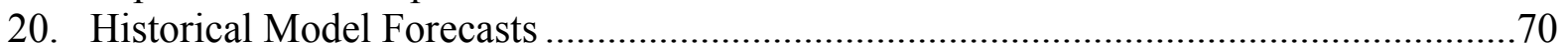

21. Historical Model Forecasts with a Risk Premium Fixed on Observed Values ............................................................................................ 71

22. Historical Model Forecasts with a Risk and Policy Rates Fixed at Observed Value

\section{Boxes}

1. Turkey: From Implicit to Full-Fledged I ................................................................... 15

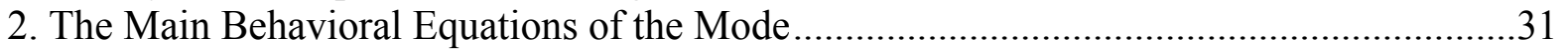

3. Non-tradable and Tradable Inflation Rates in the Reaction Function ........................... 33

\section{Appendices}

I. The Reduced Form Description of the Turkish Data ..................................................76

II. A Small DGE Model of the Turkish Economy: The Economic Foundations....................78 
Appendix Tables

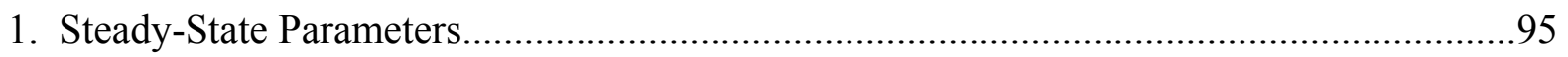

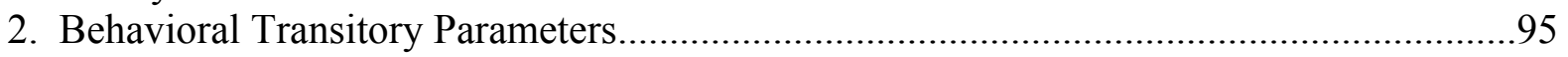

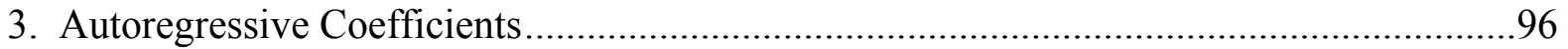

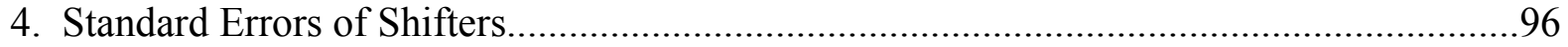

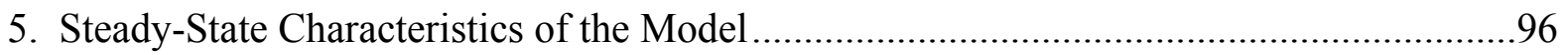




\section{GLOSSARY OF TERMS AND ABbREVIATIONS USED IN THE FigURES}

\begin{tabular}{|l|l|l|}
\hline \multicolumn{1}{|c|}{ Acronym } & \multicolumn{1}{|c|}{ Description } & \multicolumn{1}{c|}{ Source } \\
\hline CPI & Consumer Price Index before the 2004 basket change & CBT \\
\hline CPIt & CPI in Tradable Sector & CBT \\
\hline CPIn & CPI in Non-tradable Sector & CBT \\
\hline C & Household Consumption & CBT, National Accounts \\
\hline G & Government Consumption & CBT, National Accounts \\
\hline J & Investment & CBT, National Accounts \\
\hline X & Exports & CBT, National Accounts \\
\hline M & Imports & CBT, National Accounts \\
\hline Y & GDP & CBT, National Accounts \\
\hline PM & Import Deflator & CBT, National Accounts \\
\hline PX & Export Deflator & CBT, National Accounts \\
\hline PY & GDP Deflator & CBT, National Accounts \\
\hline EMBI+ & Emerging Market Bond Index & JPMorgan \\
\hline CBT Rate & Rates on the main CBT instrument (7 day reverse repo) & CBT \\
\hline TRY/USD & Exchange Rate of a New Turkish Lira per USD & CBT \\
\hline hpg & HP Gap & Own computations \\
\hline qoq & Annualized quarter on quarter change & Own computations \\
\hline yoy & Year-on-year change & Own computations \\
\hline ecd & Consumption Shock & Own computations \\
\hline etarg & Inflation Target Shock & Own computations \\
\hline eprem & Risk Premium Shock & Own computations \\
\hline ean & NT Sector Productivity Shock & Own computations \\
\hline eax & Export Sector Productivity Shock & Own computations \\
\hline eat & T Sector Productivity Shock & Own computations \\
\hline ex & Export Sector Demand Shock & Own computations \\
\hline epn & NT Inflation (cost-push) shock & Own computations \\
\hline ept & T Inflation (cost-push) shock & Own computations \\
\hline emp & Monetary Policy Shock & Own computations \\
\hline eg & Government Shock & Own computations \\
\hline etot & Terms of Trade Shock & Own computations \\
\hline eif & Foreign Interest Rate Shock & Own computations \\
\hline epmf & Foreign Inflation Shock & Own computations \\
\hline ep & NT Inflation (cost-push) shock & Own computations \\
\hline
\end{tabular}




\section{INTRODUCTION}

Structural macroeconomic models have grown in importance as central banks increasingly rely on forecast-based policies in their decision making, and inflation targeting (IT) becomes the dominant approach to monetary policy. These models aim at providing a more structured input to monetary policy making, helping to put together a consistent "story" and to explain the implications of different exogenous shocks and of following different policy rules. ${ }^{2}$ Importantly, they provide a framework for risk assessment.

The recent experience of IT central banks has shown that structural models are important tools to facilitate communication, review past decisions, and encourage learning. The use of models has greatly enhanced the collection and transfer of knowledge between technical staff and policy makers, and between policy makers and the public. Combined with proper documentation of past decisions and data input, the use of models also permits a structured review of past decisions, thus improving central banks' capacity to audit past forecasts and policies. This strengthens accountability and creates the incentive for "getting it better the next time around." The models' structure also provides a useful framework to organize a research agenda.

With the demand for macroeconomic models capable of addressing day-to-day monetary policy issues on the rise, these models have become more sophisticated. Moving away from larger scale econometric models, which are relatively expensive to develop and maintain, many central banks (e.g., in the Czech Republic, Slovakia, Peru, Colombia, to cite a few) have found useful to develop simple, largely calibrated, New-Keynesian models of business cycle fluctuations. These so-called 'gap' models are particularly attractive for their simplicity and ability to facilitate communication within the central bank and to strengthen forecast organization. However, their simplicity and the lack of a rigorous theoretical basis have limited their use, encouraging some central banks to develop more complex forecasting models with microeconomic foundations. In the most recent stage of this process, several central banks have committed large resources to developing Dynamic General Equilibrium (DGE) models that can be used for forecasting purposes.

This paper presents a DGE model designed to support IT monetary policy in emerging market economies. The model embodies the main principles of IT monetary policy, namely that monetary policy and inflation targets provide a nominal anchor for the economy, without affecting real variables in the long term. However, it also encompasses a broad range of other structural characteristics that often complicate modeling in emerging markets, such as permanent shocks to relative prices.

\footnotetext{
${ }^{2}$ For a description of a macro-model based approach to forecasting and monetary policy analysis, see Coats and others (2003) or Berg and Laxton (2006a).
} 
The quarterly projection model is designed as a tool to deal with the basic medium-term features of monetary policy transmission in emerging market economies. It combines the advantages of simple models with the theoretical foundation and insights of more sophisticated general equilibrium models. Its linearized representation is very close to gap models still used in a number of IT central banks as their core projection tools. The model is therefore more straightforward to interpret. At the same time, compared to the gap models, it features more economic variables, basic stock-flow consistency, and is able to address a wider variety of questions with rigor. Furthermore, given its microeconomic underpinnings and its simple structure, it can be easily adapted or expanded, as needed.

The model has been calibrated using Turkish data, and its properties and capacity to address emerging market phenomena are tested against recent developments in Turkey. The Turkish economy has undergone massive structural changes in the past few years, making it a particularly useful candidate for testing the model's adaptability to emerging market conditions. Following the switch to a floating exchange rate regime in 2001, the Central Bank of Turkey (CBT) adopted a new monetary policy framework based on implicit inflation targeting. In view of the successful disinflation achieved under the new framework, at end2004 the CBT announced that full-fledged IT would be introduced at the beginning of 2006. At the same time, the CBT intensified its efforts to develop a forecasting and policy analysis system (FPAS) to support inflation targeting. ${ }^{3}$

The new model can be seen as part of the ongoing agenda for developing theory-based projection models. The CBT has been very active in this regard, and has continued to expand its modeling suite in connection with IT implementation. Following its work on a standard New Keynesian 'gap' projection model, the CBT has started to develop models with more explicit economic foundations. Our model builds on the CBT's modeling agenda and retains many of its features, but organizes them from the perspective of an underlying general equilibrium model. Thinking about the simple gap models as an abbreviation of a fully optimized general equilibrium framework also enables many easy extensions of the simple models, which would be difficult without an underlying theoretical structure.

The model is designed as a projection device and not only as a research tool. Its main objective is to become a core projection model - an important piece of a central bank's forecasting and analytical system - and thus to contribute to improving the decision making process in an IT central bank. The core model deals with the main, basic, medium-term features of the monetary transmission mechanism, and is not expected to produce accurate short-term forecasts. Therefore, IT central banks will continue to rely on a variety of tools and information sources to produce their forecasts. But the main policy message is expected to emerge from the core model - this is crucial to provide medium-term consistency to the projection and to discipline the policy debate.

\footnotetext{
${ }^{3}$ The CBT's efforts to put in place a new policy framework were supported by technical assistance from the IMF since 2000. For details, see Castello-Branco (2007).
} 
The paper is organized as follows. Section II discusses the modeling strategy and implementation, providing a broader perspective to the choice of a DGE model as a core projection tool. Section III describes stylized facts about the transmission mechanism in the Turkish economy, providing the background for measuring the properties of the model. Section IV lays out the core of the model, and examines its properties as responses to shocks. Section V uses the model to examine the recent Turkish monetary policy experience. In Section VI we perform several standard forecasting tasks used frequently when constructing macroeconomic projections. Section VII concludes.

\section{Modeling STRATEGY AND IMPLEMENTATION}

\section{A. Background}

The constraints on the design of a core forecasting model for monetary policy reflect the way these models are used. Core forecasting models assist policy making by helping construct medium-term forecasts that are indispensable in supporting pre-emptive monetary policy, especially in IT central banks. In these central banks, medium-term forecasts focus on which interest rate paths are consistent with achieving pre-set medium-term inflation targets, based on various assumptions regarding variables that are outside monetary policy control.

Undertaking pre-emptive decisions for IT also involves uncertainty and risks. The forecast has to provide for explicit treatment of these risks to allow policy makers to be comfortable in making ex-ante decisions. Such decisions (as well as the forecasts) may always turn out wrong ex-post, as either the forecast or some of its assumptions are unlikely to materialize. The medium-term forecast (often accompanied by a staff policy recommendation) is the single most important input for the policy making process. Producing these forecasts in IT central banks is a very specific process, involving many different techniques and stages (Svensson, 2005; Berg and others, 2006a), which cannot be separated from the policy making process itself.

Core forecasting models can help monetary policy analysis in a distinct way. In particular, they help construct medium-term scenarios by organizing the information processed throughout the forecast, providing medium-term consistency to the various scenarios, and preparing alternative scenarios and risk assessments (Benes and others, 2003). Their role is not to track history, nor to display good forecasting properties; indeed, history is in many respects irrelevant for the future, especially when a monetary regime changes. Forecasting accuracy comes from other elements and tools of the forecasting process, not from the core model alone. Core projection models also help to establish accountability, as regards both communicating policy to the public and the integrity of staff's advice.

The core forecasting model is not the only tool used in forecast production. Normally, there are many other models contributing to the forecasting process, typically targeted at specific questions or specific sectors, usually offering more detail and (sometimes) a more theoretical foundation than the core model could provide - for the reasons discussed above. While researchers working on these specific models have the liberty of choosing the design that fits 
best the question being addressed, forecasters have to process all information in a routine way each forecasting period, not least to ensure backward compatibility and accountability of their forecasts. Although core forecasting models evolve, one model design is effectively in place for several years, changing only in incremental steps until a new design is introduced.

Designing a model that meets these requirements is very different from building models to address specific questions. For example, academic models usually represent the minimum that is required to examine the subject in question, and typically cannot be used to study other issues. On the other hand, forecasting models have to address the policy context of 'all questions,' while often lacking ingredients needed to answer properly any single one. The modelers therefore need to properly balance the detail and development of a model's various sectors and blocks. They also have to be very flexible to allow examination of new issues. While practicality and user-friendliness play little role in academic models, they are important for a core forecasting model builder who has to run a model on 'real time.'

\section{B. A Core Forecasting Model for IT Monetary Policy in an Emerging Market Environment}

There are many constraints in building core projection models for monetary policy in an emerging market economy. On the one hand, emerging market economies typically are undergoing large structural changes that are difficult to model and that (together with a general lack of reliable data) complicate data inference, while reducing its potential for understanding of the future. During a structural change, it is difficult to distinguish signs of an economic cycle from those of permanent long-term shifts, such as a productivity catch-up process, which is necessary for an adequate monetary policy response. On the other hand, the emerging market central banks starting out on the IT road are typically new to modeling and to using models for policy inference, lacking many of the required skills, organizational structure, and processes (Coats and others, 2003).

Despite the constraints, central banks in an emerging market environment need to be able to put in place a forecasting framework quickly, if they are to succeed with their IT strategy. An adequate medium-term forecasting capacity is considered one of the conditions for (and defining features of) successful IT implementation. Models are an important part of that capacity, because medium-term forecasting requires thinking about contingencies and risks, and cannot routinely be done without a model. Although the importance of this condition should not be over-emphasized against other (especially institutional) requirements, many countries have faced serious challenges in the early stages of their IT implementation related to their insufficient forecasting and modeling capacity (Otker-Robe and Vavra, 2007).

Many emerging market central banks have decided to start with very simple medium-term projection models. They need something easy to understand, communicate, and operate in creating forecast scenarios under the typically limited time available. Likewise, their models need to be flexible enough to incorporate judgment coming from experts as well as other 
(satellite) model tools often constructed only to address the particular 'question of the day.' Finally, all what is required from a theoretical perspective is the embodiment of the IT policy paradigm, that is, that monetary policy provides nominal stability for the economy by reacting to shocks, but without affecting real variables in the long term.

The (so-called) first-generation of monetary transmission models have performed very well as core projection devices in many emerging market IT central banks. These are essentially models of cyclical fluctuations (also known as a gap models), solving for the medium-term path of interest rates, exchange rates, output gap, and inflation. ${ }^{4}$ The main advantage of such models is their simplicity: they are easy to learn and use and can therefore serve as transparent communication devices. They can also be extended easily in an ad hoc way to provide more detail, and thus represent a useful starting point for organizing the projection process. They also require minimum data and modeling experience, and are suitable as research tools for many issues.

Such models can only answer directly a limited number of questions, however. Although the gap models embody all theoretical restrictions that are necessary to describe the stabilizing role of monetary policy, they also lack some detail that is often important for practical decision making. For example, the components of GDP are typically not tracked, and the distinction between tradable and non-tradable sectors is not made. In addition, long-run trends are imposed in an ad hoc manner, without reference to important economic fundamentals. Moreover, since there is no stock-flow accounting, certain issues such as investment position, or capital accumulation, cannot be addressed.

These limitations are particularly costly in an emerging market environment. In this case, IT monetary policy faces issues that developed countries faced some time ago, often before the introduction of IT. In particular, monetary policy in emerging market economies is not only confronted with temporary shocks threatening its targets (such as changes in market sentiment or in the world economic environment), but also has to develop strategies to deal with permanent economic changes. These changes can originate from monetary phenomena, such as a durable disinflation or changes in the degree of price and/or wage stickiness, or from shifts in the real economy, such as a permanent fall in country risk premium, and persistent changes in real exchange rates and other relative prices. ${ }^{5}$

It is therefore important that alternative projection models be developed to serve the needs of policy makers in an emerging market environment. With the advances in the field (e.g., in

\footnotetext{
${ }^{4}$ For an extensive discussion of the use and design of these models, see Berg, Karam, and Laxton (2006b).

${ }^{5}$ While these issues are not unique to emerging markets (see Meyer, 2003), they are often discussed in their context, probably because their relative importance is greater, compared to developed markets.
} 
terms of theories behind short-term frictions and estimation/calibration techniques) paving the way for using fully general equilibrium models for routine forecasting purposes, the future lies probably in this direction. Recognizing this, many (especially developed) countries are intensively working on building DGE models and using them for policy inference, forecasting and policy advice. Such models (or their simpler versions, with only some dynamics coming from equilibrium theory) are being developed in many well established IT central banks at the moment, including the Bank of Canada, Bank of England, ${ }^{6}$ the central banks of Finland and Norway, the Reserve Bank of New Zealand, and the Sveriges Riksbank. Several emerging market central banks have joined the trend, with the central banks of Chile and Czech Republic, for instance, close to completing this task.

The general equilibrium approach has a number of advantages. Such models feature a welldefined long-run equilibrium, and both trends and model dynamics can be clearly understood in terms of economic theory. In addition, the full specification of a general equilibrium model makes it easier for the model to be expanded (e.g., to include tradable and non-tradable sectors). The model also provides consistency between stocks and flows with a more straightforward mapping into national accounts. Moreover, microfoundations with explicit references to an underlying structure of markets and agents with objective functions facilitate the interpretation of simulation results.

Exploiting these advantages in policy analysis or/and forecasting is then a natural motivation for building DGE models. As a tool for policy analysis, DGE models allow the simulation of the responses of several variables to particular shocks under alternative scenarios. They also make it possible to isolate the effects of shocks, and compare those effects under different policy frameworks. In this context, DGE models are particularly suited for answering "whatif" type questions. As a tool for forecasting, the main advantage of DGE over other types of forecasting models is that they allow coherent story-telling (i.e., they facilitate the understanding of the economic phenomena behind the evolution of variables in the projection).

First experiences in developing DGE models show that there is a large potential for using these types of models as tools for policy analysis. The SGE concept is quickly becoming an important communication platform of monetary policy issues. As forecasting tools, the use of DGE models is a less explored area. In this case, the state of the art practices are still being formed.

On the other hand, there are many challenges in using and developing the DGE models for policy. General equilibrium systems represent rather complex theoretical structures that are more difficult to communicate and work with. Their development also requires a lot of modeling experience, good planning, and a substantial technical and human resource

\footnotetext{
${ }^{6}$ The Bank of Canada (Murchinson and others, 2006) and Bank of England (Harrison and others, 2005) have already adopted DGE models as their core projection tools.
} 
commitment over an extended period of time. The international experience shows that a full time commitment of about 2-3 staff is needed for a period of about 2 years before a consensual model structure is finalized and staff are comfortable with the model properties. Even more time (at least one more year) is needed to put the model into production as the core forecasting tool. The development process is also very intensive in staff's coordination and communication with the senior management.

For these reasons, building a general equilibrium model may not bring first order benefits at early stages of IT implementation in an emerging market economy. Central banks there often need a workable framework quickly to support their nascent IT strategy. Moreover, the experience of several central banks has shown that sophistication of the core model is relatively unimportant at the early stages. Operating dynamic general equilibrium models on a routine basis in a forecast also requires skills that are more easily developed by both model developers and model operators through learning on smaller models.

But even central banks experienced in model building and using models in monetary policy making should understand that building DGE models for monetary analysis is not an ordinary model building project. The main challenges lie in finding the right economic problems to be better addressed within the DGE framework than within the existing framework, and securing long-term support and commitment from management, while delivering according to realistic expectations. The primary benefits of embarking on such a project are not likely to come from having a workable DGE model for policy analysis and forecasting within a short period. Instead, more tangible merits of the project lie in the way it can organize the research agenda and serve as a learning/educational device for the central bank staff and management.

The DGE model building project is best defined in terms of a broader research agenda for using DGE models as tools for policy analysis. The project should not be defined in terms of developing a single use-for-all model. The risk of failing in completing a single model that encompasses all relevant features of the transmission mechanism of different shocks is high. This risk is reduced by defining a project where the process involves developing small models and then building up on those.

The DGE agenda involves several stages that should clearly be defined in terms of objectives and resources:

- At the first stage, the most important stylized facts of the economy should be documented and staff should learn to understand them in general equilibrium settings. Several small general equilibrium models can be developed, calibrated, and studied at this stage as learning devices.

- At a next stage, a parsimonious core model should be developed to study policy. In this respect, staff should think about practical policy relevant experiments that the model should be able to address, unlike the existing (say 'gap') model. At this stage, staff should also learn to strike the right balance between the model's parsimony and flexibility to 
answer various policy questions. Clones or extensions of the core model to study particular experiments can be developed at this stage.

- Finally, the model should be adjusted/extended and re-calibrated so that it can run comfortably on most recent data and be used as a regular projection device. The staff should test the new model alongside the existing projection framework in several projection exercises before it can take the role of the core projection model.

In the process, research staff will have to make number of important decisions, including the following:

- A decision will need to be made early on whether to develop a DGE core model from scratch, or to adopt and calibrate an existing model framework used in other countries. Adopting an existing DGE model framework (such as the IMF's Global Economic Model) has the advantage of requiring less human and time resources on model design. This paper also presents a blueprint model design that can be readily adopted in different settings. On the other hand, by taking an 'off-the-shelf' model, staff will not gain as much in terms of learning and understanding the model (although a significant amount of research will still have to be done internally in customizing and validating the model for the national economy).

- A decision will need to be made about the appropriate model simulation software and environment. For the success of the project it is crucial to have a seamless automated technical environment for producing forecasts and policy analysis. The currently most popular environments are based on Matlab (such as IRIS, Dynare, or other freely distributed algorithms) or Troll software platforms. The software decision needs to be backed up by adequate computer equipment.

- A number of decisions will be made how to strike the right balance between the theory, and the model's parsimony and flexibility. The research staff will need to learn how to embrace the theory without necessarily marrying it. In designing the model, staff will be distinguishing between model features that are relevant as representing an observable feature of the economy (for instance FX denominated assets in a financially dollarized economy), and those that are there purely for convenience, making the model more flexible or easier to derive (e.g., closing an open economy model with an endogenous risk premium). Several features (such as inflation persistence) can obtain in a number of general equilibrium set-ups and the particular choice (e.g., a la Calvo, or a la Rotemberg) need not be linked to an observable feature of the economy.

Despite the difficulties, progress in building DGE models for forecasting and policy analysis is made easier today by the extensive network of researchers and institutions that are ready to share their experience with others. Apart from specialized central bank seminars, conferences and bilateral expert visits, a few 'blueprint' DGE models have been developed. Our paper offers an additional contribution in that respect. 


\section{TURKEY's RECENT MONETARY EXPERIENCE: STYLIZED FACTS}

The Turkish experience provides the background against which the model properties will be examined in subsequent sections. In this section we discuss Turkey's recent monetary experience, including the workings of its monetary transmission mechanism, and some stylized features of the economy. We focus on those stylized facts that we consider most relevant for the purpose of modeling the Turkish monetary transmission mechanism. By stylized facts we understand the properties of data that can be uncovered by simple transformations of observable data, without resorting to mechanisms of a structural (general equilibrium) model. We start with a conjunctural description of recent economic and institutional developments and then characterize separately long-term phenomena and medium-term business cycle fluctuations. This approach allows us to examine the properties of the data from various angles before interpreting them using the structural model.

In characterizing the data and their properties, we use very simple techniques, such as visual correlations, first and second moments, and univariate (agnostic) filters and VAR representations of the filtered data. Unless stated otherwise, we use annualized quarterly rates of change in measuring growth of variables and the Hodrick-Prescott filter to describe business cycle fluctuations in variables. Because of a statistical break in computing tradable and non-tradable inflation series, our sample is restricted to the period 1996-2004, although where possible we also provide a longer-term perspective. We thus cover both the period before the 2000-2001 crisis, and the subsequent implicit inflation targeting period.

Successful disinflation and a declining country risk premium, amid a strong economic recovery, characterize Turkish economic history since 2001. While this success has benefited to some extent from favorable initial conditions (specifically, the collapse of the exchange rate-based stabilization policies in 2000 and the resulting economic recession of 2001), it owes much to changes in policy management. Prudent fiscal policies, together with significant institutional changes, paved the way for the gradual introduction of an inflation targeting regime, initially in an implicit form, with short-term inflation targets complementing monetary targets, and since January 2006, in a full-fledged form (Box 1). ${ }^{7}$

\footnotetext{
${ }^{7}$ For a detailed discussion of the implicit IT period, see Kara (2006).
} 


\section{Box 1. Turkey: From Implicit to Full-Fledged IT}

Following the collapse of the exchange-rate-based strategy for disinflation, the Turkish authorities launched a reform program in May 2001 to address underlying vulnerabilities and improve economic performance. The economic recovery strategy was based on high primary surpluses to achieve debt sustainability, and tight monetary policy to rein in inflation, with the exchange rate allowed to float. At the same time, the CBT was freed from any obligation to finance fiscal deficits, and given operational independence to pursue the primary objective of achieving and maintaining price stability.

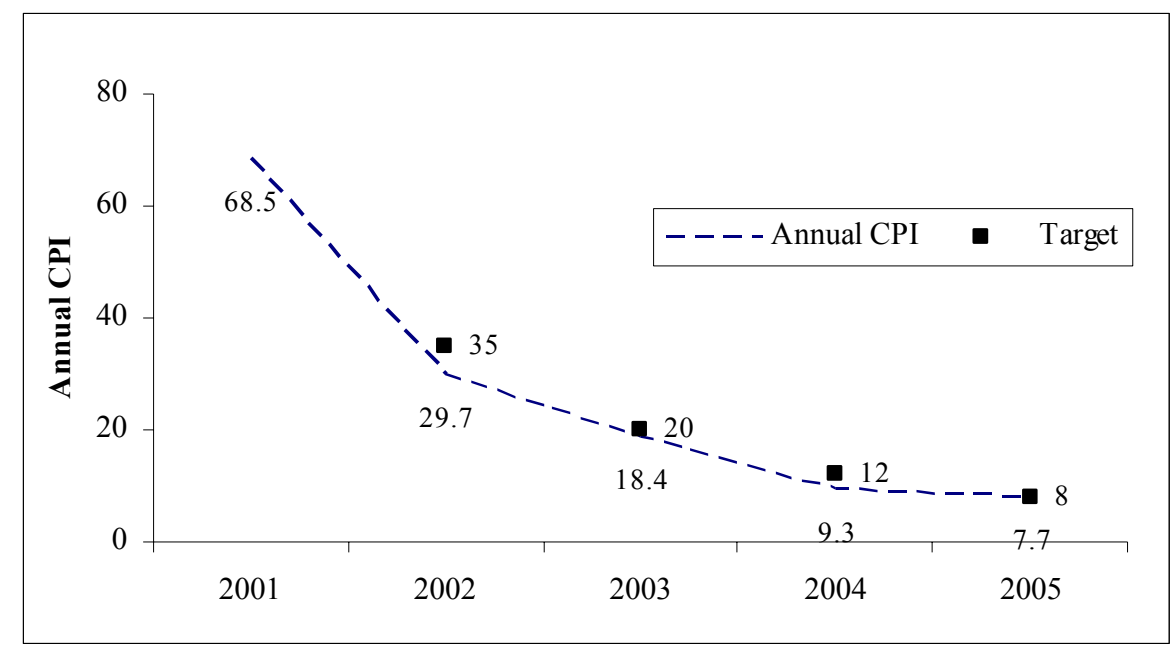

As part of the reform package, the CBT opted for the gradual introduction of an IT framework. This strategy reflected its concern about fiscal dominance and the need to strengthen fiscal discipline to reduce continuing debt-related vulnerabilities. Following the switch to a floating exchange rate regime, the authorities adopted "implicit" inflation targeting, using the interest rate as a policy instrument, while continuing to target monetary aggregates in the context of an IMF program (a stand-by arrangement covering the period 2002-05).

As a result of these measures, the economy recovered strongly from the 2000-01 crisis, while disinflating rapidly - inflation came down to single digits, from more than 70 percent in early 2001. The gradual IT implementation strategy paid off, with very positive results in terms of inflation and credibility, since inflation tracked the implicit targets very closely. The public debt/output ratio improved, leading to lower risk premia and real interest rates. Output grew rapidly, and by 2005 most of the large negative output gap that had opened after the 2001 economic crisis was eliminated. Although current account deficits remained high, there was an improvement in export performance, and the economy became more open, with both export and import GDP shares rising.

The macroeconomic achievements of the 2002-05 period - notably the successful disinflation, decline in the public debt burden, and increased fiscal discipline - together with the strengthening of the financial system, all contributed to creating an appropriate environment for full-fledged inflation targeting, introduced in January 2006. 


\section{A. Stylized Facts on Long-term Trends}

Long-term patterns in the data are important for model design and calibration of its steady state. In this section, we review the long-term trends that we consider most relevant from the perspective of building a general equilibrium model of monetary transmission.

- Within the period under examination, inflation dropped in line with targets after 2001, and other nominal variables adjusted to the falling inflation (Figure 1). After an initial hike in the wake of 2001 crisis, nominal interest rates fell in line with the decline in inflation and the risk premium. With inflation contained and interest rates reduced, the depreciation of the Turkish lira came to halt in 2002. From then on, the currency was under a mild appreciation pressure.

- The real interest rate adjusted for the risk premium fluctuated around a constant trend. A panel in Figure 1 shows the real interest rate and the real interest rate adjusted by EMBI $+{ }^{8}$ While the volatility of real interest rates was reduced after 2000 , the mean stayed approximately constant.

- The real exchange rate showed a permanent appreciating trend. A panel in Figure 1 shows the real exchange rate in terms of CPI and its tradable component (with the import deflator as a common numerator). The appreciation of both of them was temporarily halted during the crisis period, but resumed soon afterwards. In contrast to the behavior of real interest rates, fluctuations in the real exchange rate increased markedly after 2001. There is also an apparent gap in between the two series, which widened from the mid1990s.

- The price of the non-tradable component of CPI increased relative to its tradable component (last panel of Figure 1). ${ }^{9}$ This is a corollary to the previous observation that the gap between the real exchange rate series in terms of the CPI and its tradable component widened. Inspecting the relative price yields another important observation, not evident from the real exchange rate charts: the growth in the non-tradable relative price accelerated at the end of the 1990s, just before the crisis, and then a sharp correction brought it back to its previous trend.

- The terms of trade (relative price of exports and imports in domestic currency) resembles a random walk without an evident drift (Figure 2). There was a downward shift in the level of terms of trade starting at the end of the 1990s and ending right after the crisis

\footnotetext{
${ }^{8}$ In computing real interest rates, inflation expectations were considered as half adaptive and half perfect foresight.

${ }^{9}$ We make use of the CPI decomposition into the tradable and non-tradable components prepared by the CBT for the CPI until the end of 2004.
} 
period. This observation, together with the point made above, also implies that the CPI rose relative to the price of both exports and imports (Figure 1). These relative prices moved together in the 1990s, but went apart just before the crisis, illustrating the level shift in the terms of trade that occurred in that period.

- The ratio of imports to exports fluctuated around a constant (Figure 2) over the whole sample. In other words, exports and imports tend to grow at the same rate in the long term. However, there was a sharp drop in imports (and investment) at the time of the crisis, after which the import/export ratio gradually recovered to previous levels. We interpret this as a cyclical movement, associated with the crisis (more on this later).

- Household consumption fell relative to imports (and exports), but stayed constant relative to investment (Figure 2). In other words, exports and imports grew on average faster than consumption. The relationship between investment and consumption was markedly disrupted during the crisis period, when investment fell dramatically, and only gradually recovered since then. Again, we interpret this as a cyclical phenomenon rather that a change in a trend.

- Expenditure shares of household and government consumption, imports and exports in GDP fluctuated around constant trends following the crisis (Figure 2). There was a level shift upward at about the time of crisis for the nominal import and export shares, which we interpret as a structural break.

Most of these observations are visible for a long period of time and were not altered after the institutional and macroeconomic changes took place in 2001. The crisis period of 2000-2001 seems to have resulted in a few level shifts in deterministic trends, but otherwise not altered the slopes of these trends and other general observations made above. The only exceptions are the two main defining features of post-2001 Turkish development, namely sustained disinflation and a fall in the risk premium, which have their roots in institutional changes and a new set of macroeconomic policies pursued since then.

The persistent real appreciation and the permanent wedge between the tradable and nontradable consumer prices is a phenomenon widely experienced by emerging market economies in Europe and elsewhere. This phenomenon is typically associated with the so called Balassa-Samuelson effect working through productivity growth differential in tradable and non-tradable sectors of catching up economies, although empirical evidence for that explanation is mixed (see, for example, Kovács and others, 2002). 

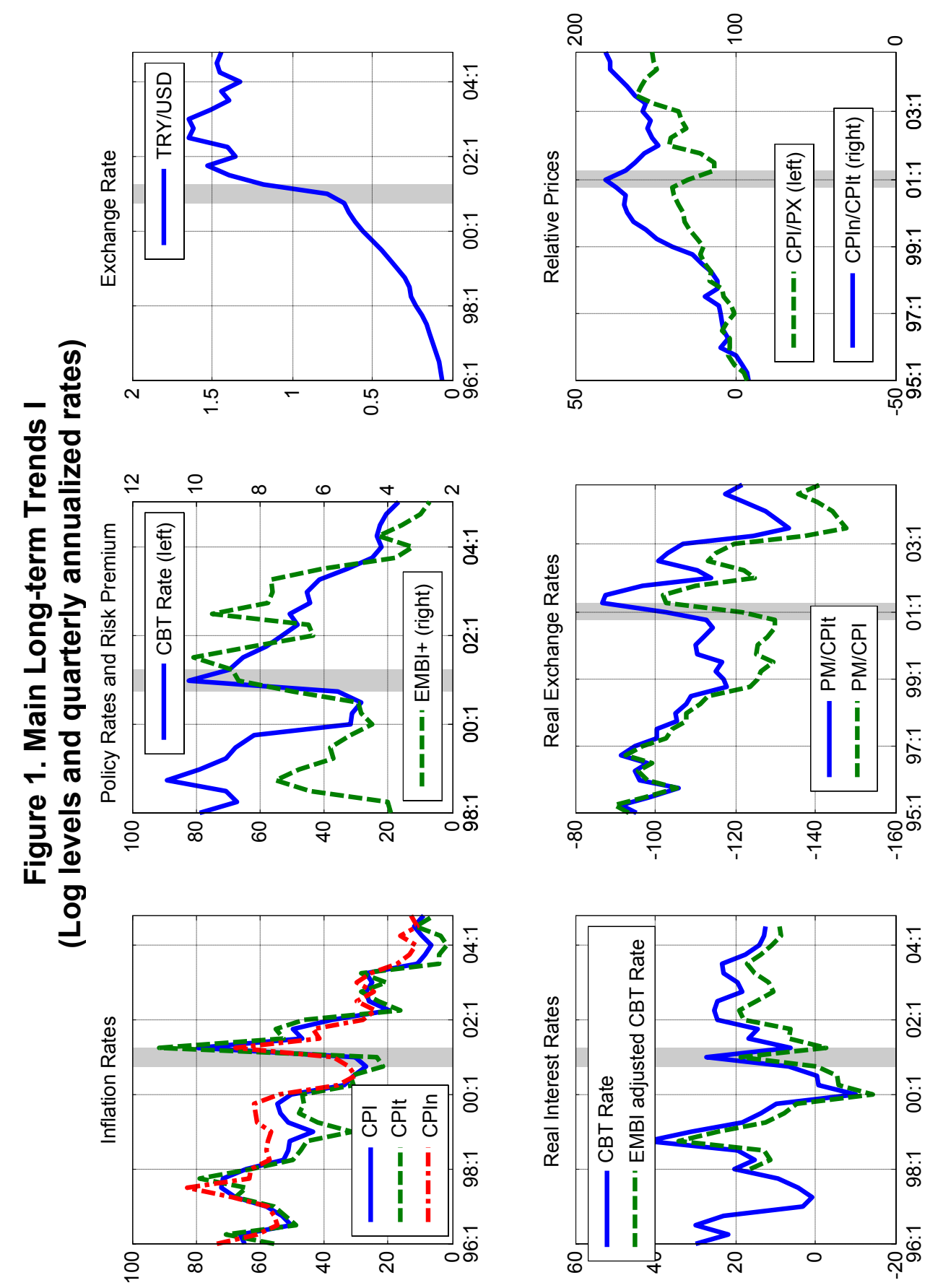


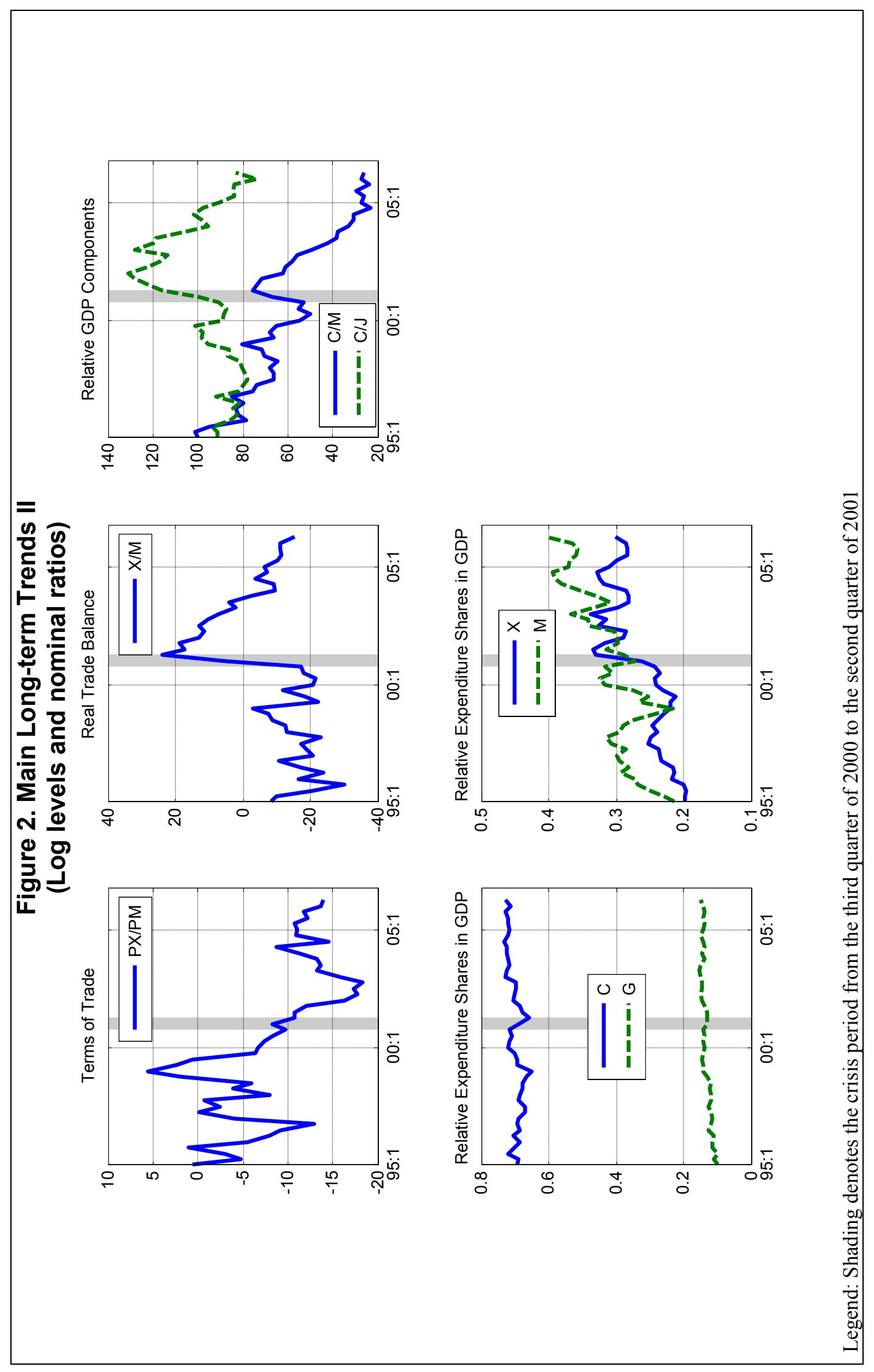


The fact that relative expenditure shares stayed constant in the long term while relative prices have not had a great significance for model design. It suggests that the long-term elasticity between relative prices and real quantities is close to one, consistent with a Cobb-Douglastype functional form. It also favors the specification of the model's steady state in terms of these shares, while allowing for persistent trends in relative prices and quantities.

\section{B. Stylized Facts on Business Cycle Fluctuations}

In contrast to long-term patterns, medium-term fluctuations in the data are related to the transmission mechanism, because central banks rely on these short-term mechanisms in controlling inflation over a business cycle. In what follows, we characterize business cycle fluctuations in two complementary ways. First, we quantify business cycle patterns by estimating the second (VAR implied) population moments of selected data series taking into account sampling uncertainty. ${ }^{10}$ Second, we examine qualitatively the correlations among data and their transformations that are typically used in describing monetary transmissions.

Appendix I describes the methodology of estimating distributions of the standard deviations, auto and cross-correlations among the variables we choose as most relevant for characterizing the monetary policy transmission. These include: tradable one-quarter inflation, non-tradable one-quarter inflation, one-quarter changes in real consumption, onequarter changes in the nominal exchange rate against the euro, and the nominal interest rate. The empirical estimates of moment distributions are used later in our calibration and empirical validation of the model (and can be found in Figures 17, 18 and 19 respectively).

The particular choice of variables in the VAR was motivated by our desire to keep the description of transmission simple and based on observable data, with minimum statistical complications. Nevertheless, it is a relatively standard way of describing transmission using a reduced form VAR. ${ }^{11}$ In other words, we wish to avoid imposing any structural identifying restrictions on the data to keep the results independent of any prior theory assumptions. When describing the data's second moments (i.e., business cycle properties), we account for

\footnotetext{
${ }^{10}$ The observed characteristics are constructed using a bootstrap exercise based on an estimated unrestricted VAR model on detrended and seasonally adjusted data. We resample 5,000 times from the estimated VAR using the so-called wild bootstrap technique (robust to conditional heteroscedasticity), re-estimate the VAR parameters and re-construct the desired characteristics. We are therefore able to describe the whole empirical distribution of each characteristic and account for sampling uncertainty. See Appendix I for more details.

${ }^{11}$ We used real consumption instead of total real output (GDP) because we believe the former is more accurate (both theoretically and empirically) for determining CPI inflation. Another feature of the model is that the cycle in consumption demand is the main driving force for domestic price changes.
} 
the possible presence of deterministic trends by regressing the series on a simple time trend. Our underlying assumption is that the time series in the VAR contain potentially deterministic trends but no stochastic trends.

In complementing the VAR estimation, a visual inspection of business cycle correlations shows that prices and exchange rate are strongly related in Turkey. This suggests that exchange rate movements play a key role in determining inflation, as expected. Inflation follows imported inflation (and hence the exchange rate) very closely, as shown in Figure 3. The strong correlation is also apparent in the co-movements between the inflation rate and fluctuations in the real exchange rate. The VAR estimates of contemporaneous correlations of both tradable and non-tradable CPI components with the nominal exchange depreciation are about 0.5 , confirming a fast and strong exchange rate pass-through to inflation noticed in other studies. ${ }^{12}$

Compared to the exchange rate, the role of economic activity in affecting inflation is more subtle and less visible in the data without further analysis. Other panels in Figure 3 show that inflation does not co-move well with a range of business cycle indicators, including the HP gaps in output, consumption, or consumption growth. Indeed, the VAR estimation shows that consumption growth correlates negatively with both tradable and non-tradable CPI components, perhaps because it also correlates with exchange rate appreciation. ${ }^{13}$

This picture does not change if we examine the tradable and non-tradable components of CPI inflation separately. As shown in the last panels of Figure 3, the tradable CPI component correlates well with the HP gap in the real exchange rate in terms of tradable CPI. On the other hand, the non-tradable component of CPI is not clearly more sensitive to the business cycle than the CPI itself, as also confirmed by the negative correlation with consumption growth in the VAR estimation.

\footnotetext{
12 There is some evidence, however, that the pass-through has declined in Turkey in recent years, as in other emerging market economies (e.g., Kara and Ogunc, 2005).

13 The negative correlation between consumption growth and inflation rate can be explained by the fact that consumption growth is affected by both transient and permanent shocks, which usually have different implications for the behavior of nominal prices.
} 

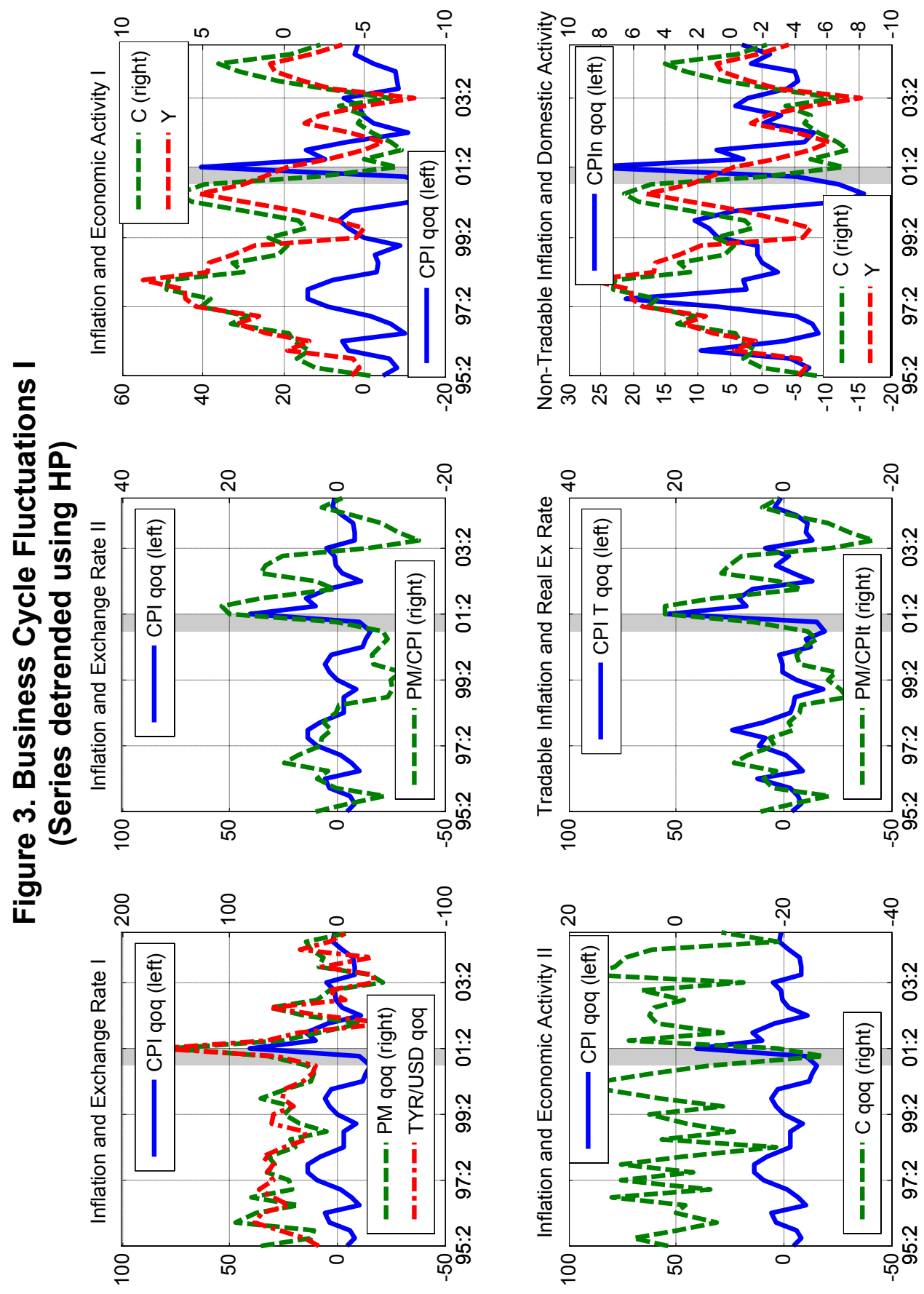

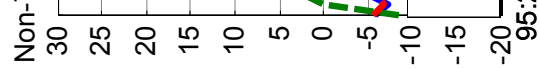

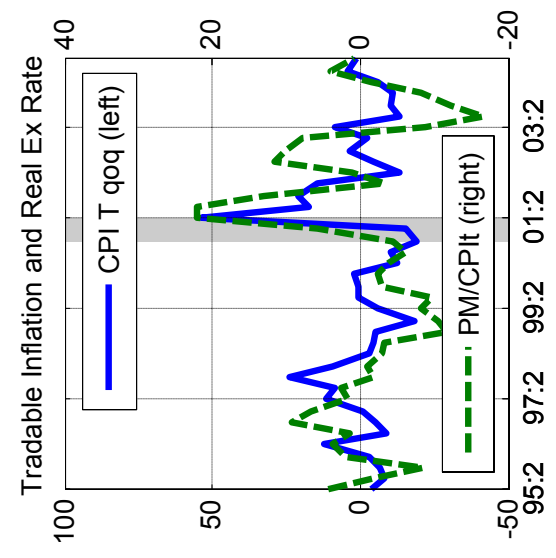


The cyclical patterns on the expenditure side of GDP show important regularities and correlations with relative prices that may reflect the nature of technology and factor substitution. The cycles in all major GDP components are very similar (Figure 4), with the variability of imports and investment much higher than that of exports and consumption. The high correlation between imports and investment reflects the high import content of investment. Indeed, the large drop in imports during the crisis period of 2000-2001 is associated with a drop in investment activity. The strong correlation between the cycle in imports to exports and terms of trade, on the other hand, suggests that a high proportion of imports is used as intermediates for re-exports. Finally, the relationship between the cycle in the ratio of imports to value added and their relative price is not clear-cut. It seems to have changed from positive to negative after the crisis, suggesting that the domestic value added became more substitutable for imports than in the past (all Figure 4).

The cycle in household consumption is inversely related to the cycle in real interest rates, a sign of inter-temporal substitution at work (Figure 4, last panel). This relationship is also seen in simple correlations between nominal interest rates and consumption growth (see Figure 19 later), and may reflect a key monetary policy transmission channel.

The costs of disinflation appear to be relatively low in Turkey in the examined period, pointing to the importance of expectations in the monetary policy transmission. The observed cyclical properties are much affected by the adjustment of the economy to the crisis and its causes in the post-2001 period. As shown in previous figures, the levels of consumption, imports and investment fell during the crisis substantially below their long-term trends, taking three-four years to fully recover. However, measured by the achieved extent of disinflation during that period, the real costs associated with disinflation appear relatively small by international standards. Simple arithmetic over the period 2002Q2-2004Q4 puts the sacrifice ratio in terms of both output and consumption loss (measured as cumulative HP gaps) at about 0.4 (compare to 1-10 ratio estimate for the US by Cecchetti and Rich, 1999). The low sacrifice ratio in Turkey was also pointed out by Cetinkaya and Yavuz (2002) when examining disinflation episodes in 1990s. These observations suggest that the expectations channel (and not the slack in the real economy) played a critical role in the successful disinflation, and hence also in the monetary transmission in that period.

As in the case of long-term trends, most of the cyclical patterns described above have remained qualitatively similar over an extended period. Only a handful have changed after 2001 , most notably the inflation rate and other nominal variables that adjusted to it. Closely associated with this change, the cyclical fluctuations of real exchange rates have markedly increased, while those of real interest rates decreased following the crisis period. This probably reflects the changes in monetary policy management, when policies aimed at stabilization of the real exchange rate were replaced by policies oriented toward stabilizing inflation through steering real interest rates and allowing large enough real exchange rate 


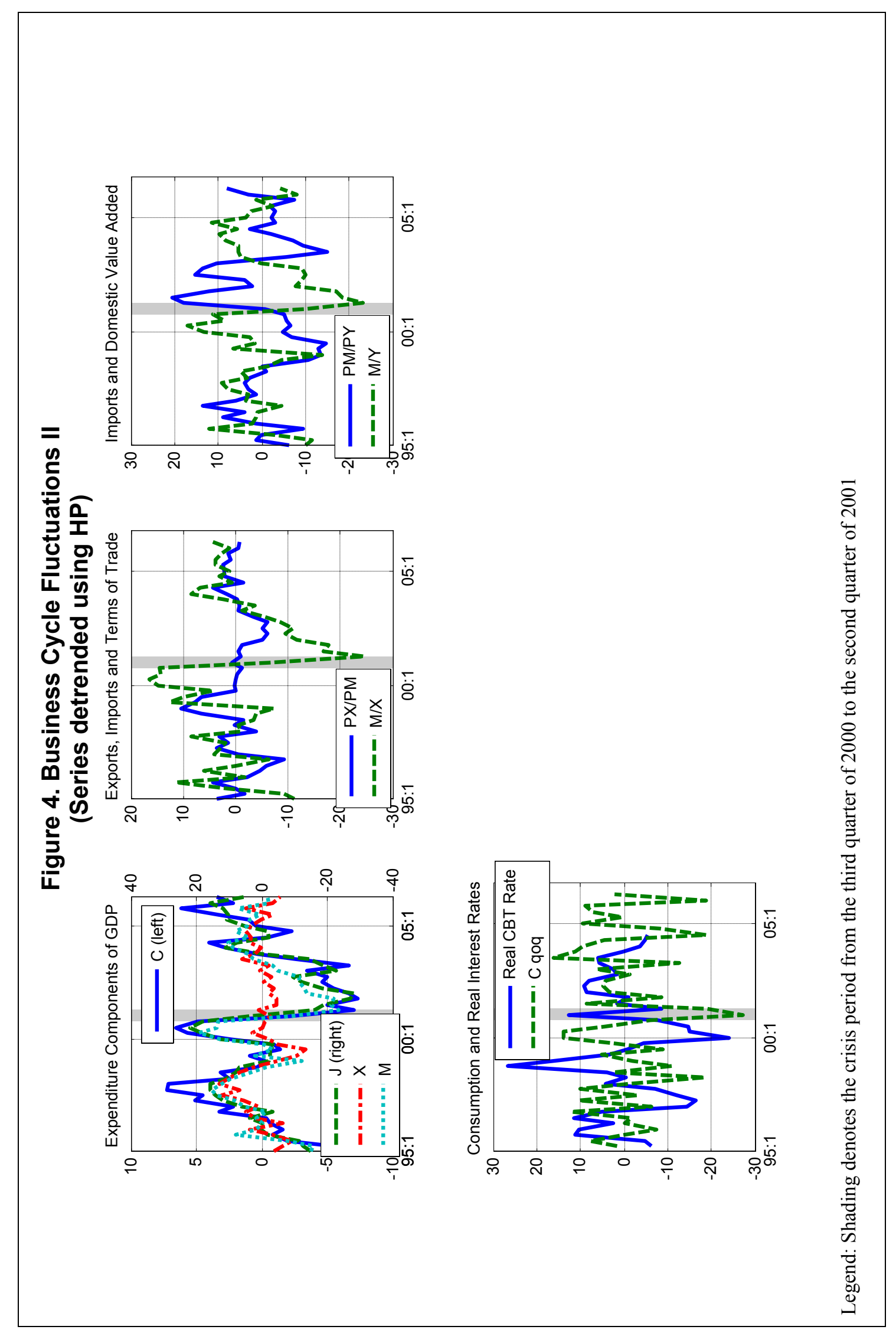


fluctuations. ${ }^{14}$ As another example, the correlation between the cycles of the relative price of imports and value added and their quantities seemed to change after the crisis. This stands in contrast to the co-movements between the cycles in other real ratios and relative prices, which have remained unchanged, but the evidence is weak to attach more significance to this.

\section{Core Model Design}

This section presents the main features of the model. We start by summarizing the requirements imposed on the model, and then explain the main elements and features of model design. The model's derivation and a full code are presented in Appendices I and II, and the model's calibration and properties are examined in Section V.

\section{A. Requirements}

To summarize the requirements laid out in the previous sections, we build a model with:

- monetary policy providing a nominal anchor to the economy without affecting real variables in the long term;

- a malleable structure enabling further model development and expansion at low cost, depending on the policymaker's questions and needs;

- full theoretical consistency behind short-term and long-term macroeconomic dynamics; and

- the capacity to address a selected range of emerging market phenomena related to monetary policy making.

The model's structure should be able to address the following phenomena relevant for monetary policy making in Turkey in recent years:

- ongoing disinflation and the associated gain in central bank credibility (manifested also in a falling risk premium);

- real costs in terms of output/consumption loss associated with the disinflation caused by the intrinsic persistence in price and/or wage inflation, not only price and/or wage levels;

${ }^{14}$ The emphasis on stabilizing inflation as opposed to the real exchange rate may also explain the marked reduction in unofficial dollarization, so prevalent in Turkey before 2001. Exchange rate stabilization stabilizes real returns in foreign currency, thereby inducing dollarization, whereas inflation stabilization stabilizes real returns in the domestic currency, supporting the use of Turkish lira. 
- $\quad$ ongoing real appreciation of the exchange rate; and

- flexible exchange rate management, primarily through interest rates changes.

In capturing the long-term features of the Turkish economy, the model's steady state should display the following properties:

- constant real interest rates, adjusted for the risk premium;

- constant nominal expenditure on consumption, exports, and imports; ${ }^{15}$

- real exports and imports rising faster than real consumption;

- constant export/import ratio; and

- long-run trends (both stochastic and deterministic) in relative prices and real exchange rates; ${ }^{16}$

In capturing the shorter-term dynamics of monetary policy transmission in Turkey over the business cycle, the model should account for the following transmission channels:

- the interest rate channel, that is, the inter-temporal consumption-savings choice;

- the expenditure-switching channel (or the indirect "real exchange rate" channel), that is, the intra-temporal choice between domestic and foreign goods;

- the direct exchange rate channel, that is, a certain degree of pass-through of nominal exchange rate fluctuations into final domestic prices; and

- the expectations channel, that is, the dependence of today's price developments on the future business cycle and on the monetary policy stance.

${ }^{15}$ This particular feature of the model may seem too restrictive for some. However, it would be extremely difficult (not only from the technical point of view) to build, operate, and interpret a model that fails to display fixed nominal expenditure shares in the long run.

${ }^{16}$ A stochastic trend accounts for the fact that there can be shocks with permanent effects on a particular variable. On the other hand, a deterministic trend means that a particular variable can be potentially growing over time, but its long-run developments are not affected by shocks (the variable reverts to its deterministic time path). 


\section{B. Main Model Features}

When designing the model, we acknowledge the fact that many economic relationships have very different quantitative properties over a business cycle and in the long term (as described in the previous section). Households' elasticity of substitution between tradable and nontradable goods is a good example. While the relatively stable nominal expenditure ratios observed in the long term suggest that the elasticity is close to unity, the observed short-term consumption patterns are much less sensitive to fluctuations in the relative price. We therefore build the model so as to clearly distinguish between these and flexibly calibrate them as independently as possible.

The model has two production sectors, producing non-tradable (domestic) and export goods for domestic consumption and export respectively, and an import sector selling tradable (imported) goods for domestic consumption (Flowchart 1). It involves the following types of agents:

- households, who consume tradable (imported) goods and non-tradable goods, and trade domestic currency-denominated assets (we assume that there is no international trade in these assets);

- foreign exchange dealers, who are trade in foreign-currency-denominated assets on behalf of households;

- firms, who produce non-tradable goods using a round-about production technology (i.e., with intermediate inputs produced by the sector itself) and sell them domestically;

- importers, who purchase tradable goods abroad and sell them domestically to households;

- exporters, who use imported intermediate inputs (re-exports) to produce export goods sold abroad;

- the monetary authority, who sets the nominal interest rate; and

- the fiscal authority, who levies lump-sum taxes and purchases consumption goods.

It is important to note that, for simplicity, there are no explicit input factor markets in the model. Instead, we assume a round-about production structure to achieve realism in the behavior of the costs of domestic producers in the non-tradable sector. This assumption has the power to generate pro-cyclical real marginal cost patterns over the business cycle in sticky-price models, and thus to mimic deeper interactions in the labor (and capital) market. As a result, we get a Phillips curve in which the main driving force is related to the cycle in output. 


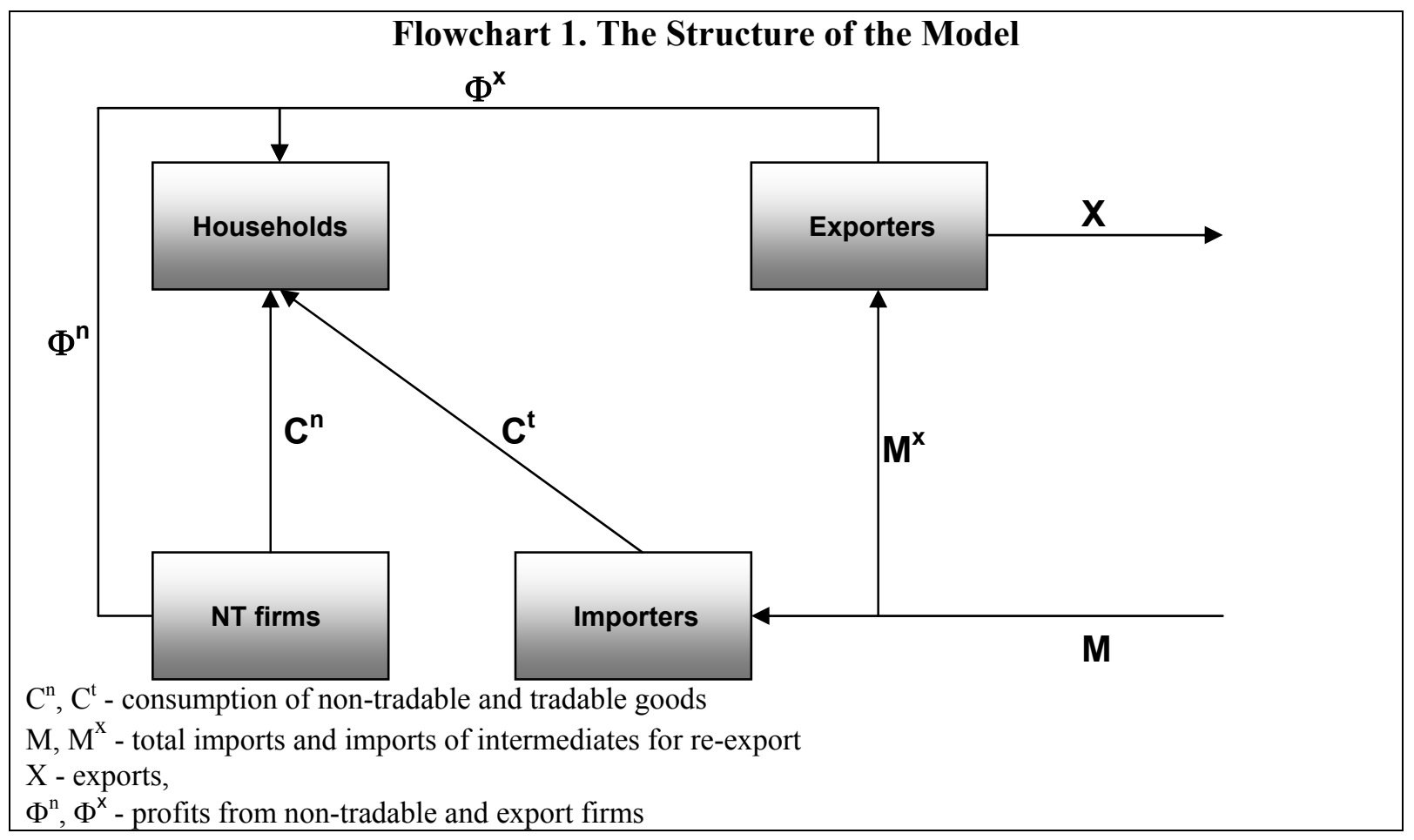

The sectoral approach is necessary for capturing the medium and long-term features of the Turkish economy. In particular, it is necessary for describing the dynamics between the three real exchange rates involved in the model's monetary transmission mechanism (note that all these three real exchange rates are a random walk, i.e., contain unit roots):

- the relative price of tradables and non-tradables: in the long term their trend is determined by the productivity differential between the export and non-tradable production functions and the level of the terms of trade; short-term fluctuations provide for expenditure switching effects;

- the relative price of imports and tradables: in the long term this relative price is determined by the optimal mark-up (in turn, determined by the degree of competition in the sector) and an exogenous tradable productivity trend. In the short term, the relative price can deviate from it due to nominal rigidities and the cycle in the relative price is the key factor driving tradable inflation; and

- the terms of trade: they determine the dynamics of exports, and, through wealth effects, also the rest of the economy. They are assumed to be exogenous to the Turkish economy.

The model follows the tradition of New-Keynesian models of monetary transmission. It is built on a mainstream neo-classical core defining the model's balanced growth path. Nominal and real rigidities are added to the core, generating business cycle fluctuations and providing 
for the main monetary policy transmission channels. The nominal and real rigidities do not affect the model's balanced growth path (and the neoclassical core), allowing for an intuitive understanding of the model's dynamics around the steady state. The interpretation of the model's dynamics and monetary transmission is thus similar to that in ad hoc 'gap' models that also separate between the steady state and business cycle dynamics. The separation of the neoclassical core (or the 'steady state model') from the full model is very convenient for the model's derivation, shown in Appendix II, and model's calibration.

A simple neo-classical multi-sector stochastic growth model provides the backbone for the model's long-term properties. There are three independent exogenous stochastic productivity trends (containing unit roots), one in each sector. Those in non-tradable and export sectors have also drifts making them grow at (potentially) different rates along a balanced growth path (BGP). This allows for permanent wedges in real variables (including real exchange rates and the relative price of tradable and non-tradable goods) in the steady state. In addition to the three productivity trends, there is one stochastic trend related to the rest of the world, namely the terms of trade, assumed to be a random walk without a drift.

With non-stationary relative prices and relative real allocations along the BGP, the model's steady state is defined in terms of nominal expenditure shares. The core of the model features Cobb-Douglas functional forms in both utility and production to ensure unitary long-run elasticities of intra-temporal substitution between input factors and final goods in the long run. As a result of changing relative prices, the relative real quantities move in the opposite direction, leaving nominal expenditure shares unchanged. Note that eventually, one of the sector tends to dominate the other ones in real terms, with its relative price going to zero. While such an implication may appear counter-intuitive, there is much anecdotal evidence worldwide supporting such a formulation (e.g., relative prices of computers falling, the quantity purchased increasing, but expenditures remaining approximately unchanged). Similar modeling strategies are also used in the literature to address both longer-term and business-cycle implications of various types of sectoral productivity differentials, see Greenwood and others (2000); Whelan (2003); or Fisher (2006).

This approach to modeling of long-term features has many practical modeling advantages. First is a great flexibility in capturing various long-term properties and shock transmission. Specific assumptions about preferences and technology allow for various types of permanent real shocks, such as productivity or terms of trade shocks, while retaining the balanced growth path property of the model in terms of its nominal expenditure shares unaffected by these shocks in the long term. Second, the model's steady state can easily be parameterized using the readily available data on nominal expenditure shares. Third, having a model's steady state defined in terms of growing ratios of prices and real variables (that are observable features of the data) helps in using the model for regular forecasting. It allows forecasters to keep the steady state close to the recent (or foreseeable) data evidence instead of making a judgment about an 'unrealistic' stationary steady state in a very distant future.

The mechanics of the steady state are relatively easily understood, thanks to the simple neoclassical design (see Appendix II). With the terms of trade constant in the long term, export 
production and imported intermediates grow at the (parameterized) rate of the productivity growth in the export sector. In keeping the current account unchanged, the imports of consumption goods grow at the same rate as productivity in the export sector. By analogy, the consumption (and production) of domestic (i.e., non-tradable) sector goods grows at the (parameterized) rate of the non-tradable sector productivity growth. The growth of overall consumption is therefore a weighted average of the growth rates in the two production sectors of the economy. Real interest rates are constant at a level inducing consumers to choose such a consumption-smoothing pattern. As the consumed quantities of tradable and non-tradable goods grow at different rates, the relative prices of tradable and non-tradable goods evolve in line with the productivity growth differential between the two sectors. With a perfect exchange rate pass-through (adjusted for permanent changes in the tradable productivity trend), the real exchange rate in terms of tradable inflation is constant, while that in terms of the headline inflation is growing at a fraction of the productivity differential in the non-tradable and export sectors (the Balassa-Samuelson effect).

Monetary policy determines headline consumer inflation (through its inflation target) and provides the anchor for other nominal variables. The split of the headline inflation into the tradable and non-tradable inflation rates is given by the respective sector's weight in the consumer basket and by the relative productivity growth differential (in the non-tradable and export sector). The inflation target has one-to-one implications for the nominal rates of interest and exchange rate depreciation.

Various nominal and real rigidities are introduced atop the neoclassical core to achieve realistic profiles of shock propagation over the business cycle, including the transmission of monetary policy reactions. ${ }^{17}$ The unitary elasticities of intra and inter-temporal substitution in production and consumption in the neoclassical core considerably restrict the model's capacity to capture different profiles of shock propagation. Moreover, prices adjust instantaneously, so monetary policy does not have any capacity to influence the business cycle fluctuations. Both types of frictions are introduced in a way that does not affect the long-term properties of the model. As a result, the linearized form of the model features a block of equations that is almost identical to those used in 'ad hoc' gap models (see Box 2). ${ }^{18}$

\footnotetext{
${ }^{17}$ Transitory random shifters (shocks) into the specifications of preferences and technology are the main sources of business cycle fluctuations in the model economy.

${ }^{18}$ The linearized market clearing conditions were omitted from the equations listed in the box, because they are typically not used in ad hoc gap models. However, their eventual inclusion does reduce the appeal of using a linearized version of our model as a simple but more micro-founded 'gap' model.
} 


\section{Box 2. The Main Behavioral Equations of the Model}

In this box we set forth the main relationships of the model. We present the most important equations is their (log-)linearized forms and explain basic intuition. For simplicity, we treat all real variables, including relative prices and real interest rates, as percent deviations from their underlying long-run trends.

\section{Households}

Households make decisions about the aggregate level of consumption (the intertemporal consumption/savings plan) and about the relative quantity of tradables and non-tradables they purchase. These consumption choices are affected by deep habit. The importance of habit is controlled by the parameter $\chi \in(0,1)$ which, in turn, has the power to reduce both the short-run elasticity of intertemporal substitution (between consumption today and tomorrow) and the short-run elasticity of intra-temporal substitution (between tradables and non-tradables). Higher values of $\chi$ lead to a higher dependence of today's consumption on its past level. The real interest rate and the relative price of tradables and non-tradables (a sort of real exchange rate) then determine a smaller proportion of the whole consumption in the short run.

$$
\begin{gathered}
\mathrm{E}_{t} c_{t^{+} 1}-c_{t}=\chi \cdot\left(c_{t}-c_{t^{-} 1}\right)+(1-\chi) \cdot\left(i_{t}-\mathrm{E}_{t} p_{t+1}\right)+\epsilon^{\prime} \\
c_{t}^{\tau}-c_{t}^{n}=\chi \cdot\left(c_{t^{-} 1}^{\tau}-c_{t^{-1}}^{n}\right)+(1-\chi) \cdot\left(p_{t}^{n}-p_{t}^{\tau}\right) \\
c_{t}=\omega \cdot c_{t}^{\tau}+(1-\omega) \cdot c_{t}^{n} \\
p_{t}=\omega \cdot p_{t}^{\tau}+(1-\omega) \cdot p_{t}^{n}
\end{gathered}
$$

\section{Non-tradable firms}

Non-tradable firms have technology with procyclical real marginal costs. Because they face, at the same time, costs of price adjustments, their aggregate pricing behavior can be described by a Phillips

curve in which today's inflation is driven by the cycle in the real marginal cost, $p_{t}^{n} *_{-} p_{t} \propto y_{t}^{n}$. Real marginal cost fluctuations are related to shifts in private and government demand for non-tradables through the market clearing condition. The price setting is subject to sector-specific cost-push shocks, $\epsilon^{p n}$, as well as economy-wide cost-push shocks (perfectly correlated across the tradable and nontradable sectors), $\in^{p}$.

$$
\begin{gathered}
\Delta p_{t}^{n}=\frac{1}{1+\beta} \Delta p_{t-1}^{n}+\frac{\beta}{1+\beta} \Delta \mathrm{E}_{t} p_{t+1}^{n}+\frac{\xi_{n}}{1+\beta} \cdot\left(p_{t}^{n *}-p_{t}\right)+\epsilon^{p n}+\epsilon^{p} \\
p_{t}^{n} *-p_{t}=\frac{1-\gamma_{n}}{\gamma_{n}} \cdot y_{t}^{n} \\
y_{t}^{n}=\frac{1}{1+\alpha} \cdot c_{t}^{n}+\frac{\alpha}{1+\alpha} \cdot g_{t}^{n}
\end{gathered}
$$

\section{Tradable firms (importers)}

Similarly to non-tradable firms, importers also face costly price adjustments. Their marginal costs are, however, determined purely by the price of foreign goods purchased abroad, and independent of the domestic cycle. As a result, the aggregate tradable Phillips curve is driven by another measure of the real exchange rate, the relative price of domestic tradables and imported foreign goods, $p_{t}^{m f}-s_{t}-p_{t}^{\tau}$. The price setting is subject to sector-specific cost-push shocks, $\in_{t}^{p \tau}$, as well as 
economy-wide cost-push shocks (perfectly correlated across the tradable and non-tradable sectors),

$$
\begin{aligned}
& \in{ }_{t}^{p} \\
& \Delta p_{t}^{\tau}=\frac{1}{1+\beta} \Delta p_{t-1}^{\tau}+\frac{\beta}{1+\beta} \Delta \mathrm{E}_{t} p_{t_{+}}^{\tau}+\frac{\xi_{\tau}}{1_{+\beta}} \cdot\left(p_{t}^{m f}-s_{t}-p_{t}^{\tau}\right)+\stackrel{p}{\epsilon}+\stackrel{p}{\epsilon}
\end{aligned}
$$

\section{The foreign exchange market}

The forex market no-arbitrage condition (the uncovered interest rate parity) is modified by two disparity terms. A debt-elastic disparity, $\mathrm{v} \cdot \hat{b}$, helps to close the small economy model in the long run and induce stationary nominal consumption shares. We calibrate $\mathrm{V}$ small enough not to distort the business cycle properties of the rest of the model. An autonomous disparity, or a risk premium, $u_{t}$, can capture various factors, such as the time-varying riskiness of domestic assets, other changes in investors' preferences, capital controls, etc.

$$
\hat{\imath}_{t}-\hat{\imath}_{t}^{\dagger}=\mathrm{E}_{t} \Delta s_{t+1}+v \cdot \hat{b}+u_{t}
$$

\section{Monetary policy}

The systematic behavior of the monetary authority is described by a rule in which the policy rate response to deviations in tradable and non-tradable inflation from the target (see Box 3). The target

levels for these two inflation rates are derived from the headline CPI inflation target, $\pi_{t}$, adjusted for the long-run inflation differential. The inflation differential is given by the long-run productivity differentials in the export sector and the non-tradable sector, $\pi_{t}^{n}-\pi_{t}^{\tau} \rightarrow \alpha_{x}-\alpha_{n}$. Moreover, the monetary authority engages in policy rate smoothing for precautionary or other reasons.

$$
i_{t}=\rho_{i} i_{t-1}+\left(1-\rho_{i}\right)\left[l+\kappa_{n} \cdot\left(\Delta p_{t}^{n}-\pi_{t}^{n}\right)+\kappa_{\tau} \cdot\left(\Delta p_{t}^{\tau}-\pi_{t}^{\tau}\right)\right]+\epsilon^{m p}
$$

There are two types of real rigidities in the model: deep habit (Ravn and others, 2006) in household's consumption, and costly output adjustments in the export sector. These frictions expand the model's possibilities in calibrating shock profiles, as they: (i) reduce the shortterm (instantaneous) elasticity of inter-temporal substitution in overall consumption below unity (deep habit). Deep habit also introduces intrinsic persistence (auto-regression) into consumption demand; (ii) reduce the short-term (instantaneous) elasticity of intra-temporal substitution between tradable and non-tradable consumption below unity (deep habit); and (iii) reduce the short-term responsiveness of exports to changes in the terms of trade (costly output adjustments).

Nominal rigidities in the model provide for the main channels of monetary policy transmission through a business cycle (Appendix II). As a consequence, monetary policy has real effects in the medium term and is one of the driving forces of business cycle fluctuations. We introduce nominal rigidities in two ways: (i) through costly price 
adjustments, making the final prices of tradables and non-tradables sticky and reducing their responsiveness to changes in producers' cost conditions, and (ii) by assuming precaution in the central bank's behavior, and distributing monetary policy reactions over time (policy rate smoothing).

As a result of the pricing friction, the behavior of inflation over the business cycle is led by fluctuations in real marginal costs of firms in the tradable and non-tradable sectors: the higher the deviation of the sector's real marginal cost from its long-run (flexible price) optimum, the higher the changes in today's inflation.

- In the non-tradable sector, the real marginal cost moves together with the deviations of non-tradable production (and hence demand for non-tradable output) around its flexible price level, giving rise to a conventional New-Keynesian Phillips Curve with backward indexation à la Christiano and others (2005). This relationship provides the channel of monetary policy transmission working through real economic activity, and helps describe (inter alia) real costs of disinflation.

- In the tradable sector, inflation responds to fluctuations of the real exchange rate (in terms of tradable prices, the relevant real marginal cost concept for this sector) around its constant BGP level. This relationship embodies the exchange rate channel of monetary transmission and provides for an imperfect exchange rate pass-through in the short term.

The real and nominal frictions in the model provide for a stabilizing monetary policy that associates policy rates (as instruments) with inflation forecasts (as targets) through conventional monetary policy transmission channels (see also Box 3).

- Policy rates (through real rates) affect consumption, feeding into production of domestic (non-tradable) goods and imports. Fluctuation of non-tradable output (as real marginal costs) feeds into non-tradable inflation.

- Policy rates affect nominal and hence real exchange rate changes. Fluctuations in the real exchange rate (in terms of tradable goods) affect inflation in the tradable sector. At the same time, fluctuations in the relative price of tradable to non-tradable goods affect the substitution between imported and domestic goods in consumption, thereby affecting non-tradable inflation and also the trade balance. 


\section{Box 3. Non-tradable and Tradable Inflation Rates in the Reaction Function}

Our choice of policy rule allows us to differentiate between the reaction of the monetary authority to domestic inflationary pressures on the one hand, and imported inflationary pressures on the other. More specifically, the non-tradable component of CPI inflation is usually driven by the cycle in domestic production, and hence in domestic consumption demand, and displays more sluggishness. On the other hand, reaction to the more flexible tradable component can be viewed more as related to the nominal exchange rate fluctuations and their pass-through onto domestic agents. Given the prominent role of the nominal exchange rate, especially in emerging economies, central banks often express different preferences when responding to these two types of phenomena.

Furthermore, the structure of our DGE model allows for a permanent differential between the tradable and non-tradable inflation rates in the long run. This differential is given fundamentally by the fact that productivity growth in tradable sectors (exporting industries) exceeds productivity growth in nontradable sectors. As a result, the central bank can fully control the long-run inflation rate in the headline CPI but not the inflation rates in the underlying tradable and non-tradable components. In other words, for any given headline target we can uniquely determine the inflation rates for tradables and non-tradables that are consistent with it in the long run. These inflation rates will be, in general, given by the tradables (or non-tradables) share of consumption and by the productivity growth differential, for example, by economic parameters that are beyond control of the central bank.

When empirically evaluating the model on the history, we thus need to construct these underlying, or implicit, targets for tradables and non-tradables, and use them in our reaction function.

We make several important simplifications in model design, noting that several missing elements can be added to the model relatively easily. The absence of the labor market and investment behavior (and hence only a partial capture of import dynamics) is perhaps the most visible limitation of the model. ${ }^{19}$ While we acknowledge that the coverage of these features is important in many ways, we do not consider them essential for the purposes of describing the monetary policy transmission in Turkey. We deliberately abstract from explicit primary input factor markets (such as labor and capital markets) to keep the model and modeling issues on a small and understandable scale. For instance, the round-about production assumption in the non-tradable sector is a short-cut to a full modeling of the labor-intensive domestic sector of the Turkish economy (Basu, 1995). Capital accumulation is omitted, because it would unnecessarily add to the complexity of model's calibration, and also would force forecasters to take a stance on the steady state evolution of the capital stock. The absence of investments also implies that the import dynamics is only partially captured

${ }^{19}$ Exports also are semi-exogenous to the model in the sense that their dynamics is completely driven by exogenous fluctuations in the terms of trade (and the sector-specific real rigidities), but their wealth and income effects are fully incorporated. Based on the discussion in Section III, we believe that the changing dynamics of Turkish exports is still much more dependent on exogenous drivers (for example, terms of trade) than on the fluctuations of domestic (labor) cost conditions, justifying our specification. 
in the model, because of the high import content of investment in Turkey. ${ }^{20}$ Despite these limitations, the model can easily be extended to capture all or some of these elements, as shown in Benes and others (2006).

\section{Calibrating the Model and Model Properties}

We parameterize the model using both economic and more formal econometric criteria. In following a long tradition (see Canova and Ortega, 1996, for a discussion), we choose the model parameters to achieve realistic dynamic properties and a reasonable match between the model's implied business cycle correlations and those observed in the data. In doing so, we analyze some of the first and second-moment features of the model against the background of observed data and economic intuition, with emphasis placed on the model's capacity in storytelling (exemplified by the model's impulse responses) and forecasting (variance decomposition). In Section VI we investigate how the model performs on the observed Turkish data by examining its other properties, such as serial and cross-correlations, historical residuals, and their contributions to the observed paths of key variables, historical forecast errors.

\section{A. Calibration}

We use a combination of estimation and less formal calibration approaches in parameterizing the model. Taking advantage of the separation between the non-stochastic steady state (BGP) and the transitory dynamics of the model, we can distinguish, and adopt different strategies in calibration of, three basic groups of parameters: (i) non-stochastic steady-state parameters, (ii) behavioral transitory parameters, and (iii) standard deviations of shocks and the autoregression coefficients of some variables. We parameterize the first group by matching the model implied first unconditional moments to those observed in the data. This is, in fact, an exactly identified method of moments. We then estimate the other two groups of parameters. However, prior to estimation, we impose a number of restrictions (especially in the form of lower bounds and/or upper bounds for behavioral parameters) to preserve the economic interpretation of some parameters, or to guarantee that the model lies within the Blanchard-Kahn stability region. The estimation is run on a data sample covering the period 1996 Q1 to 2004 Q4.

There are a total number of 11 non-stochastic steady-state parameters. We fix two steadystate parameters: the discount factor of households $\beta$, and the tradable share of

${ }^{20}$ It should be noted, however, that the investment cycle has usually very limited impact on the first-round determination of CPI inflation. On the demand side, investment producers or investment importers are rather distinct from those operating in a consumption goods market. Cycles in their real marginal costs are therefore linked through second-round effects only. On the supply side, fluctuations in physical capital (inducing changes in the cost position of producers) are typically rather small and distributed over a long time. 
consumption $\omega$. The first parameter is rather weakly identified from the data. The second parameter is directly determined by the definition of the CPI basket. Other five steady-state parameters, that is, non-tradable growth $\alpha_{n}$, export growth, $\alpha_{x}$, the re-export share of exports $\gamma_{x}$, the government consumption to private consumption ratio $\sigma$, and the average markup $\mu$, are set to exactly reproduce the sample averages of five observed first-moment characteristics (Table 1): consumption growth, export growth, the tradable/non-tradable inflation differential, the export to private consumption ratio, and the government consumption to private consumption ratio (the last two in nominal expenditure terms). ${ }^{21} \mathrm{The}$ results are reproduced in Table 2 .

Table 1. Steady-state Characteristics of the Model

\begin{tabular}{ll}
\hline Real consumption log-growth & 3.87 \\
Real export log-growth & 6.11 \\
Non-tradable vs. tradable inflation differential & 4.98 \\
Government consumption to private consumption & 0.19 \\
Exports to private consumption & 0.38 \\
Imports to private consumption & 0.38 \\
Intermediates share of model GDP & 0.20 \\
Re-exports share of model GDP & 0.06 \\
\hline
\end{tabular}

Table 2. Steady-state Parameters

\begin{tabular}{clr}
\hline$\alpha_{n}$ & Non-tradable sector log-growth & 1.13 \\
$\alpha_{x}$ & Export sector log-growth & 6.11 \\
$\omega$ & Tradables share of consumption & 0.55 \\
$\gamma_{n}$ & Intermediates share of non-tradables production & 0.59 \\
$\gamma_{x}$ & Imports share of export production & 0.18 \\
$\sigma$ & Ratio of government to private consumption & 0.19 \\
$\pi$ & Ultimate log inflation target & 5.83 \\
$\pi_{m f}$ & Foreign-currency import price inflation & 0.80 \\
$\eta_{\mathrm{s}}$ & Systematic disparity & 17.06 \\
\hline
\end{tabular}

There are six behavioral transitory parameters in the model, excluding the autoregression coefficients introduced in the external processes and in the policy reaction function. We estimate these parameters by a standard maximum likelihood method together with the

${ }^{21}$ There are also four other auxiliary level constants: the permanent wedge between the interest rate implied by the model and observed in the data for both the domestic economy and the rest of the world (see Appendix II), the long-run disparity term, and the long-run level of foreign-price import inflation. We can identify these parameters out of the likelihood function in the subsequent estimation step, and make them linear functions of observed data. 
standard deviations and autoregressions. Some of these parameters, however, hit the lower or upper bound imposed on them to induce the Blanchard-Kahn stability or to preserve their economic interpretation. We may thus think of these parameters as being calibrated rather than estimated. This is the case regarding the following three parameters: the policy reaction to fluctuations in tradable inflation, $Y_{\beta}$, and non-tradable inflation, $Y_{n}$, and (the inverse of) the relative importance of export output adjustment costs, $\Psi_{x}$. We report the behavioral parameters in Table 3.

Table 3. Behavioral Transitory Parameters

\begin{tabular}{llr}
\hline$\chi$ & Habit & 0.66 \\
$v$ & Debt elasticity of premium & 0.001 \\
$\xi_{\tau}$ & Tradable price elasticity & 0.28 \\
$\xi_{\mathrm{n}}$ & Non-tradable price elasticity & 0.10 \\
$\xi_{\mathrm{x}}$ & Export output elasticity & 0.05 \\
$\kappa_{\tau}$ & Policy reaction to tradable inflation & 0.55 \\
$\kappa_{\mathrm{n}}$ & Policy reaction to non-tradable inflation & 0.55 \\
\hline
\end{tabular}

An important part of the calibrating procedure for the transitory parameters was crosschecking of the model shock responses and other model properties. The model is designed to have realistic and economically plausible properties, in which the estimation procedure and/or peculiarities of observed data should not be a constraint. We therefore examined both transitory shocks (such as demand, cost-push, or risk premium shocks) and permanent shocks (such as disinflation, shocks to the terms of trade or technology) and other economic properties (such as the sacrifice ratio, the on-impact pass-through of the nominal exchange rate following various shocks, or relative stickiness of inflation in both sectors) to see whether they conform to economic intuition and other evidence we have for the Turkish economy. Since the maximum likelihood procedure described above does indeed yield parameter values that produce reasonable model properties, no adjustments were made.

The standard deviations (a total of 14 relative standard deviations), autoregression coefficients (a total of five autoregressions), and a subset of three behavioral transitory parameters were estimated by a standard maximum likelihood function. We use the Kalman filter to evaluate the likelihood function, find the estimates of parameters concentrated out of the likelihood function (the three level constants described above and the common scaling factor for standard deviations), and compute the optimal linear projection of the unobserved model variables including the structural shocks, on the observables. Our set of observables consists of the following 10 variables: tradable inflation, non-tradable inflation, import price inflation, the domestic nominal interest rate, the rate of change in the nominal exchange rate, real private consumption growth, real export growth, the ratio of the nominal government consumption to private consumption, the foreign interest rate, and the rate of change in the terms of trade. The point estimates are summarized in Tables 4 and 5. 
Table 4. Autoregressive Coefficients

\begin{tabular}{clr}
\hline$\rho_{\mathrm{u}}$ & AR of forex premium & 0.66 \\
$\rho_{\mathrm{i}}$ & Policy rate smoothing & 0.31 \\
$\rho_{\text {targ }}$ & AR of inflation target & 0.993 \\
$\rho_{\text {tot }}$ & AR of terms of trade & 0.00 \\
$\rho_{\mathrm{if}}$ & AR of foreign interest rate & 0.91 \\
$\rho_{\mathrm{pmf}}$ & AR of foreign-currency import inflation & 0.06 \\
\hline
\end{tabular}

Table 5. Standard Errors of Shifters

\begin{tabular}{clr}
\hline$\varepsilon_{\mathrm{t}}^{\mathrm{cd}}$ & Consumption demand shifter & 1.10 \\
$\varepsilon_{\mathrm{t}}^{\mathrm{gd}}$ & Government consumption shifter & 7.97 \\
$\varepsilon_{\mathrm{t}}^{\mathrm{u}}$ & Forex premium shifter & 7.29 \\
$\varepsilon_{\mathrm{t}}^{a \tau}$ & Tradable technology shifter & 0.50 \\
$\varepsilon_{\mathrm{t}}^{\mathrm{p} \tau}$ & Tradable cost shifter & 3.07 \\
$\varepsilon_{\mathrm{t}}{ }^{a n}$ & Non-tradable technology shifter & 1.95 \\
$\varepsilon_{\mathrm{t}}^{\mathrm{pn}}$ & Non-tradable cost shifter & 0.83 \\
$\varepsilon_{\mathrm{t}}^{a x}$ & Export technology shifter & 2.00 \\
$\varepsilon_{\mathrm{t}}{ }^{a}$ & Transitory export output shifter & 5.70 \\
$\varepsilon_{\mathrm{t}}^{m p}$ & Monetary policy shifter, PA & 11.91 \\
$\varepsilon_{t}^{\text {targ }}$ & Inflation target shifter & 6.28 \\
$\varepsilon_{t}^{\text {tot }}$ & Terms of trade shifter & 3.67 \\
$\varepsilon_{t}^{i f}$ & Foreign interest rate shifter, PA & 0.29 \\
$\varepsilon_{t}^{p m f}$ & Foreign-currency import inflation shifter & 3.94 \\
\hline
\end{tabular}

\section{B. Model Properties}

Given the model calibration, we examine two types of model properties. First, we investigate the model's behavior in response to shocks (impulse responses). In addition to helping understand model behavior, these experiments have been an important part of our calibration strategy. Second, we perform a forecast variance decomposition, implied by the estimated variance of the model residuals, in order to see which shocks are the most important in explaining the variation of model forecasts.

\section{Impulse Responses}

Two types of model properties are investigated in these experiments: (1) the transitory behavior of the model in response to a temporary shock, before the model settles back in its original steady state (impulse response); and (2) the model response to permanent shocks that change its steady state; in this case we want to investigate both the nature of the new steady state and the transition toward it. 


\section{Temporary Shocks}

Each of the model's temporary innovations are shocked by an unexpected one percentage point change in the first period of the simulation. The economic interpretation of the shocks depends on which model agent's behavior they affect, but in most cases is very intuitive, with direct counterparts to shocks in simpler 'gap' models of the monetary transmission (see for example, Benes and others, 2003; or Berg and others, 2006a and 2006b).

There are nine temporary shocks in the model, affecting the transitory behavior of the model around the BGP. Of these, the consumption (demand), inflation (cost push), monetary and risk premium shocks are found most important in explaining the observed features of the Turkish data, when matching the model with historical data in the next section.

\section{Demand Shock (Figure 5)}

- The shock temporarily lowers the inter-temporal elasticity of consumption, making current consumption more desirable. In the linearized version of the model, the shock enters the consumption Euler equation ('IS' curve), making it a counterpart to conventional demand shocks in non-microfounded models. When matching the model with historical data in the next section, we find the shock important in explaining the behavior of household consumption, but not so for the other variables.

- The level of consumption rises on impact, driving up both domestic non-tradable production and imports, while the trade balance deteriorates. As inflation goes up in response to rising non-tradable production (real marginal costs), monetary policy reacts by raising interest rates, and thus appreciating nominal and real exchange rates. Despite the real exchange rate appreciation, tradable inflation rises, as economy wide inflation expectations increase, overriding the real exchange rate appreciation effect.

- Economic stabilization works through the domestic sector and takes about five years to complete. Consumption falls back in response to rising interest rates, bringing down nontradable output and imports. The fall in output stabilizes non-tradable inflation within two years, while tradable inflation overshoots the target temporarily, as the nominal exchange rate depreciates toward its new steady state level which is reached in about five years after the shock. 


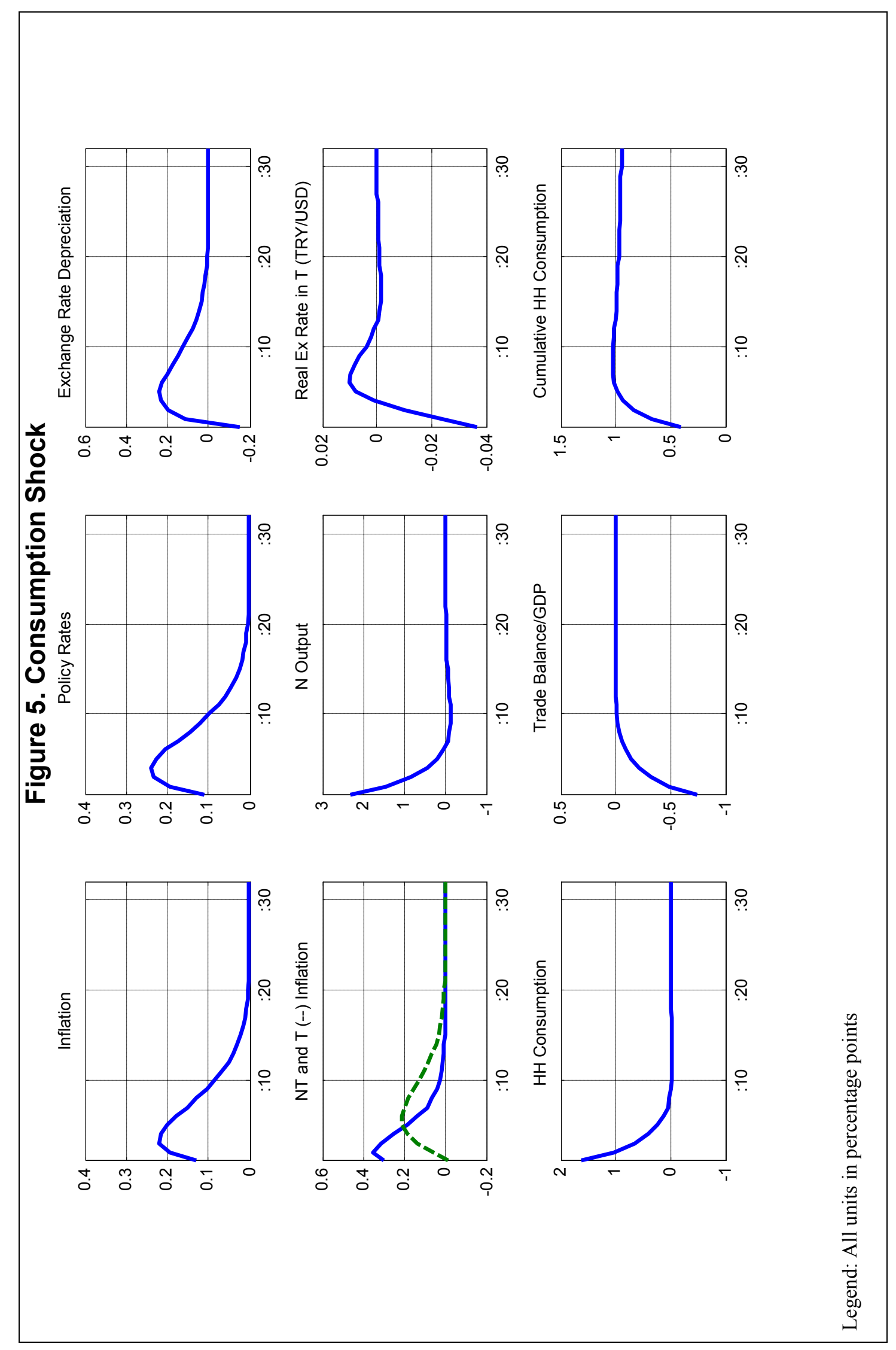




\section{Inflation (cost-push) shocks (Figures 6-8)}

- There are three inflation shocks in the model—one in each sector (idiosyncratic cost-push shocks), and a general one (an economy-wide cost-push shock) affecting simultaneously inflation in both sectors. These shocks push up temporarily the marginal cost curves of producers in the tradable and non-tradable sectors, increasing inflation rates above of what would be implied by forward-looking optimization based on the expected evolution of real marginal costs. In the linearized version of the model, the shocks enter the Phillips curves in each sector, making them counterparts to inflation shocks (such as an increase in inflation expectation) in non-microfounded models. Below we find the general and tradable sector inflation shocks important in accounting for the observed behavior of inflation, interest rates and consumption growth. On the other hand, the non-tradable sector shock is not very significant.

- Following the cost-push shock, the inflation rate in the affected sector rises on impact, driving up headline inflation, but also inducing a substitution effect between the two types of goods in consumption. The substitution effect is absent with the general inflation shock. Monetary policy raises interest rates in response to rising inflation, bringing about a nominal and real exchange rate appreciation, and lowering consumption. In all three inflation shocks the trade balance improves as a result of falling consumption and imports, but the improvement is negligible and short-lived in the non-tradable shock because of the substitution effect between domestic and imported goods. For the same reason the non-tradable production and consumption stay put in the case of the tradable sector shock, despite the overall consumption decline.

- Stabilization works through the real marginal costs in the affected sector and lasts about four years (three in the tradable sector shock). The contraction of non-tradable output following the decline in consumption gradually brings down non-tradable inflation in both the non-tradable and general shocks, while a persisting real appreciation drives down the tradable and overall inflation in the case of the tradable and general shocks. Tradable inflation temporarily overshoots in case of the non-tradable shock, as the nominal exchange rate depreciates toward its new steady state level. The same is true for non-tradable inflation after the tradable shock, induced by the substitution effect. 


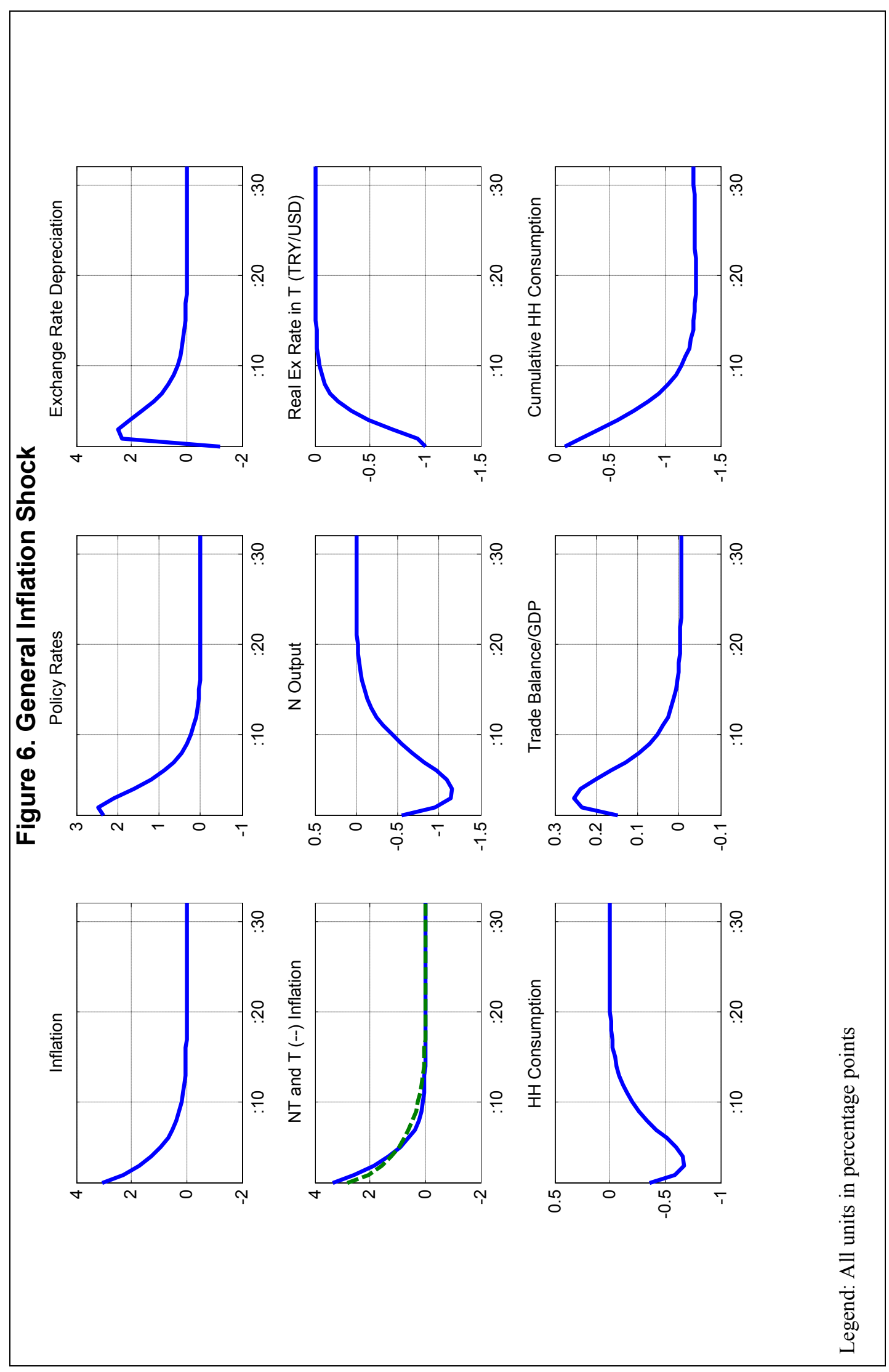




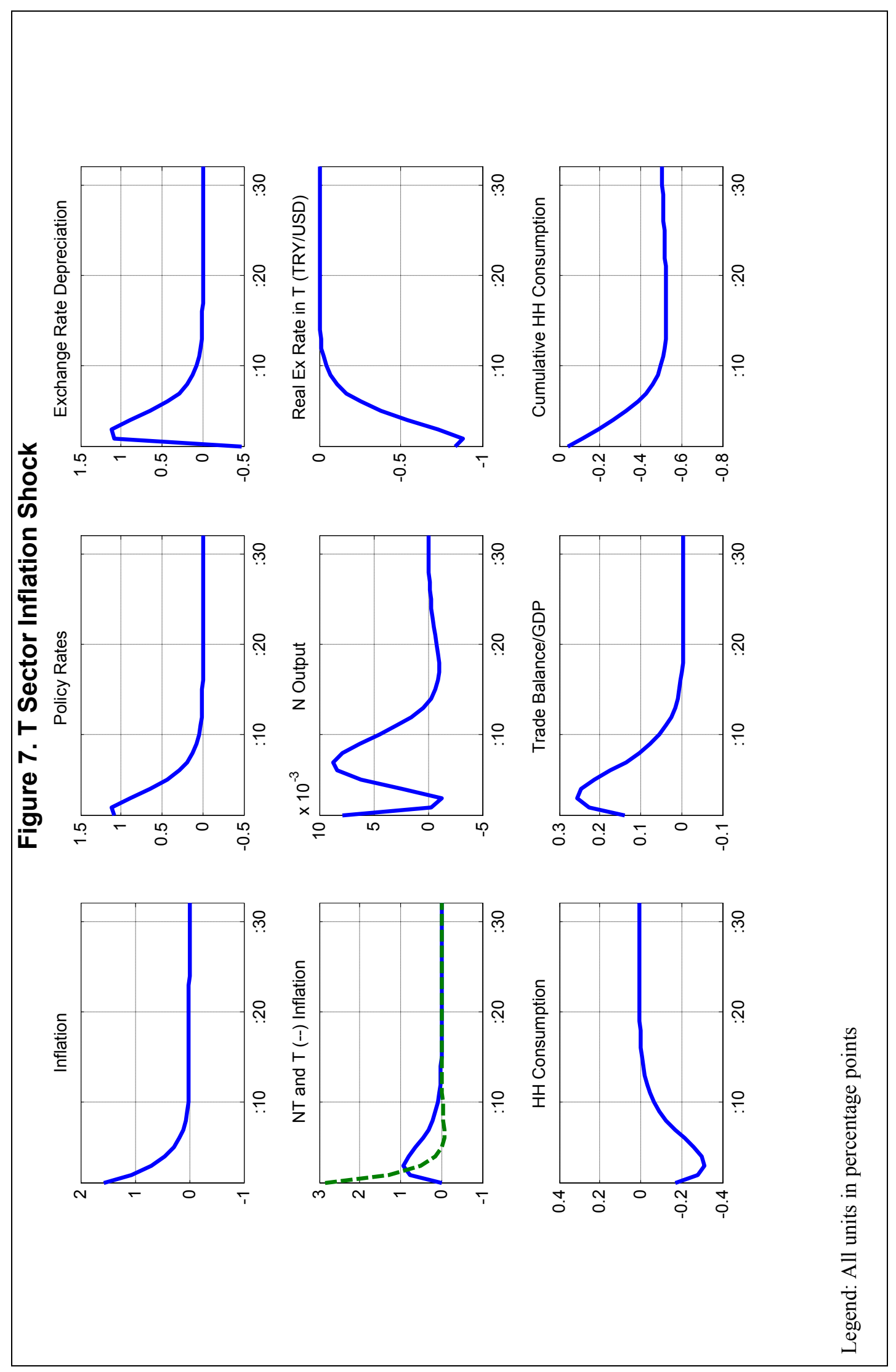




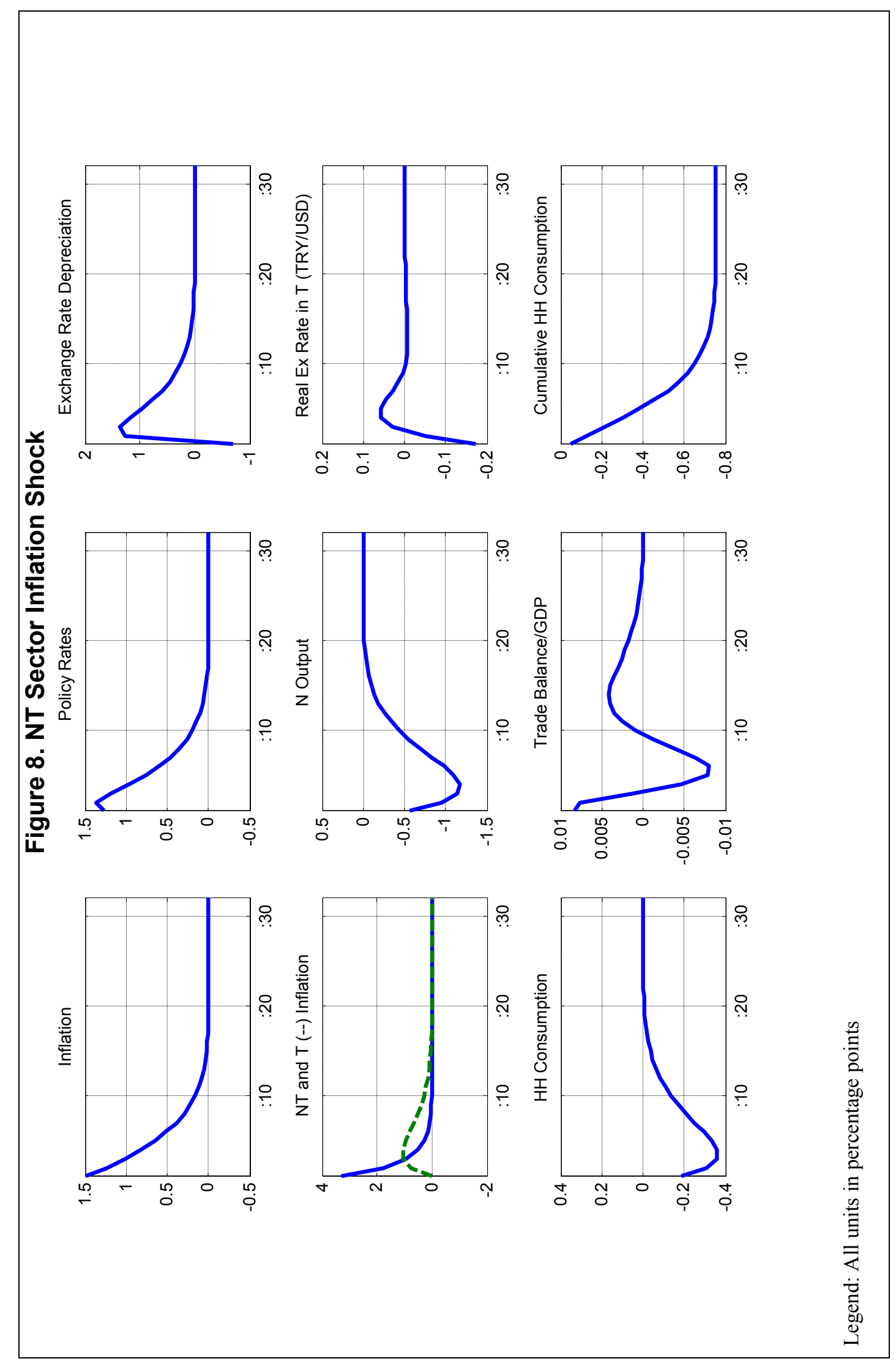




\section{Monetary policy shock (Figure 9)}

- The shock assumes that the monetary authority temporarily deviates from its rule by unexpectedly raising policy rates (and realizing this error in the next period). In the next section, we find such shocks important in explaining the actual behavior of interest and exchange rates, and also consumption in Turkey, especially before the crisis period.

- Interest rates rise on impact, bringing down consumption and appreciating the exchange rate, which overshoots its new steady state level. Following the decline in consumption, output declines in the non-tradable sector, bringing down non-tradable inflation. Tradable inflation falls too, as the real exchange rate appreciates. The trade balance improves, as imports fall together with consumption.

- In stabilizing the economy (that lasts about four years), interest rates fall, thus correcting for its previous 'erroneous' hike. Consumption and the non-tradable output recover, bringing non-tradable inflation back to target. Tradable inflation also recovers, as the

nominal exchange rate depreciates somewhat, partly offsetting the previous appreciation.

\section{Risk premium shock (Figure 10)}

- The shock raises the premium over the world rate required by investors into domestic assets, which is otherwise related to the overall stock of the country's debt. In the model, the shock is persistent (with a degree of persistence parameterized in a calibration procedure above) but not permanent - in the sense that it does not alter the model's steady state. The shock affects the UIP equation in the linearized model, and so its counterparts in 'gap' models are foreign exchange market shocks to the exchange rate or risk premium.

- The exchange rate depreciates on impact, overshooting its new BGP trajectory. The simultaneous depreciation of the real exchange rate drives up tradable sector inflation. Monetary policy reacts to the rising inflation by tightening interest rates, pushing down domestic consumption. The trade balance improves significantly because of both falling consumption and substitution of the more expensive tradable goods for domestic nontradables.

- The behavior of the real exchange rate is a key channel in stabilizing the economy, which takes six long years. The nominal exchange rate starts appreciating mildly toward its new BGP trajectory, as the risk premium gradually reverts to its steady state level. The real exchange rate follows suit, bringing tradable inflation back to target. The stabilization of headline inflation is delayed by a temporary rise in non-tradable inflation that is spurred by a rise in the consumption (and production) of non-tradables due to the substitution effect. 


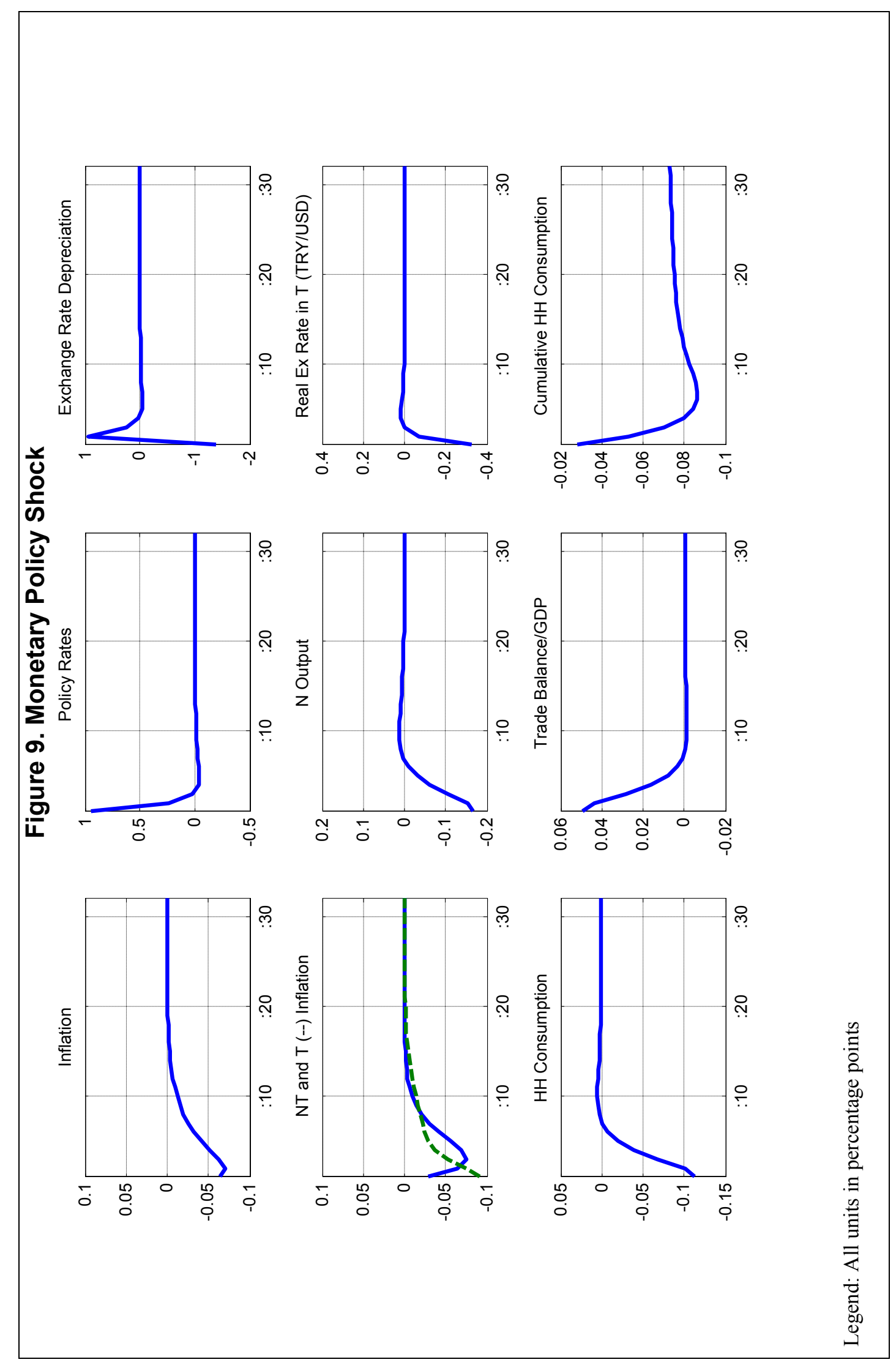




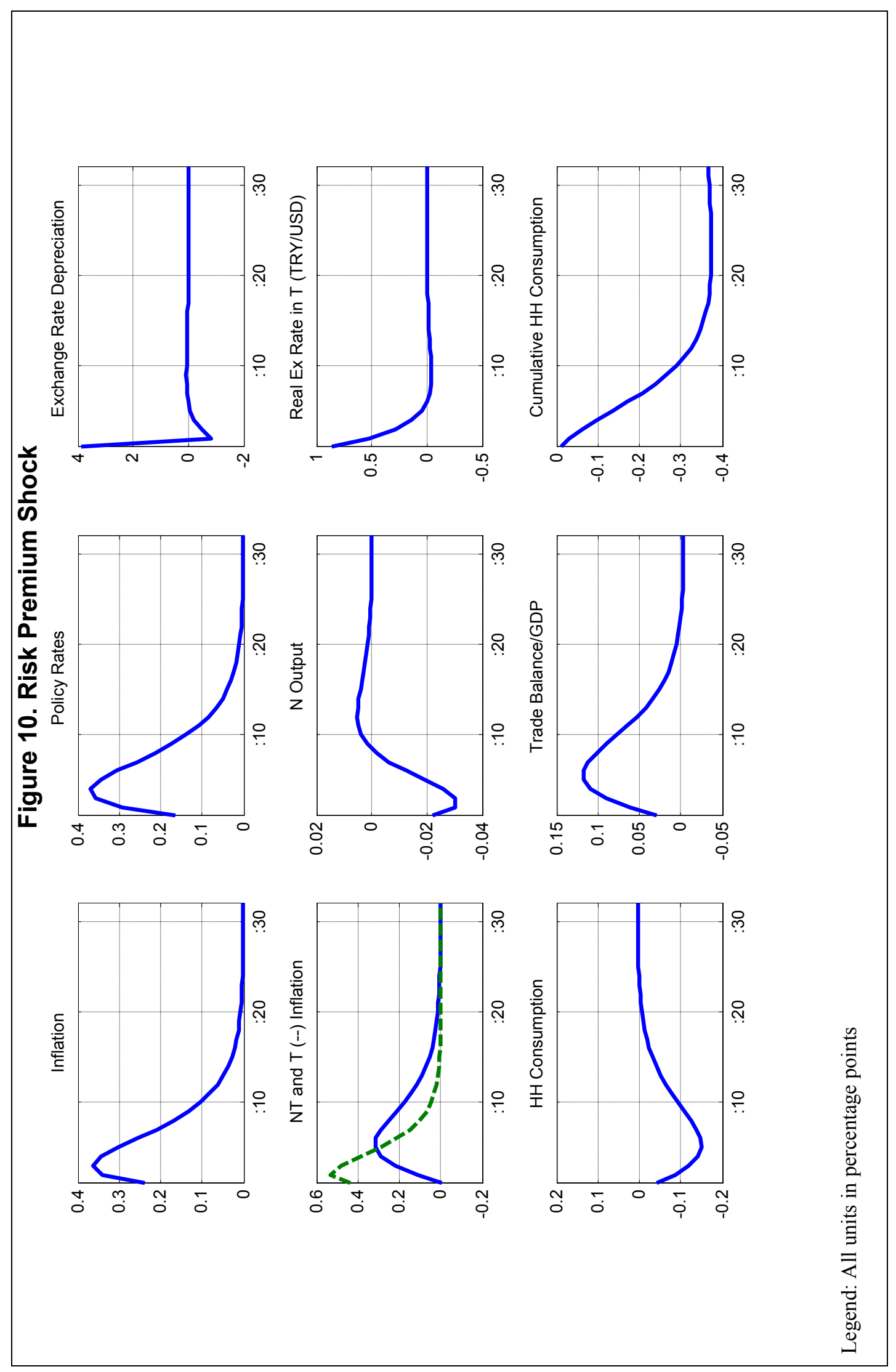




\section{Permanent shocks}

Unlike temporary shocks, permanent shocks alter the model's steady state or its balanced growth path. It should be noted, however, that all nominal expenditure ratios and real growth rates remain unchanged (these are determined solely by the model's parameters and are pathindependent). It is only the relative prices and the allocation of real resources that change in response to permanent shocks.

The changing steady state often calls for a different type of monetary reaction than would be required by a temporary shock. For instance, a temporary rise in output (e.g., through a consumption spending shock above) will require interest rate tightening, unlike an increase in output and consumption triggered by a permanent productivity improvement.

Compared to temporary shocks, permanent shocks can often be more informative about the model's properties and its capacity to replicate observed data features, because they are typically more easily detected in an ex-post data analysis than temporary shocks. For instance, in the Turkish economy, we know when the disinflation program began and inflation targets were set. We can also observe the fall in the risk premium associated with building credibility in a new monetary and fiscal policy mix. In other instances, we may know (with the benefit of hindsight) that a technology productivity shift has occurred. ${ }^{22}$

There are permanent shifters for five variables in the model: the inflation target, the productivity levels in the tradable and export sectors, the real exchange rate in the tradable sector, and the terms of trade. In Section VI, we find that permanent changes in the inflation target and in the terms of trade are the most important factors in the Turkish data.

\section{Permanent Disinflation (Figure 11)}

- We lower the inflation target permanently by one percentage point. In the exercise performed in the next section, changes in the inflation target appear by far to be the most important drivers of inflation and nominal interest rates in Turkey.

- In the new steady state, all nominal variables adjust according to the new inflation target, while the paths of real variables are not affected. Inflation rates in both sectors permanently drop by one percentage point; the same is observed in nominal interest rates, while real interest rates remain unchanged. The nominal exchange rate settles on a new trajectory that is stronger compared to that prior to the shock, because the price level is also lower than without disinflation. The slope of the exchange rate trajectory is different

\footnotetext{
${ }^{22}$ Typically, we can distinguish permanent from temporary shocks only after enough data have been collected, which greatly complicates monetary policy making. The use of structural (and general equilibrium in particular) models should help policy makers in uncovering permanent shocks faster.
} 
too: the nominal exchange rate is now appreciating by one percentage point faster (or depreciating less, depending on the pre-shock conditions) than before in order to keep the pace of real appreciation unchanged.

- The transition toward the new steady state involves real variables and lasts about three years, so it is relatively quick. The model was calibrated so that the disinflation process is initiated without an initial rise in the policy rate. Since model agents are very forwardlooking, the price-setting relatively flexible, and monetary policy is known to be very reactive, agents' inflation expectations fall, pushing real interest rates up. Higher real interest rates bring down consumption, associated with declining domestic output and imports. The trade balance improves. As the negative output gap opens in the nontradable sector, non-tradable inflation falls. The initial rise in real interest rates also triggers a real exchange rate appreciation, putting a downward pressure on tradable inflation.

- The real adjustment of the economy in terms of output and consumption fall reflects the costs of disinflation. The implied sacrifice ratio is about 0.35 for consumption and somewhat higher for non-tradable sector output, implying relatively low real costs of disinflation. ${ }^{23}$ While these numbers are higher than the maximum estimate of 0.16 obtained by Cetinkaya and Yavuz (2002) based on disinflation episodes in the 1990s, we believe they are more relevant for a more recent period in which the ratio likely increased as the inflation rate and inflation expectations became more anchored at low levels. The model implied ratio is also more consistent with the observed facts after 2001.

${ }^{23}$ Following standard practice, we compute the sacrifice ratio as $1 / 4$ of the cumulative real consumption loss (relative to the no-disinflation case) induced by a 1 percentage point (annualized) unanticipated and instantaneous drop in the inflation target. 

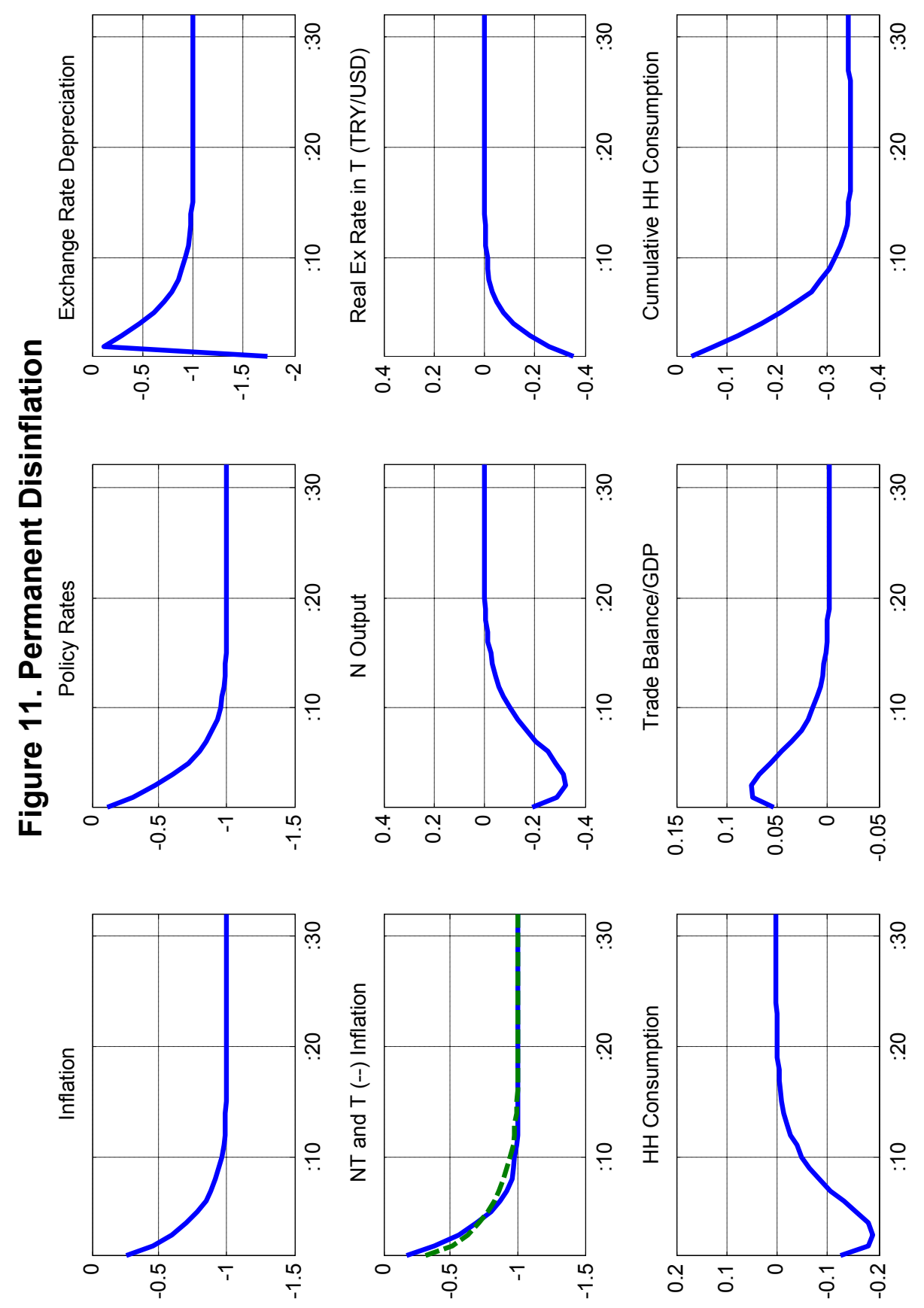

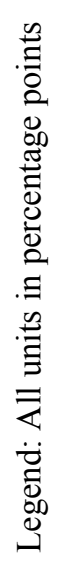




\section{Permanent terms of trade shock (Figure 12)}

- We permanently increase the terms of trade by one percentage point. The permanent shift in the terms of trade has been found important in explaining the circumstances of the 2001 crisis and the dynamics of consumption in the Turkish data (see Section VI).

- On the new steady state, the permanent improvement in the terms of trade changes the levels of real variables without affecting their growth rates. The shock permanently raises the level of exports and imported intermediates and through income effects also consumption and imports for consumption. Non-tradable production, on the other hand, is unaffected, because the relative price of tradables declines, inducing substitution away from the domestic production. Inflation remains on target and the steady state levels of real and nominal interest rates are unaffected, as the growth rates of real variables remain unchanged. The rate of nominal depreciation is unchanged too, but the level of the nominal exchange rate is on a permanently stronger BGP trajectory, owing to the overall decline in the price level.

- In transiting toward the new steady state (which takes about four years), exports rise on impact improving the trade balance, and the nominal exchange rate appreciates. The associated real appreciation brings down tradable and headline inflation rates, which triggers a monetary policy loosening. The loosening initiates a gradual rise in consumption toward its new steady state level. The rising consumption also spills over to imports, and trade balance reverts to its initial position. The monetary loosening also slows down the speed of nominal appreciation, and the real exchange rate gradually depreciates bringing the inflation back to the target. 


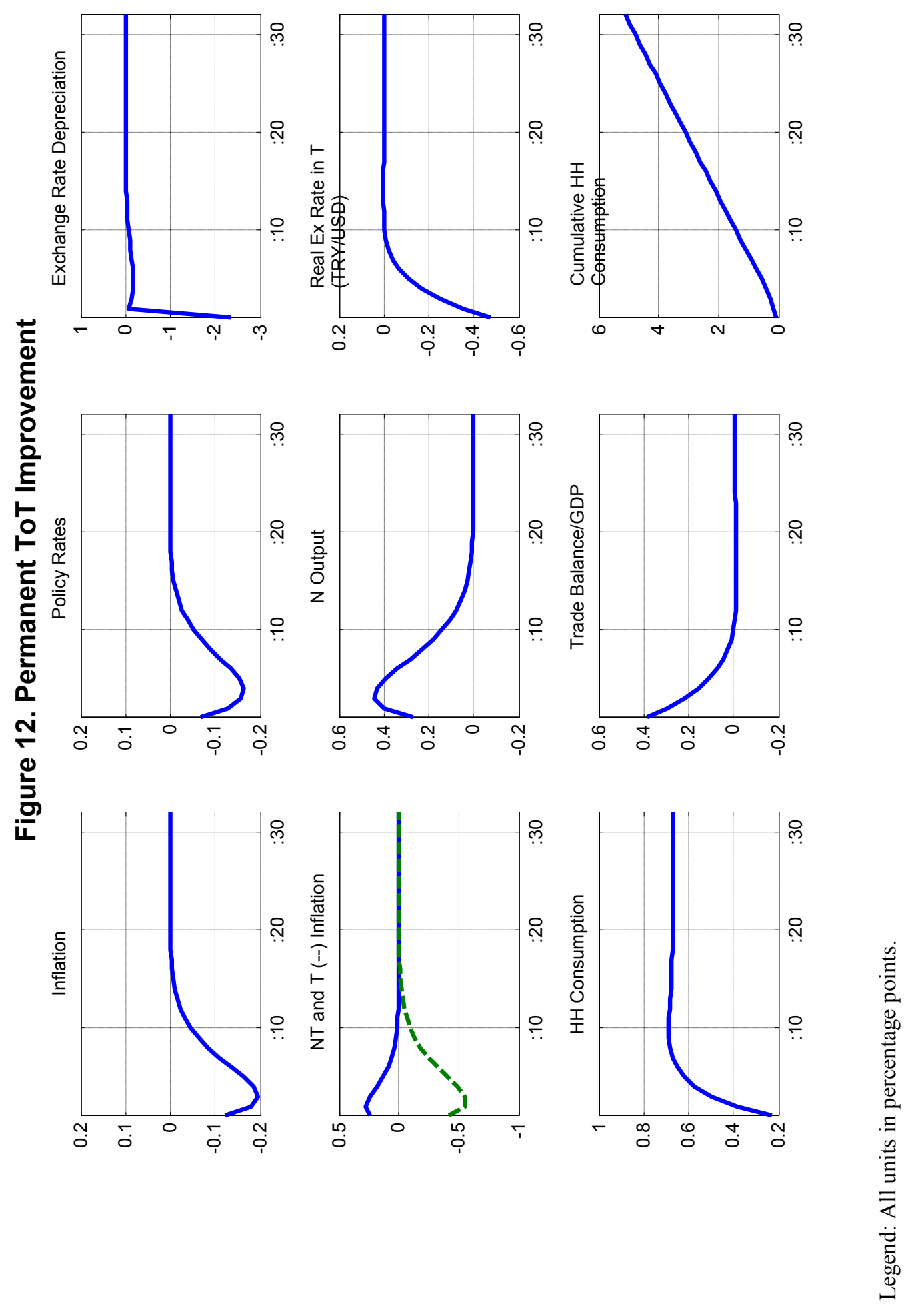




\section{Forecast error variance decomposition}

Variance decomposition is a useful tool for understanding which shocks account for most of the model's forecasting errors. The procedure decomposes the variance of the conditional $k$ quarters ahead forecast of each variable into the contributions of each of the model's structural shocks. With the forecast horizon going to infinity forecast variance approaches its asymptotic (unconditional) bounds. For the purpose of the exercise, we set the target shock variance to zero, as the target is deterministic in a credible inflation targeting regime.

Figure 13 shows the relative contributions of model shocks to the variability in the rates of tradable and non-tradable inflation, interest, nominal exchange rate growth, and consumption growth for up to five years. ${ }^{24}$ The decomposition shows that general (economy-wide costpush) shocks to inflation play a large role in explaining the variability of inflation and interest rates:

- The initially large importance of monetary shocks in explaining interest rate variability is reduced over the forecast horizon in favor of general inflation shocks. The importance of specific tradable and non-tradable inflation shocks rises, too.

- Non-tradable inflation variability is dominated by the general inflation shocks on the entire horizon, with the importance of sector specific shocks rising on longer horizons.

- The variation in tradable inflation is driven primarily by inflation shocks. While the specific shock to tradable inflation is most important in short horizons, a general inflation shock explains an increasing proportion of the variation with a rising forecasting horizon.

Figure 13 also shows that a mixture of shocks explains the variability in consumption and exchange rate growth.

- Demand, monetary policy, general inflation, and terms of trade shocks are the most important for consumption growth, with similar weights over the forecasting horizons.

- For exchange rate variability, the risk premium, interest rate, foreign inflation, and terms of trade are the most important shocks in short horizons, while the contribution of general inflation shocks rises somewhat on longer horizons.

\footnotetext{
${ }^{24}$ In inspecting absolute contributions (not reported here), we find additionally that the forecast variances for most variables reach levels close to their asymptotic bounds (i.e., stabilize) within a horizon of about 2 and a half years.
} 


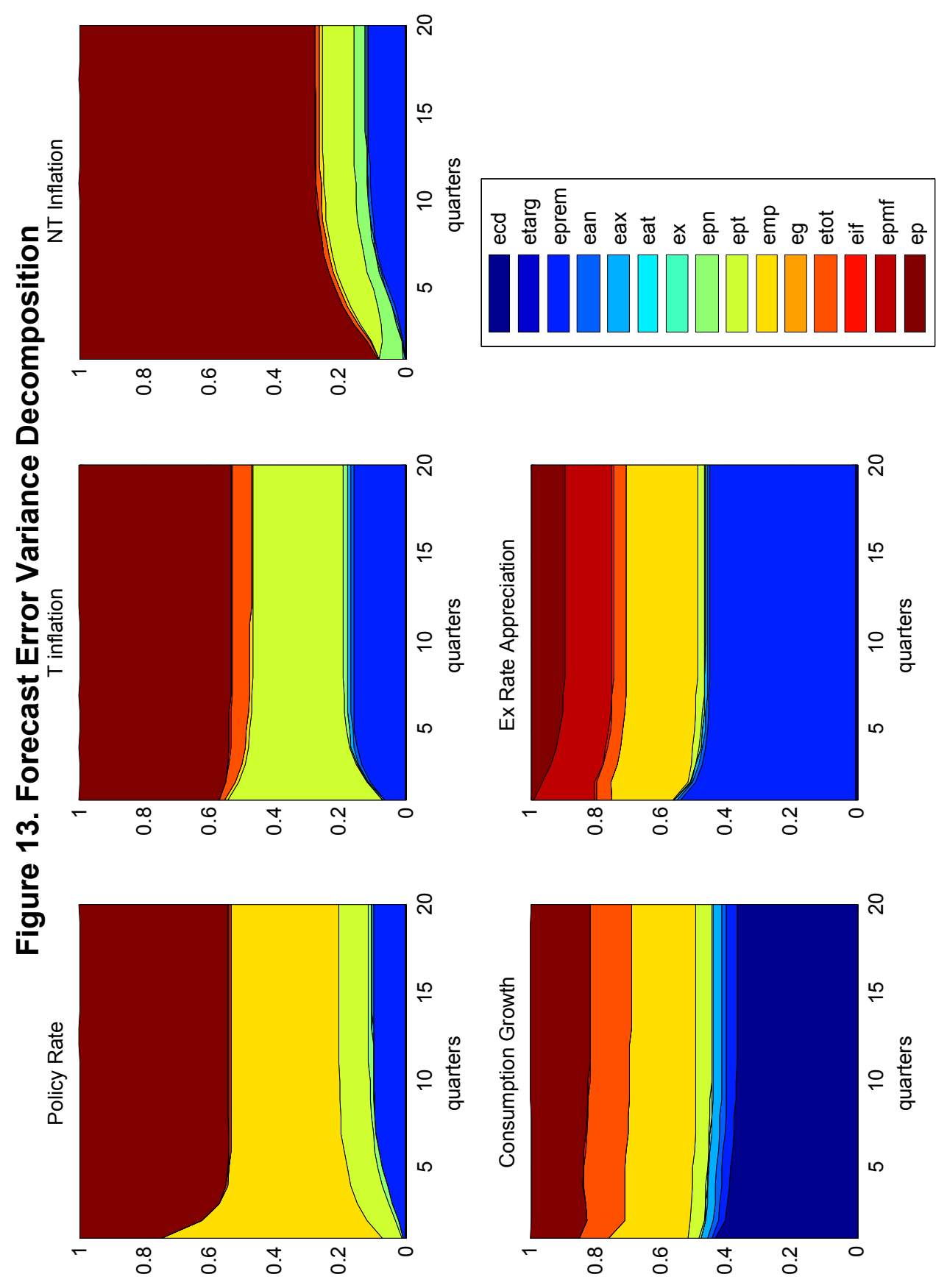




\section{Learning From Recent Turkish Data Using The Model}

In this section we apply our model to Turkish data, investigating what aspects of data described in the previous sections the model replicates. We perform a set of exercises, whose purpose is not so much to find out how the model fits the data, but rather to learn something about Turkish economic history and also about the model's capacities and limitations.

In examining the aspects of data the model replicates we use the results from the maximum likelihood estimation from the previous section. Maximum likelihood is the last step in parameterizing the model. When evaluating the likelihood function we also obtain the estimates of all unobserved components, including the model's various structural shocks. These estimates are optimal linear projections consistent with (i) the model structure and (ii) the historical paths of observable variables. We analyze these shocks in order to get an economic interpretation of the model-consistent forces behind the observed Turkish data. Second, given the parameterization of the model, including the standard deviations of shocks, we compare the asymptotic distributional aspects of the Turkish data to those predicted by the model. Third, we examine the model's in-sample forecasting properties by performing a series of historical forecasts with the model.

\section{Analysis of historical shocks}

Figures 14-16 summarize the estimation results in terms of shocks, their contributions to the development of observed variables, and the profile of key unobserved variables. The estimated shocks from Figure 14 are translated into their contribution to the evolution of the observed variables in Figures $15 \mathrm{a}$ and $15 \mathrm{~b}$ through recursive model representation. In Figures 15a and 15b, we plot only the contributions of the four most important shocks (with the highest absolute mean contributions over the plotted sample) before and after the crisis respectively, not considering the effect of the deterministic component (related to the parameterization of the steady state) and the initial condition. ${ }^{25}$ Figure 16 then plots some of the observed variables with the Kalman filter estimates of the most important unobserved ones - such as implicit inflation targets and real marginal costs in the tradable and nontradable sectors.

An interesting feature of the estimation is that the estimated target is much lower than both the actual inflation and the official targets (Figure 16). ${ }^{26}$ Since the beginning of 1999 the

\footnotetext{
${ }^{25}$ We treat the initial condition as deterministic, too, for the sake this exercise. This is, however, not fully consistent as the initial condition could be further decomposed into asymptotic contributions of all shocks that could have hit the economy in pre-sample periods.

${ }^{26}$ Note that the implicit tradable and non-tradable inflation targets plotted in this figure are calculated by adjusting the headline CPI target for the systematic steady-state inflation differential between the two sectors.
} 
estimated target starts falling below the actual inflation-perhaps a sign of public confidence in the early inflation stabilization efforts. Although the fall in the estimated target stops temporarily in the crisis period, it soon resumes, becoming faster than both official inflation targets and actual inflation. As explained in the previous section, a decline in the model's target is the main driver of inflation expectations and disinflation in the model. In other words, the inflation target has to fall faster than actual inflation in a disinflation experiment when there is intrinsic persistence in inflation. Because in Turkey inflation actually undershot official targets for several years in a row, it follows that the 'true' inflation target implicitly perceived by the public was below both of them. ${ }^{27}$ The estimation thus points to a strong public confidence on the inflation stabilization program. Only toward the end of the 2004 is the estimated target close to actual inflation.

The estimation results place the financial crisis of the late 2000 in a broader economic context, revealing some of its important circumstances. In particular, although the immediate causes of the crisis were financial, Figure 14 show that a mixture of large real and monetary shocks began hitting the economy about a year and half before the crisis ${ }^{28}$

- A negative terms of trade shock was being offset by fiscal and monetary loosening that temporarily insulated the economy from an adjustment in 1999 (Figures 14 and 16). Fiscal policy became relaxed in early 1999 at the time when the economy was being hit by persistently negative terms of trade shocks and the non-tradable sector's productivity was falling sharply. Monetary policy loosening peaked in early $2000 .{ }^{29}$ Domestic consumption growth went up in late 1999/early 2000 in response to the monetary loosening, despite the negative terms of trade effect and the slowdown in export growth that occurred earlier in 1998. Disinflation did not proceed. The reaction of monetary policy thus went against the model implied reaction to a negative terms of trade shock, exacerbating the need for an adjustment later on.

${ }^{27}$ This conjecture assumes that the lowering of inflation targets was indeed the major source of the observed disinflation and not other shocks. It holds, although the surveyed public's inflation expectations were consistently above the declared targets. Inflation expectations and expectations about the target are different concepts, though the latter influences the former.

${ }^{28}$ According to OECD Economic Surveys (Turkey 2000/2001), the fragility of the banking sector, over-reliance on short-term capital inflows, and monetary injections of liquidity in violation of a fixed ex rate arrangement were the most important contributors.

${ }^{29}$ The monetary policy shocks have to be interpreted with caution though - they point to a policy too relaxed than what would be advocated by the expected future developments including the crisis - which clearly was not anticipated at the time. 
- The new stabilization program of 2000 led to monetary tightening, making the economy adjust to the terms of trade and other adverse real shocks. The fixed exchange rate based program and its quasi currency board rules lead to a gradual reversal of the loose monetary stance in 2000 (Figures 14, 15a). This allowed the already existing disinflation pressures in the economy to materialize: strong disinflation pressures from the overappreciated real exchange rate in the tradable sector and a temporary cyclical slow-down in the non-tradable sector were bringing inflation down sharply in early 2000 (Figure 16). However, as Figure 15a reveals, the decline in inflation in both sectors also owed much to the public's perception of a declining inflation target and the disappearance of general inflationary shocks from the previous period, which could be interpreted as a sign of public confidence in the new stabilization program and reduced inflationary expectations. Falling consumption growth caused large adjustments in the domestic sector, whose output began falling dramatically in early 2001, opening a large negative output gap in that sector and putting a further downward pressure on domestic prices (Figure 16).

- A sudden rise in the risk premium and shattered credibility into the new stabilization program stopped the disinflation process in 2001. The risk premium reversed its previous declining trend (Figure 16), probably reflecting foreign investors' doubts that the real costs of the stabilization program were sustainable and a loss of confidence in the program itself, after the monetary authority injected large amounts of liquidity in an effort to bail out the ailing banking system in late 2000 (OECD, 2000/1). The rise in the risk premium caused the exchange rate to depreciate and tradable inflation to soar. Nontradable inflation soon followed, despite the hugely negative output gap, owing to an economy-wide cost push shock (Figures 14,15a). This shock could (among other things) reflect a temporary rise in inflation expectations against the backdrop of these developments. Consistent with this hypothesis, the public's perception of the inflation target level rose after years of a steady decline (Figure 16), another sign of reduced credibility in the stabilization program.

- Tight monetary policy in the new stabilization program based on a floating exchange rate and implicit inflation targeting renewed investors' and public's confidence in 2001, eventually stabilizing the economy and bringing inflation down. Monetary policy stood tight for a while in 2001, gradually calming the markets (Figure 16). The risk premium stabilized, reducing the pressure on accelerating depreciation and tradable inflation. ${ }^{30}$ The new stabilization package was gradually gaining credibility (public's perception of inflation targets began falling again), which allowed the negative output gap in the domestic sector to eventually bring down non-tradable inflation. The relaxation of monetary policy in line with falling inflation and inflation expectations gradually allowed

\footnotetext{
${ }^{30}$ A panel in Figure 16 shows the estimated risk premium against the observed EMBI+ risk premium for Turkey that was not used in the estimation. The estimation captures very well the observed profile and fluctuations, although the level is shifted, reflecting the level wedges in interest rate estimation discussed earlier.
} 
consumption growth to recover, although it took three years for the non-tradable sector's output and for the cost position of producers (measured by real marginal costs) to recover fully from the 2001 recession.

The analysis of shock contributions to the observed developments in Figures 15a and 15b reveals that similar shocks were important drivers of the observed variables both before and after the crisis, although their relative importance changed in certain cases. For instance, the public's perception of declining inflation targets played an important role in driving inflation even before the inflation targeting regime was put in place. This could reflect the public's trust in the efforts to bring inflation under control when the first stabilization program based on the fixed exchange rate commenced in 1999.

The same analysis also shows that monetary shocks played much lesser role in driving economic variables after inflation targeting was put in place:

- The target shocks replaced monetary shocks as the most important driver of nominal interest rates, probably reflecting the more systematic nature of monetary policy reaction function after the crisis.

- Monetary policy shocks ceased to be an important driver of non-tradable inflation after 2001.

- The importance of monetary shocks for explaining consumption growth also declined after the crisis. In periods to follow, consumption was driven most by specific demand and inflation shocks, rather than terms of trade and monetary policy shocks as was the case before the crisis.

- Finally, the monetary shock's role in driving the exchange rate also declined after the crisis. While it was the chief factor behind the exchange rate before the crisis, risk premium, imported inflation and change in the target became more important with the advent of inflation targeting. 

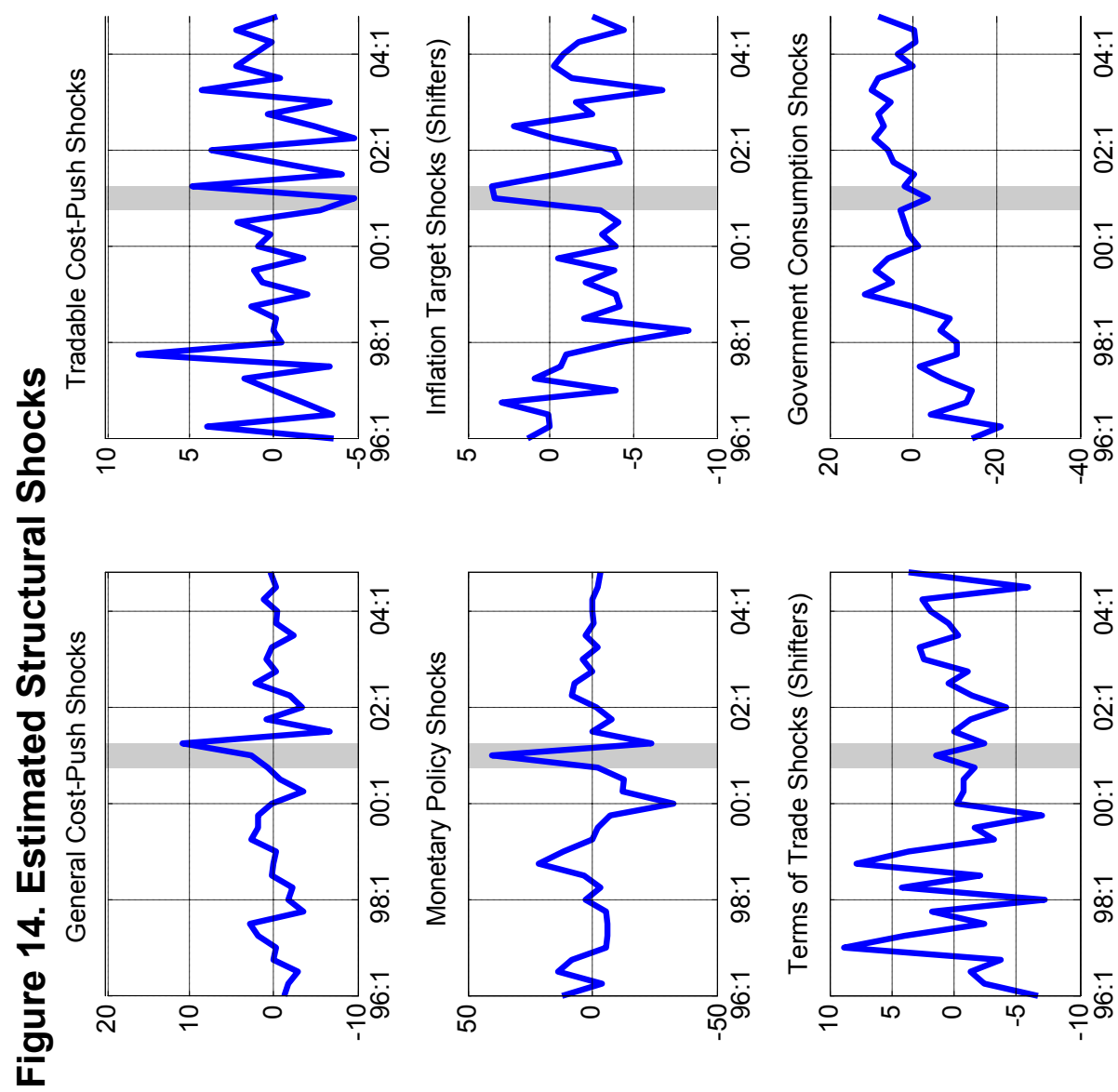

$$
\text { 广 }
$$




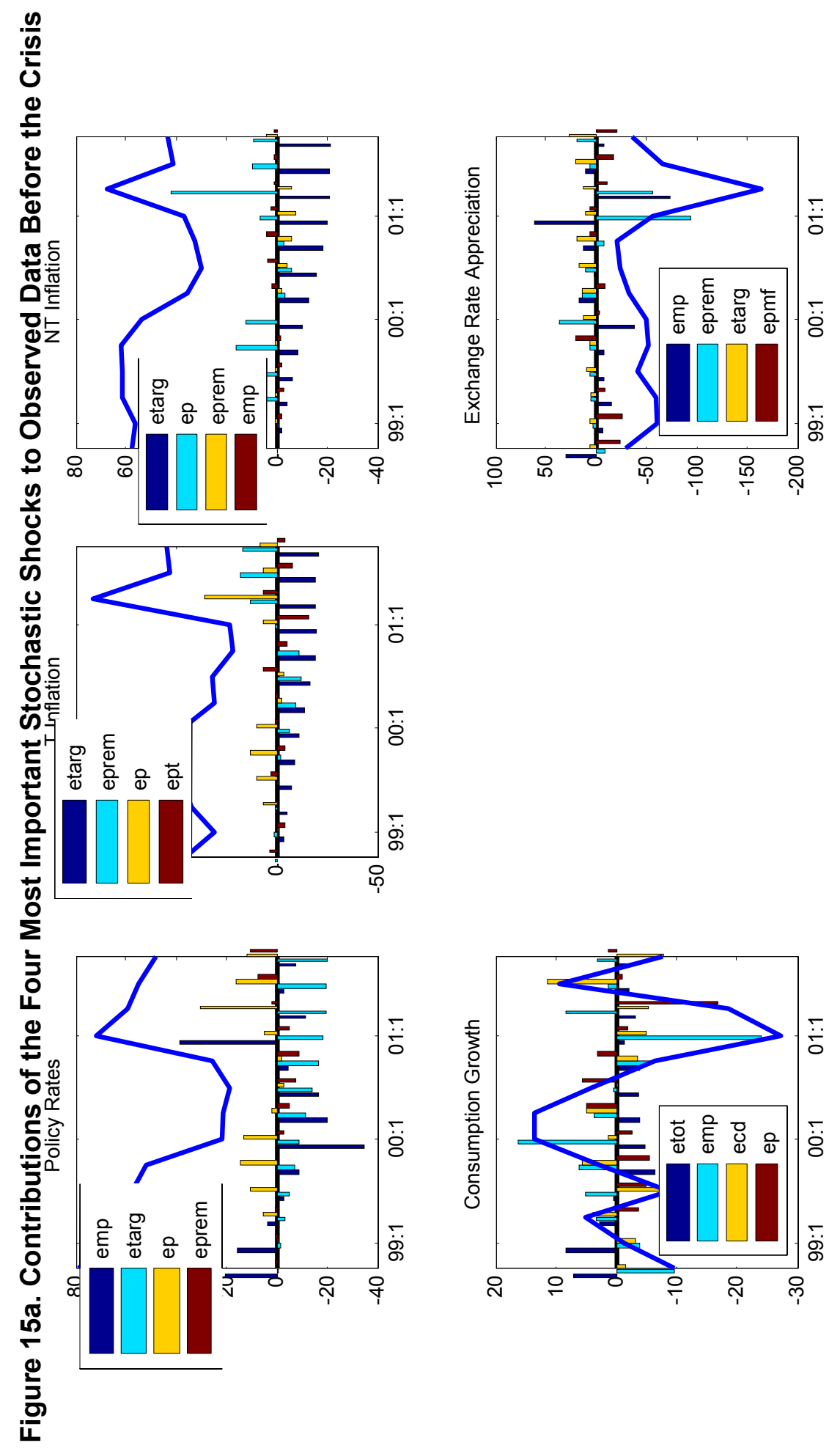




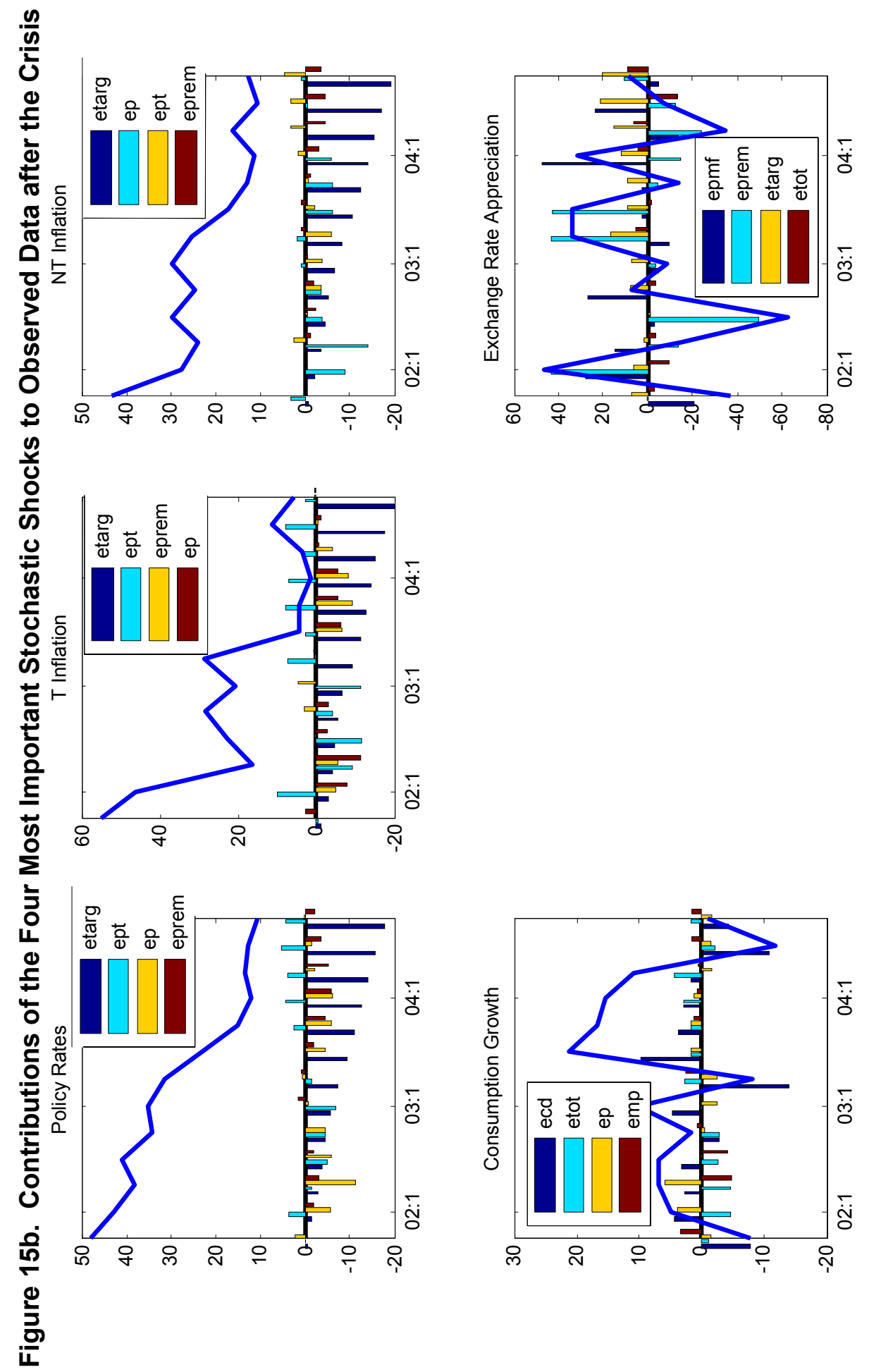




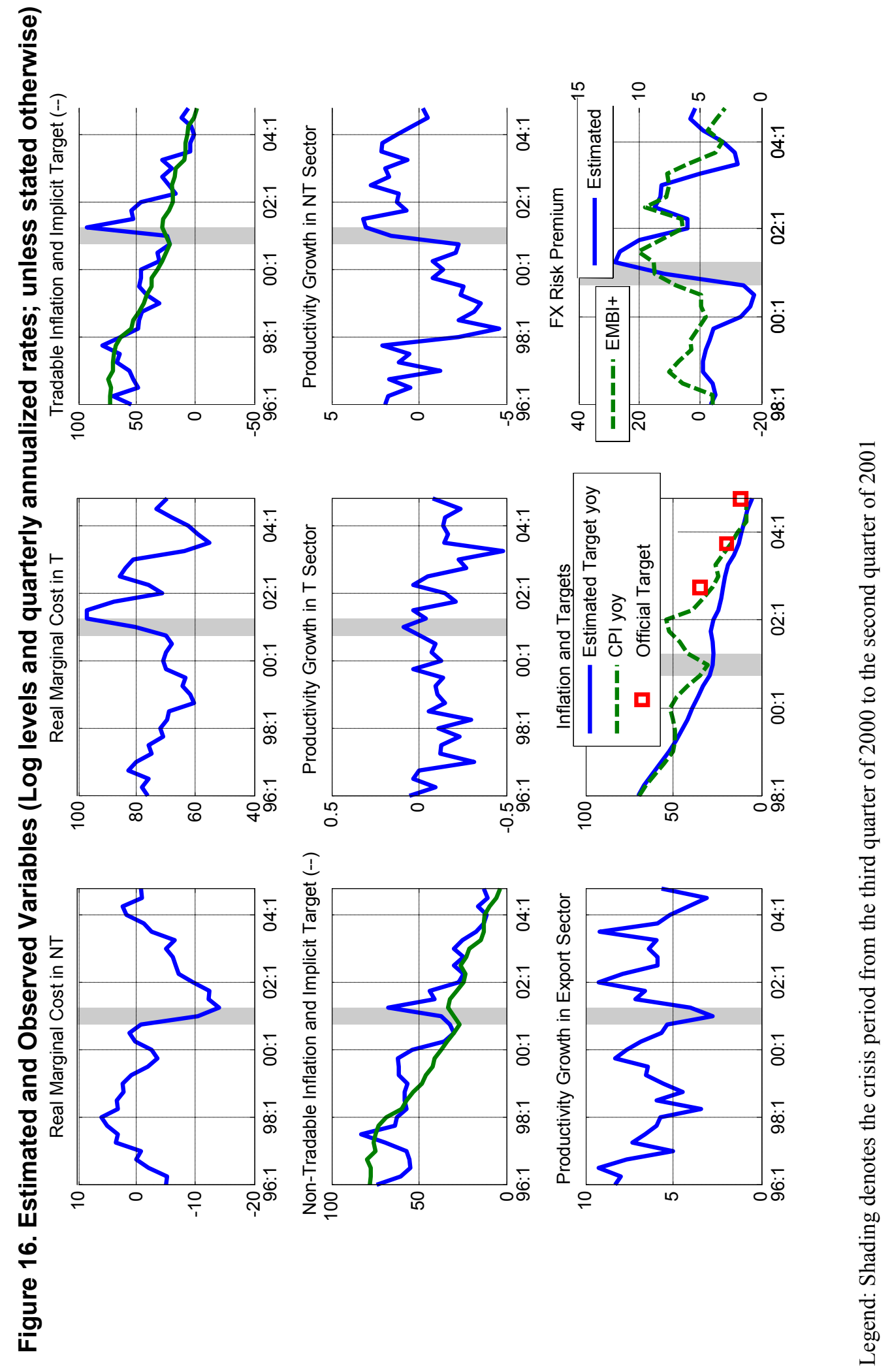




\section{Stochastic properties of data}

In comparing the asymptotic distributional aspects of the Turkish data with those predicted by the model, we analyze three types of second-moment characteristics for key macroeconomic variables: relative standard deviations (to measure the overall volatility of these variables), autocorrelations (to measure their persistence), and cross-correlations (to describe their co-movements). We compare the model-implied properties with their observed counterparts for non-tradable inflation, tradable inflation, quarterly CPI inflation, private consumption growth, the policy rate and the nominal exchange rate. The observed characteristics are based on the bootstrap exercise based on an estimated unrestricted VAR model on detrended data, as described in Section III and Appendix I.

The model-implied moments are functions of both the behavioral parameters (such as the habit persistence parameter) and the standard deviations of structural shocks. In order to focus on the properties implied by relevant shocks only, the model moments are calculated for two versions of the model: version A with disinflation shocks and version B without disinflation shocks. This is because we model the disinflation process over the historical sample by introducing a time-varying stochastic inflation target with an extremely high autocorrelation (around 0.995 , i.e., nearly a unit root). The autocorrelation parameter is extremely important for forming model-consistent expectations about the future developments of the target, and hence also for inflation expectations themselves. While setting the coefficient to a high value is vital for modeling a longer-lasting disinflation process, such as in Turkey, it also necessarily results into high asymptotic volatility implied by the model that distorts the stochastic properties of other variables. The disinflation eigenvalue naturally feeds through the policy reaction function into both tradable inflation and non-tradable inflation and pushes their autocovariances and cross-covariances with other variables towards infinity. In version B of the model we therefore describe the economy as though disinflation were a deterministic process instead. This is also more appropriate when a low inflation profile is achieved and the target is fixed, as is the case in Turkey after declaring official IT in January 2006.

Visual inspection of the reported characteristics in Figure 17 shows that the model captures very well the relative variability of the observed data series (reported are standard deviations relative to the point estimate of non-tradable inflation standard deviation). The model matches very closely the standard deviations of the tradable and non-tradable inflation rates, and policy rates. The results are less compelling for the nominal exchange rate and consumption growth rates that are below the VAR estimated volatilities and where we also see a difference between the model with and without inflation target shocks. As expected, the model without target shocks performs better in capturing the observed variances. 

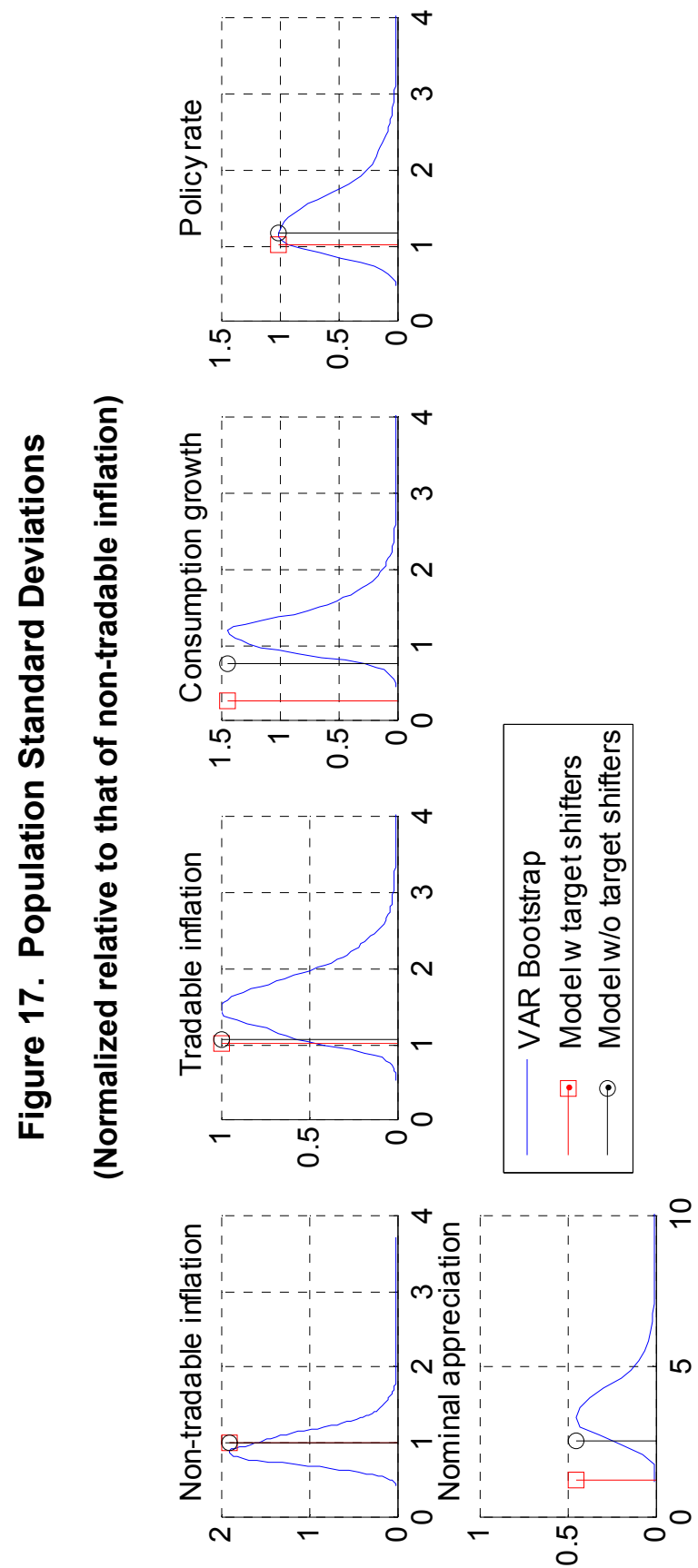
In capturing the estimated data persistence the model performs somewhat worse. There are also large differences between both versions of the model. As shown in Figure 18, the model with target shocks implies persistence very far from the estimated empirical distributions for all variables except for nominal exchange rate change. The model without target shocks performs better, capturing well the persistence in inflation and policy rates. Still, it understates the persistence of consumption and exchange rate growth. For instance, while the data show the autocorrelation coefficient of consumption significantly above 0.5 , the model implies only about 0.25 coefficient. The sign for exchange rate growth is also wrong: while the data show a significantly positive autocorrelation, the model implies a much jumpier behavior with a negative autocorrelation (though close to zero). This suggests that persistence in model's structural shocks may be needed to account for the observed persistence in these variables. ${ }^{31}$

The model matches reasonably well the observed co-movements in the data, although the differences between both model versions are large (Figure 19). For instance, the model with target shocks captures very well the positive correlation of non-tradable and tradable inflation rates, as well as the strongly negative correlation between the consumption growth and both inflation rates. This latter observation is important, because it confirms that the economic activity (which is the driving force of the non-tradable sector inflation in the model) may indeed be an important factor of inflation in Turkey, although the simple correlations in the data conceal this (Figures 3 and 19). The model also matches well the negative correlation of the policy rate with the consumption growth, confirming the already discussed role of the inter-temporal substitution in the policy transmission.

The model, however, does not do that well with the cross-correlations involving inflation rates, policy rate, and nominal appreciation. The model overstates the correlation between the policy rate and inflation, probably due to the very stylized nature of the reaction function. The model also implies a lower immediate exchange rate pass-through, as the correlation coefficients between the nominal appreciation and both inflation rates are close to zero, while those in the data are strongly negative. Although the model with target shocks performs in general worse than without them, it does capture much better the contemporaneous correlations between the exchange rate and inflation.

${ }^{31}$ However, when designing future improvements of the model we need to discount this conclusion by a relatively large degree of uncertainty surrounding the empirical estimates of persistence. 

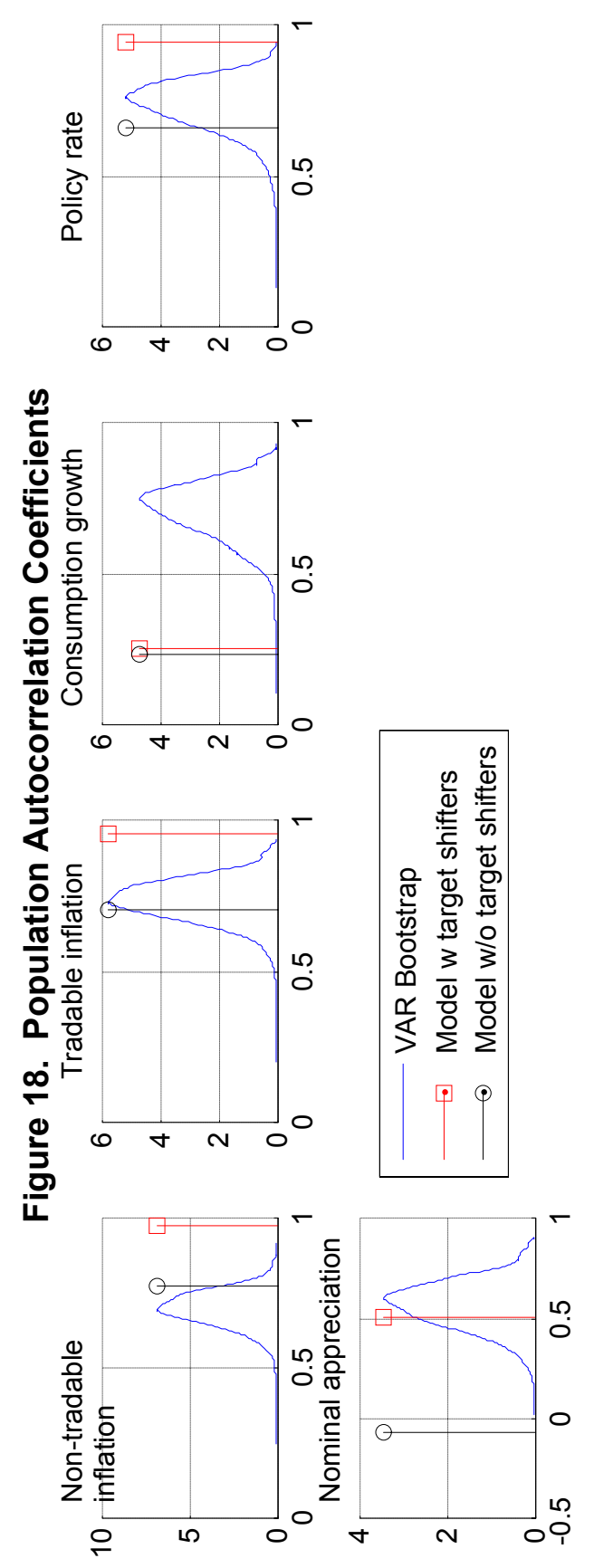


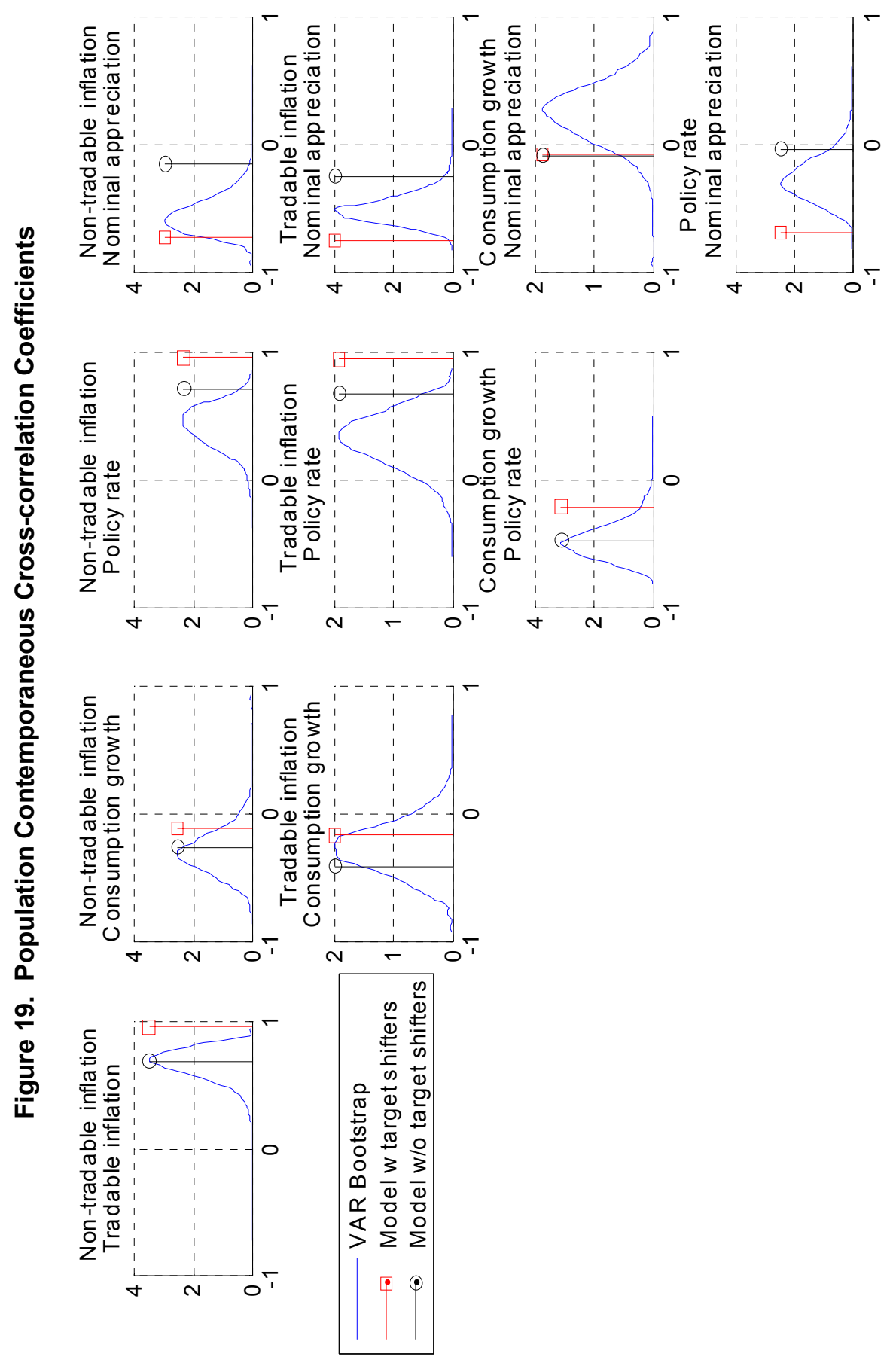




\section{Historical simulations}

Another way of looking at model's capacity to address observed phenomena is to test its forecasting properties on the historical sample. Although forecasting accuracy comes also from other elements of central banks forecasting systems than the core model, the core model should still forecast the basic business-cycle profiles and turning points well enough to help avoid major mistakes in policy making. In this experiment we perform a series of model simulations starting at various points of history, examining how helpful the model would have been in capturing the most important issues the Turkish monetary policy was being confronted with.

In investigating the historical forecasting properties, the assumptions about 'exogenous' variables and shocks are important. ${ }^{32}$ In all model simulations we fix foreign interest rates, the inflation target, and government spending on their sample (in the case of the target estimated) values, as the model is not designed to forecast these variables and assumptions about them come typically as exogenous to a forecast. We set all model shocks to zero. In testing for robustness, we experiment with fixing of a risk premium on the estimated values, because (though notoriously difficult to predict ex-ante) risk premium assumptions are likely to play an important role in forecasting Turkish economy. Finally, when studying the forecasting properties of the model before the crisis, we also experiment with fixing interest rates on the observed values, for the model's stylized reaction function gives too different predictions in that period. Figures 20 to 22 summarize our results. ${ }^{33}$

The model performs very well in capturing the trends of the post-crisis period (Figure 20). The model predicts well the overall trends in inflation, interest and exchange rates, although it implies somewhat tighter monetary policy in 2001 and slower disinflation in the early period-2001 and 2002. It also captures well the size and speed of the post-crisis economic recovery through consumption growth. Forecasting accuracy is better when the risk premium is fixed on the observed values (Figure 22), but this assumption is not crucial for the post-2001 period.

In forecasting the period before the crisis, the assumptions about the risk premium and monetary policy are critical (Figure 20). Fixing of the risk premium helps the model to

\footnotetext{
${ }^{32}$ As shown in Appendix II, all model variables are endogenous, including those typically thought of as coming from outside the system, such as a foreign interest rate, inflation target or the risk premium. This is only a technical requirement and clearly the model is not designed to forecast and provide insight about all these variables.

${ }^{33}$ This exercise also yields formal characteristics of the forecasting properties in terms of RMSE and other statistics that can be used for comparison with other models. We do not report them here for brevity, but also because in practice the model is never the sole tool used to produce a central bank's forecast.
} 
account well for the exchange rate depreciation and the inflation hike in the tradable sector, while the rise in non-tradable inflation is still underestimated and delayed in model's simulations (Figure 21). The model also predicts systematically tighter monetary policy in 1999 (corroborating our discussion above) and does not capture well the subsequent real adjustment through the falling consumption that occurred in 2001. Simulating the model with historical values of interest rates improves this feature, however, and the model tracks the actual size of the consumption slowdown very well (Figure 22). 


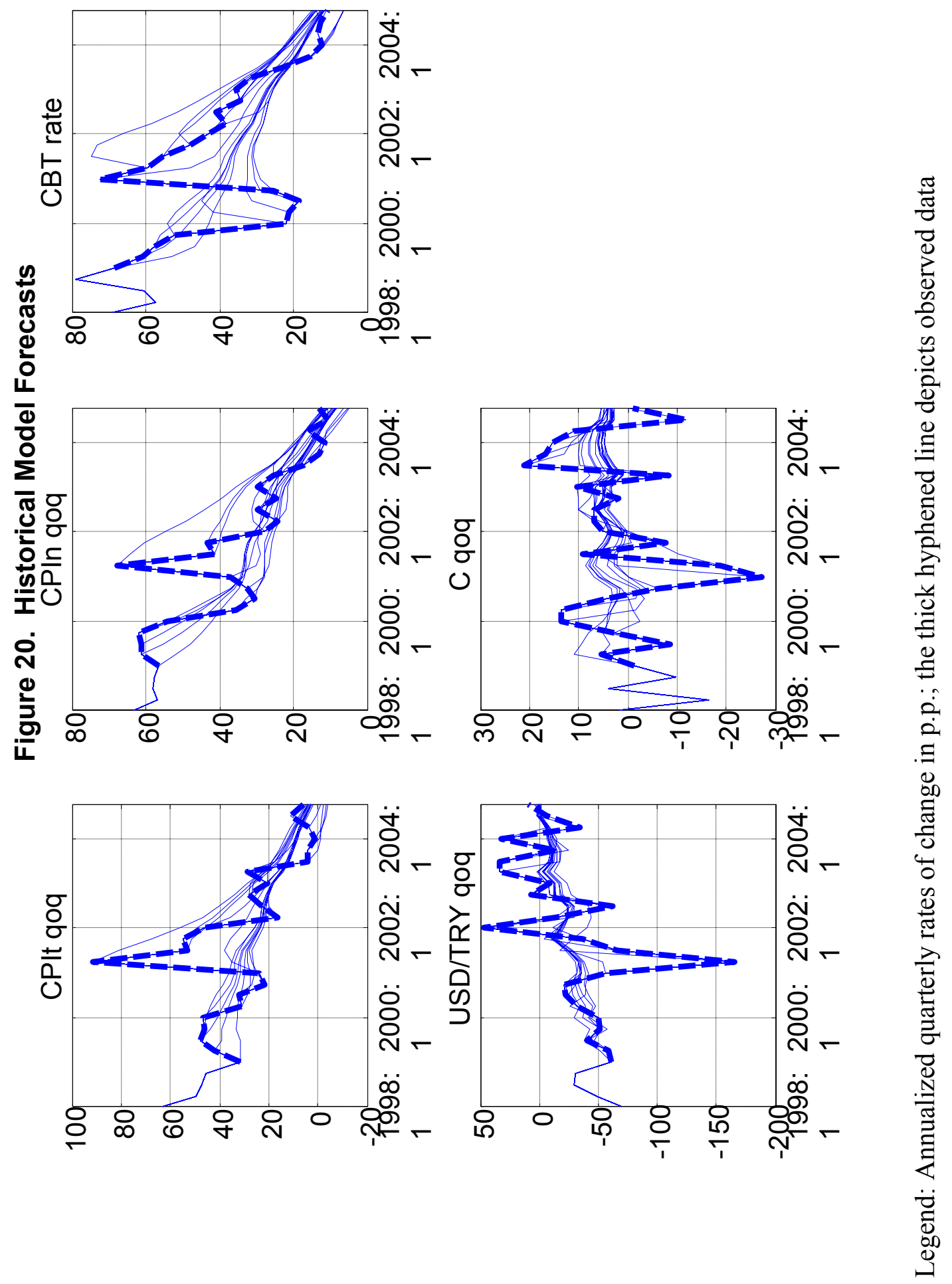




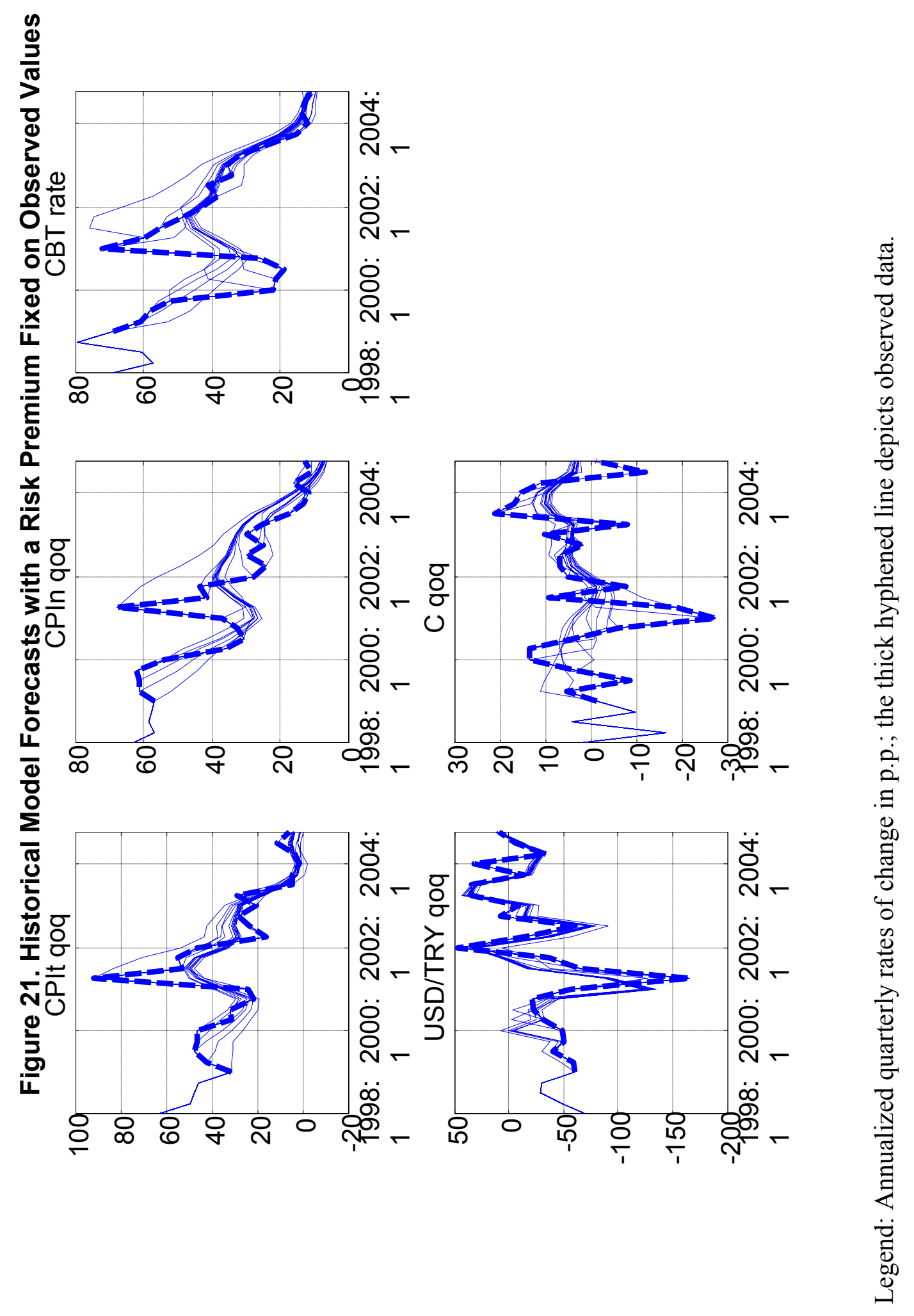




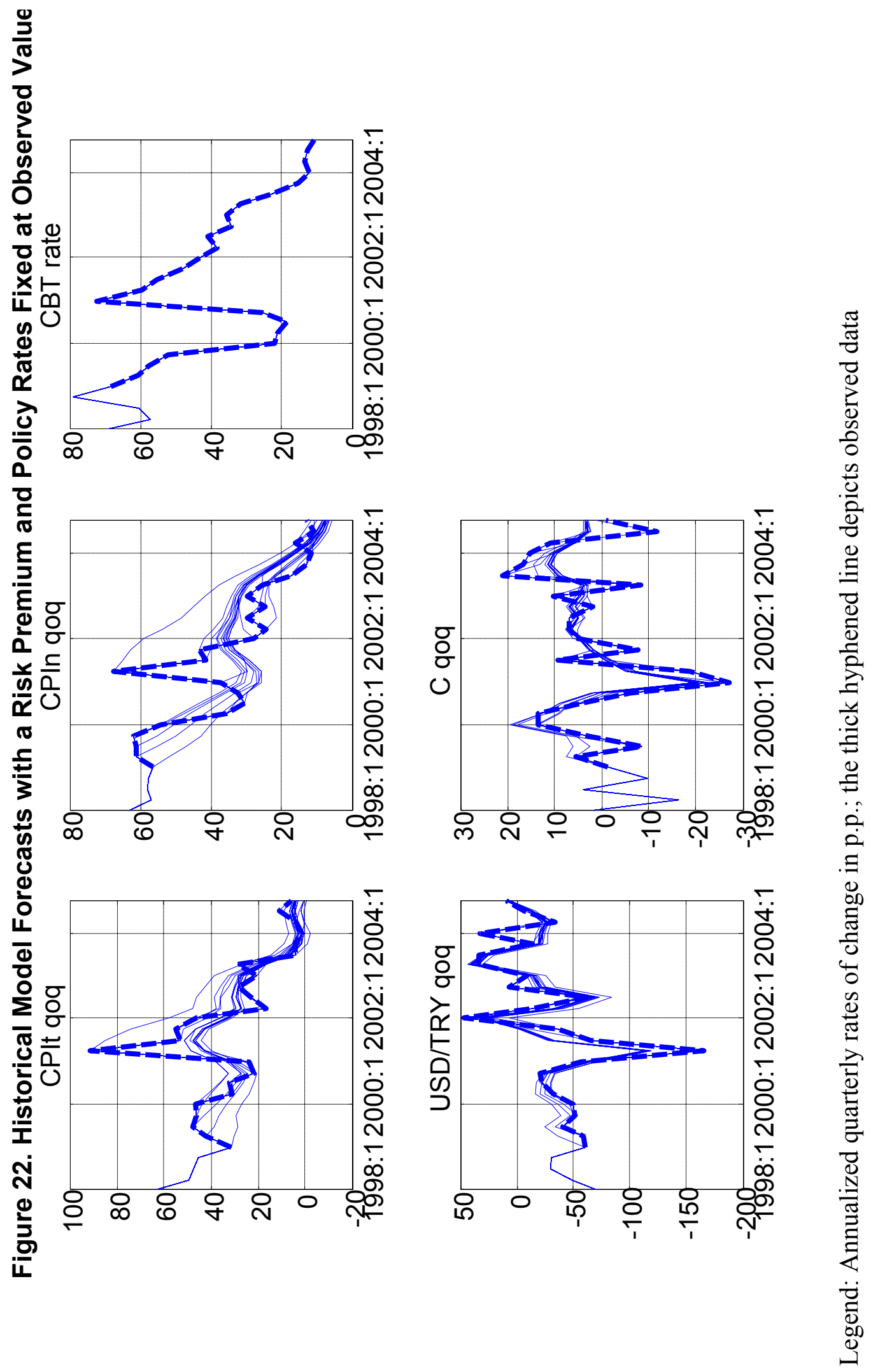




\section{Conclusions}

Using Turkey as an example, we present a DGE model designed as a forecasting and policy analysis tool for an Inflation Targeting central bank. Our contribution lies in presenting a relatively simple DGE model that can be easily adapted to various environments and used by emerging market central banks. The model preserves the simplicity and flexibility of gap models, but includes more theoretical consistency and a richer structure, allowing the capture of more country-specific features. The model is capable of replicating key long-term features of the Turkish economy and its business cycle, relevant for monetary policy. In satisfying a number of practical constraints of a forecasting tool, the model displays a malleable structure, easily interpretable dynamics around a balanced growth path, and the capacity to address many observed features of data, such as deterministic trends. It is also easy to calibrate and operate on a regular basis.

Thanks to its general equilibrium structure, the model is capable of rigorously addressing a host of issues important for monetary policy making in a number of different environments. These include persistent changes in relative prices among different sectors of the economy, different trends in GDP expenditure components, as well as real costs of disinflation.

The value-added of a general equilibrium structure does not come at the cost of excessive human resource needs, which often hinder the regular use of DGE models in forecasting. The model's derivation distinguishes between a simple neoclassical growth model determining the model's balanced growth path, and a business cycle model with nominal and real rigidities added to the neoclassical core. As a result, the model is easy to build, calibrate, extend, or simplify according to the need. Moreover, the model's dynamics can easily be interpreted in a framework of a simple gap model—often used in central banks today for its power to communicate important issues in an understandable way.

In calibrating the model to Turkish data, we demonstrate the model's capacity to capture a range of emerging market phenomena, such the ongoing disinflation process, and the associated economic adjustments and their real costs. We also show that the model would have been of value in the past for forecasting the economic adjustments and policy responses needed following the shocks hitting the economy in the pre-crisis period of 2000-2001. 


\section{REFERENCES}

Basu, S. (1995). "Intermediate Goods and Business Cycles: Implications for Productivity and Welfare", Americal Economic Review, 85(3), 512-531

Benes, J., Binning, A., Lees, K. and McCaw, S. (2006), "A DSGE Designed for the New Zealand economy", mimeo, Reserve Bank of New Zealand.

Benes J., Vavra, D. (2006). "Examining Fisher Information in Multi-Sector DGE Models," Central Bank Workshop on Macromodelling, Santiago de Chile

Benes, J., Hledik, T., Vavra, D., Vlcek, J. (2003). "The Quarterly Projection Model and its Properties" in Coats, Laxton and Rose (eds.): The Czech National Bank's Forecasting and Policy Analysis System, CNB, Prague.

Berg, A., Karam, P. D. and Laxton, D. (2006a). "A Practical Model-Based Approach to Monetary Policy Analysis-Overview," IMF Working Paper No. 06/80.

Berg, A., Karam, P. D. and Laxton, D. (2006b). "A Practical Model-Based Monetary Policy Analysis-A How-To Guide". Working Paper No. 06/81.

Canova, F. and Ortega, E. (1996). "Testing calibrated general equilibrium models," Department of Economics and Business, Universitat Pompeu Fabra, Economics Working Papers.

Castello-Branco, M. (2007). “ Turkey: Moving Toward Full-Fledged Inflation Targeting”, in Castello Branco, Enoch, and Habermeier (eds): Building Monetary and Financial Systems: Case Studies in Technical Assistance (forthcoming).

Cecchetti and Rich, (1999). "Structural Estimates of the U.S. Sacrifice Ratio", Staff Reports 71, Federal Reserve Bank of New York

Cetinkaya and Yavuz (2002). "Calculation of Output-Inflation Sacrifice Ratio: The Case of Turkey". Research Department Working Paper No: 02/11, The Central Bank of The Republic of Turkey.

Christiano, L. J., Eichenbaum, M. and Evans, C. L. (2005). "Nominal Rigidities and the Dynamic Effects of a Shock to Monetary Policy," Journal of Political Economy 118(1), $1-45$.

Coats, W., Laxton, D. M. and Rose, D.(2003). “The Czech National Bank's Forecasting and Policy Analysis System," Czech National Bank. http://www.cnb.cz/en/publications

Fisher, J. D. M. (2006). "The Dynamic Effects of Neutral and Investment-Specific Technology Shocks," Journal of Political Economy. 114(3), 413-451.

Geweke, John F. (1999). "Computational Experiments and Reality", Computing in Economics and Finance, Vol. 410.

Gonçalves, Silvia, and Lutz Kilian (2002). "Bootstrapping Autoregressions with Conditional Heteroscedasticity of Unknown Form”, ECB Working Paper, No. 196.

Greenwood, J., Hercowitz, Z. and Krusell, P. (2000). "The Role of Investment-Specific Technological Change in the Business Cycle," European Economic Review. 44(1),

91-115.

Harrison, R., Nikolov, K., Quinn, M., Ramsay, G., Scott, A. and Thomas, R. (2005). "The Bank of England Quarterly Model," Bank of England.

Kara, H. (2006). "Turkish Experience with Implicit Inflation Targeting”, Research and Monetary Policy Department Working Paper No: 06/03, The Central Bank of The Republic of Turkey. 
Kara, H. and Ogunc, F. (2005). "Exchange Rate Pass - Through in Turkey: It is Slow, but is it Really Low?" Research Department Working Paper No: 05/10, The Central Bank of The Republic of Turkey.

Kovács A. M. (2002). "CEC5: On The Estimated Size of the Balassa-Samuelson Effect in CEC5 Countries," MNB Working Papers 2002/5, Magyar Nemzeti Bank (The Central Bank of Hungary).

Meyer, L. H. (2003). "What I Learned at the Fed," Bank of Canada. http://www.bankofcanada.ca/fr/conference/2003/learned.pdf

Murchison, S. and Rennison, A. (2006). “ToTEM : The Bank of Canada`s New Quarterly Projection Model," Bank of Canada`s Technical Report No.97.

OECD (2001), “OECD Economic Surveys: Turkey 2000/2001,” OECD, also http://oecdobserver.org/news/fullstory.php/aid/435/Turkey's_crisis.html

Otker-Robe, I. and Vavra, D. (2007). “Operational Aspects of Moving To Greater Exchange Rate Flexibility: Lessons from Detailed Country Experiences," IMF Occasional Paper, forthcoming.

Ravn, M., Schmitt-Grohe, S. and Uribe, M. (2006). "Deep Habits," Review of Economic Studies 73(1), 195-218.

Svensson, L. E.O. (2005). Monetary Policy with Judgment: Forecast Targeting. International Journal of Central Banking. 1(1), 1-54.

Weil, P. (1989), Appendix II. "The Equity Premium Puzzle and the Riskfree Rate Puzzle," NBER Working Papers 2829, National Bureau of Economic Research, Inc.

Whelan, K. (2003). "A Two-Sector Approach to Modeling U.S. NIPA Data," Journal of Money, Credit and Banking. 35(4), 627-656. 


\section{APPENDIX I}

\section{A. The Reduced-Form Description of the Turkish Data}

When examining the DGE properties, we compare some of the model's implied secondmoment characteristics (relative standard errors, serial correlations and cross-correlations for the main macroeconomic indicators) with their empirical counterparts estimated without imposing any structural identifying restrictions, that is, using reduced-form methods only. To obtain these estimates we use a VAR-based recursive-design wild bootstrap as proposed by Gonçalves and Kilian (2002). This simple method is, at least in our context, superior to matching the estimated sample coefficients, or to the more traditional bootstrap designs in the following dimensions:

- It enables us to characterize the population, and not sample, moments consistently with the population moments computed from the theoretical model. This closely relates to Geweke's (1999) so-called "minimal econometric interpretation" of DGE models.

- We can assess the sampling uncertainty of our estimates by characterizing their whole empirical distributions, not only point estimates. This is important especially because of the short length of the Turkish data available or usable for our analysis.

- Bootstrap methods, in general, needn't rely upon specific distributional assumptions as they draw directly from estimated empirical distributions.

- The wild recursive design of the bootstrap is robust to the conditional heteroscedasticity of the VAR's residuals.

More specifically, we proceed as follows:

First, as we only wish to describe the stochastic second-moment properties of selected indicators we remove deterministic trends (by regressing the variables on a simple linear trend) from the following five variables: 1-quarter tradable inflation $\mathrm{SA},{ }^{34}$ 1-quarter nontradable inflation SA, the 1-quarter rate of change in private consumption SA, the nominal TB rate, and the 1-quarter rate of change in the nominal exchange rate, on the sample 1996 Q1 to 2004 Q4.

Second, we fit a third-order VAR to the above five variables (stacked in a vector ${ }^{x} t$ ):

${ }^{34} \mathrm{SA}=$ seasonally adjusted using Census X12-Arima. 


$$
x_{t}=\sum_{k=1}^{p} A_{k} \check{x}_{t-k}+\epsilon t, \quad t=1, \ldots, T
$$

with $p=3$ and fixed pre-sample value ${ }^{x_{-p+1}}, \ldots, x_{0}$. Based on our estimates of $A_{k}$ and $\Omega=E \epsilon_{t} \epsilon_{t}^{\prime}$ we can now analytically compute the point estimate of the population auto covariance function for $x_{t}, \Gamma_{k}=\mathrm{E} x_{t} x_{t-k}$, and the corresponding autocorrelation function.

Third, we resample the vector ${ }^{x} t$ a large number $(N=5,000)$ of times from its empirically estimated distribution using a wild recursive-design bootstrap procedure:

$$
\widetilde{x}_{t}^{i}=\sum_{k=1}^{p} \widehat{A}_{k} \widetilde{x}_{t-k}^{i}+\widehat{\epsilon}_{t} \eta t, \quad t=1, \ldots, T, \quad i=1, \ldots, N,
$$

where $\widehat{A}_{k}$ and $\hat{\epsilon}_{t}$ are our estimates of $A_{k}$ and $\epsilon_{t}$, respectively, obtained in the previous step, $\eta^{7}$ is an independent and identically distributed scalar drawn from a normal distribution $N(0,1)$, and $\otimes$ denotes the element-by-element (or scalar) product. In constructing $\hat{x}_{t}^{i}$ we fix the pre-sample values,

$\hat{x}_{t}^{i}=x_{t}, t=-p+1, \ldots, 0$

Finally, for each resampled vector time series $\widetilde{x}_{t}^{i}, t=1, \ldots, T$, we re-estimate the ${ }^{\prime}$ th order VAR's matrices, $\widetilde{A}_{k}^{i}$ and $\widetilde{\Omega}^{i}$, using again the fixed pre-sample values. Based on these estimates we can compute a total of $N$ of implied auto covariance and autocorrelation functions, and draw their empirical distributions. In plotting the empirical distribution we evaluate the kernel density with a normal smoother (see the ksdensity function in Matlab). 


\section{APPENDIX II}

\section{B. A Small DGE Model of the Turkish Economy: The Economic Foundations}

We first describe the steady-state model and its properties (subsections A to E) and then detail the introduction of frictions that help make the model's dynamics realistic over the business cycle (subsections $\mathrm{E}$ to F). In our notational conventions, upper-case letters denote competitive prices or quantities supplied, lower-case letters denote individual (monopolistically competitive) prices or quantities demanded, and lower-case Greek letters are mostly reserved for parameters.

\section{Structure of the Model}

The model is designed to capture the basic medium-run monetary policy transmission channels from the policy rate to inflation working over the business cycle:

- $\quad$ the interest rate channel, that is, the intertemporal consumption choice;

- $\quad$ the expenditure switching channel (or the "real exchange rate" channel), that is, the intratemporal choice between domestic and foreign goods;

- the direct exchange rate channel, that is, a certain degree of pass-through of nominal exchange rate fluctuations into final domestic prices; and

- the expectation channel, that is, the dependence of today's prices and wages on the future business cycle and monetary policy stance. The expectation channel can be fully introduced only after we add frictions (i.e., stickiness) into price and/or wage setting.

Moreover, specific assumptions about preferences and technology allow us to introduce various types of permanent real shocks, such as productivity shocks or terms of trade shocks, while retaining the balanced growth path property of the model in terms of its nominal expenditure shares in the steady state. This means that the model's nominal expenditure ratios are stable and unaffected by these shocks in the long run. A prerequisite for this feature is unit long-run elasticities of substitution between various input factors and final goods. More realistic, that is, lower, short-run elasticities are then achieved by various behavioral mechanisms presented in the version with frictions.

Our small open economy consists of: 
- $\quad$ households who consume tradable (imported) goods and non-tradable goods and trade domestic-currency denominated assets (we assume that there is no international trade in these assets);

- $\quad$ foreign exchange dealers who trade foreign-currency denominated assets in households' interest;

- $\quad$ firms who produce non-tradable goods sold domestically;

- $\quad$ importers who purchase tradable goods abroad and sell them domestically to households;

- $\quad$ exporters who use imported intermediate inputs (re-exports) to produce export goods sold abroad; and

- $\quad$ the government who sets the nominal interest rate, levies lump-sum taxes, and make purchases of consumption goods.

Appendix Figure 1. Flow Chart of Goods and Payments

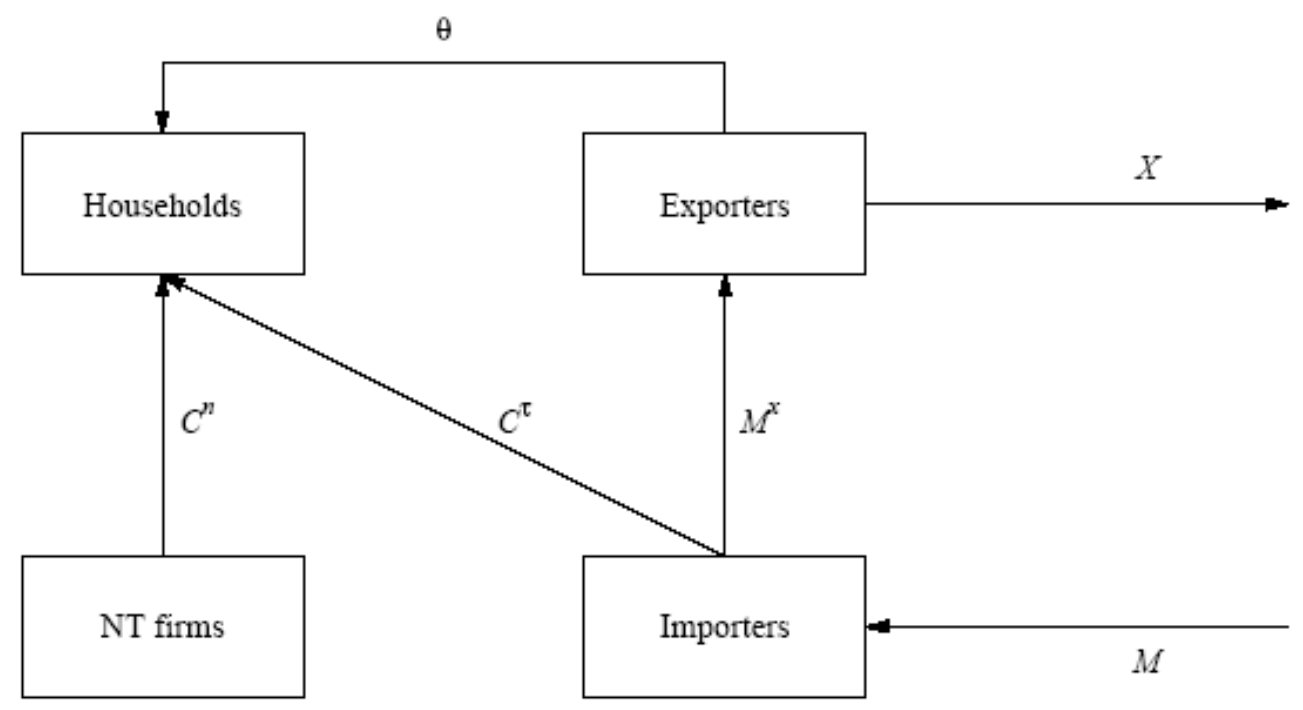

The tradable and non-tradable markets are monopolistically competitive. We assume that (i) a continuum of firms indexed on the interval $[0,1]$ exist in each market with each firm producing differentiated goods, and (ii) household have tastes for these varieties of goods. On the other hand, exporters are assumed to be international price takers. Without loss of 
generality, we can furthermore assume that the economy is populated by a single representative household and a single representative exporter.

Finally, we deliberately abstract from explicit primary input factor markets (such as labor or capital markets) to keep the model and modeling issues on a rather small scale and understandable.

\section{Preferences}

\section{Households}

The representative household has utility from consuming varieties of tradable and nontradable goods, $c_{j t}^{\tau}$ and $c_{j t}^{n}$. Her expected lifetime utility function:

$$
\mathrm{E}_{t} \sum_{k=0}^{\infty} \beta^{k} \cdot \log c_{t+k}
$$

is maximized subject to the following nominal budget constraint:

$$
b_{t}+\int_{0}^{1} p_{j t}^{\tau} c_{j t}^{\tau} \mathrm{d} j+\int_{0}^{1} p_{j t}^{n} c_{j t}^{n} \mathrm{~d} j=b_{t-1}\left(1+i_{t-1}\right)-\tau_{t}+\mathbf{I}_{t}+\theta_{t}
$$

where $b_{t}$ denotes the household's net position in the domestic-currency denominated asset market, $i_{t}$ is the domestic-currency nominal interest rate, $\tau_{t}$ are net taxes or government transfers, $\Phi_{t}$ is a sum of net earnings (positive or negative) paid lump-sum to the household by the model's various types of firms (foreign exchange dealers, non-tradable firms, importers, and exporters), and $\theta_{t}$ are the revenues from letting distribution channels owned by the household to exporters. Note that trade in foreign-currency denominated assets is delegated to foreign exchange dealers whose behavior is described later.

The overall consumption utility index, $C_{t}$, is defined as a two-stage CES index over the quantities of tradables and non-tradables consumed:

$$
\begin{gathered}
c_{t}=\left(c_{t}^{\tau}\right)^{\omega}\left(c_{t}^{n}\right)^{1-\omega}, \\
c_{t}^{\tau}=\left[\int_{0}^{1}\left(c_{j t}^{\tau}\right)^{1 / \mu} \mathrm{d} j\right]^{\mu}, \\
c_{t}^{n}=\left[\int_{0}^{1}\left(c_{j t}^{n}\right)^{1 / \mu} \mathrm{d} j\right]^{\mu},
\end{gathered}
$$


where $c_{t}^{\tau}$ and $c_{t}^{n}$ are sub indices relating to the household's utility of consuming tradables and non-tradables, respectively, and $\mu /(\mu-1)$ is the elasticity of substitution between any two tradables or any two non-tradables. This allows us to split the household's choice conveniently into three stages. The first two stages are static expenditure minimization problems while the third stage is a dynamic optimization problem:

1) Taking the consumption indices of tradables and non-tradables, $c_{t}^{\tau}$ and $c_{t}^{n}$, respectively, as given we find the optimal demands for individual goods, $c_{j t}^{\tau}$ and $c_{j t}^{n}$, respectively, by solving two expenditure-minimization problems. As a result, we obtain the optimal individual quantities together with corresponding minimum-expenditure indices, $P_{t}^{\tau}$ and $P_{t}^{n}$. The first-order conditions for this problem are:

$$
\begin{aligned}
& c_{j t}^{\tau}=c_{t}^{\tau} \cdot\left(p_{j t}^{\tau} / P_{t}^{\tau}\right)^{-\frac{\mu}{\mu-1}}, \\
& c_{j t}^{n}=c_{t}^{n} \cdot\left(p_{j t}^{n} / P_{t}^{n}\right)^{-\frac{\mu_{n}}{\mu_{n-1}}},
\end{aligned}
$$

where

$$
\begin{aligned}
& P_{t}^{\tau}=\left[\int_{0}^{1}\left(p_{j t}^{\tau}\right)^{\frac{1}{\mu-1}} \mathrm{~d} j\right]^{\mu-1}, \\
& P_{t}^{n}=\left[\int_{0}^{1}\left(p_{j t}^{n}\right)^{\frac{1}{\mu-1}} \mathrm{~d} j\right]^{\mu-1}
\end{aligned}
$$

2) Taking overall consumption as given we solve for the optimal levels of $c_{t}^{\tau}$ and $c_{t}^{n}$. As a result, we obtain the optimal sub indices $c_{t}^{\tau}$ and $c_{t}^{n}$ together with an overall minimum-expenditure index, $P_{t}$, which can be interpreted as the cost of living index or the CPI. The first-order conditions for this problem are:

$$
\begin{gathered}
P_{t}^{\tau} c_{t}^{\tau}=\omega \cdot P_{t} c_{t}, \\
P_{t}^{n} c_{t}^{n}=(1-\omega) \cdot P_{t} c_{t},
\end{gathered}
$$

where

$$
P_{t}=\frac{\left(P_{t}^{\tau}\right)^{\omega}\left(P_{t}^{n}\right)^{1-\omega}}{\omega^{\omega}(1-\omega)^{1-\omega}}
$$

3) Finally, we solve for the intertemporal consumption and savings plan, that is, ${ }^{C t}$ and $b_{t}$. By substituting the Lagrange multiplier on the budget constraint out of the first- 
order conditions with respect to overall consumption, ${ }^{C t}$, and the net position in domestic-currency assets, ${ }^{b}$, we get:

$$
\begin{gathered}
1 / c_{t}=\lambda_{t} P_{t} \\
\beta \mathrm{E}_{t} \lambda_{t+1}=\lambda_{t} \cdot\left(1+i_{t}\right) .
\end{gathered}
$$

Note that when deriving the conditions in paragraphs 1-3 above we make use of the fact that

$$
P_{t}^{\prime} c_{t}=P_{t}^{\tau} c_{t}^{\tau}+P_{t}^{n} c_{t}^{n}=\int_{0}^{1} p_{j t}^{\tau} c_{j t}^{\tau} \mathrm{d} j+\int_{0}^{1} p_{j t}^{n} c_{j t}^{n} \mathrm{~d} j,
$$

at optimum which follows from the construction of CES indices.

\section{Foreign exchange dealers}

The representative forex dealer buys or sells foreign-currency denominated assets in the household's interest maximizing the stream of expected earnings evaluated at the household's shadow value of an extra unit of domestic currency,

$$
\mathrm{E}_{t} \sum_{k=0}^{\infty} \beta^{k} \lambda_{t+k} \cdot \mathrm{I}_{t}^{d}
$$

where the instantaneous cash flow is given by

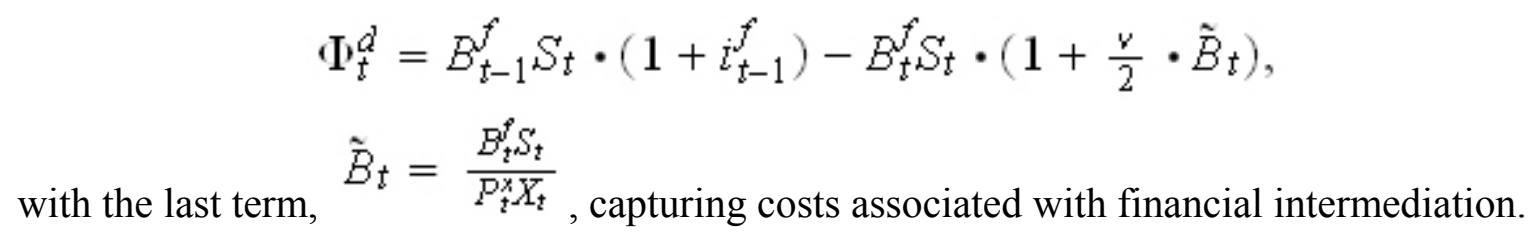

The first order condition with respect to the volume of foreign-currency denominated assets is:

$$
\lambda_{t} \cdot\left(1+v \cdot \tilde{B}_{t}\right)=\beta \cdot \mathrm{E}_{t} \lambda_{t+1} \frac{S_{t+1}}{S_{t}} \cdot\left(1+i_{t}^{f}\right)(1+v),
$$

where we introduce a permanent disparity term, $v$, to account for longer-term countryspecific risk premium or investors' preferences. The first-order condition can be logapproximated using the household's condition (1) as

$$
\hat{l}_{t}-\hat{l}_{t}^{*}=\mathrm{E}_{t} \hat{s}_{t+1}+v \cdot \hat{b}+\hat{v}
$$


where $\hat{l}_{t}=\log \left(1+i_{t}\right), v \cdot \hat{b}_{t}=\log \left(1+v \cdot \tilde{B}_{t}\right)$, and $\hat{v}=\log (1+v)$.

\section{E. Technology}

\section{Non-tradable firms}

Non-tradable firms uses intermediate inputs to produce their output. The technology of firm $j$ is described by the following production function:

$$
Y_{j t}^{n}=\left(z_{j t}\right)^{\gamma_{n}}\left(A_{t}^{n}\right)^{1-\gamma_{n}}
$$

where $z_{j t}$ is a CES bundle of intermediate inputs purchased from other firms in the sector with an elasticity of substitution $\mu /(\mu-1)$, and $A_{t}^{n}$ is an exogenous technology process. The total nominal costs of the firm are:

$$
P_{t}^{n} z_{j t}=P_{t}^{n} / A_{t}^{n} \cdot\left(Y_{j t}^{n} / A_{t}^{n}\right)^{1 / \gamma_{n}}
$$

where $P_{t}^{n}$ is the price at which the bundle $z_{j t}$ can be purchased. The nominal marginal costs are then:

$$
\frac{1}{\gamma_{n}} P_{t}^{n}\left(Y_{j t}^{n} / A_{t}^{n}\right)^{1 / \gamma_{n}-1}
$$

The profit maximization can now be expressed as:

$$
\mathrm{I}_{t}^{n}=\max _{\left\{p_{j t}^{n}, Y_{t}^{m}\right\}} p_{j t}^{n} Y_{j t}^{n}-P_{t}^{n} / A_{t}^{n} \cdot\left(Y_{j t}^{n} / A_{t}^{n}\right)^{1 / \gamma_{n}}
$$

subject to a demand curve resulting from the household's, the government's and other nontradable firms' problems,

$$
Y_{j t}^{n} \leq y_{j t}^{n}=\left(p_{j t}^{n} / P_{t}^{n}\right)^{\mu /(\mu-1)}\left(c_{t}^{n}+g_{t}^{n}+z_{t}\right),
$$

where $P_{t}^{n}$ is taken as given. The first-order condition with respect to output and the price are:

$$
\begin{gathered}
Y_{j t}^{n}=\left(p_{j t}^{n} / P_{t}^{n}\right)^{\mu /(\mu-1)}\left(c_{t}+g_{t}+z_{t}\right), \\
p_{j t}^{n}=\mu \cdot \frac{1}{\gamma_{n}} P_{t}^{n}\left(Y_{j t}^{n} / A_{t}^{n}\right)^{1 / \gamma_{n}-1} .
\end{gathered}
$$


Equation (2) is a standard mark-up rule: a firm posts its final price as a constant mark-up over the nominal marginal cost.

\section{Importers (Tradable firms)}

The representative importer purchases foreign goods abroad and sells them domestically to households (as consumption goods) and exporters (as intermediate goods). This can be described by a simple production function:

$$
Y_{t}^{\tau}=m_{t} \cdot A_{t}^{\tau}
$$

where ${ }^{m_{t}}$ are foreign goods, and $A_{t}^{\tau}$ is a technology process that allows for permanent shifts in the relative price of imports and tradables. The total cost function is:

$$
P_{t}^{m} m_{t}=P_{t}^{m} \cdot\left(Y_{t}^{\tau} / A_{t}^{\tau}\right)
$$

and marginal costs being determined by the foreign-currency price of imports, $P_{t}^{m}=P_{t} S_{t}$

The profit maximization can be then written as:

$$
\mathbf{\Psi}_{t}^{\tau}=\max _{\left\{p_{j t}^{\tau}, Y_{j t}^{\tau}\right\}} Y_{j t}^{\tau}\left(p_{j t}^{\tau}-P_{t}^{m} / A_{t}^{\tau}\right)
$$

subject to a demand curve resulting from the household's, government's, and exporter's optimization,

$$
Y_{j t}^{\tau} \leq y_{t}^{\tau}=\left(p_{j t}^{\tau} / P_{t}^{\tau}\right)^{-\mu /(\mu-1)}\left(c_{t}^{\tau}+g_{t}^{\tau}+m_{t}^{x}\right)
$$

The first-order condition with respect to output and the price are:

$$
\begin{gathered}
Y_{j t}^{\tau}=\left(p_{j t}^{\tau} / P_{t}^{\tau}\right)^{-\mu /(\mu-1)}\left(c_{t}^{\tau}+g_{t}^{\tau}+m_{t}^{x}\right), \\
p_{j t}^{\tau}=\mu \cdot P_{t}^{m} / A_{t}^{\tau} .
\end{gathered}
$$

\section{Exporters}

We assume that exporters are world price takers so we can represent them with a single firm behaving competitively. The exporter needs to use the distribution channels who are owned by households. There is an auction at the beginning of each period (but after the realization 
of all shocks) and the distribution channels are let to the highest bid $\theta_{t}$. The export production function is:

$$
X_{t}=\left(m_{t}^{x}\right)^{\gamma_{x}}\left(A_{t}^{x}\right)^{1-\gamma_{x}}
$$

where $m_{t}^{x}$ is a CES bundle of intermediate inputs purchased from importers (i.e., reexports) with an elasticity of substitution identical to the household's elasticity $\mu /(\mu-1)$, and $A_{t}^{X}$ is an exogenous technology process. The exporter's total nominal costs are:

$$
P_{t}^{\tau} m_{t}^{x}+\theta_{t}=P_{t}^{\tau} / A_{t}^{x} \cdot\left(X_{t} / A_{t}^{x}\right)^{1 / \gamma_{x}}+\theta_{t}
$$

while the marginal costs,

$$
\frac{1}{\gamma_{x}} P_{t}^{\tau}\left(X_{t} / A_{t}^{X}\right)^{1 / \gamma_{x}-1}
$$

are unaffected by $\theta_{t}$.

The profit maximization can then be written as:

$$
\Phi_{t}^{x}=\max _{\left\{X_{t}\right\}} P_{t}^{x} X_{t}-P_{t}^{\tau} / A_{t}^{x} \cdot\left(X_{t} / A_{t}^{x}\right)^{1 / \gamma_{x}}-\theta_{t},
$$

for which the first-order condition is:

$$
P_{t}^{x}=\frac{1}{\gamma_{x}} P_{t}^{\tau}\left(X_{t} / A_{t}^{x}\right)^{1 / \gamma_{x}-1}
$$

that is, output in the export sector is such that the price equals the nominal marginal cost. Moreover, free entry into the auction guarantees that profits are driven to zero at all times in the export sector and

$$
\theta_{t}=\left(1-\gamma_{x}\right) \cdot P_{t}^{x} X_{t}
$$

\section{F. The Rest of the Model}

\section{The Government}

The government sets the nominal interest rate, levies lump-sum taxes on the household, and makes purchases of tradables and non-tradables.

The interest rates are set to stabilize the economy around a possibly time-varying inflation target, $\pi_{t}$. We, however, assume that there is an ultimate inflation target, and that $\pi_{t}$ converges to it at a sufficiently slow rate $\rho$, 


$$
\pi_{t}=\rho \pi_{t-1}+(1-\rho) \pi+\epsilon_{t},
$$

where $\epsilon_{t}$ is a target shifter. The interest rate setting is detailed in Appendix I. Bear in mind that the parameter $\rho$ primarily controls the expectations of private agents about future monetary policy targets which considerably affects inflation expectations and the price setting process.

Government consumption is given by the following three rules:

$$
\begin{gathered}
P_{t} g_{t}=\sigma \cdot P_{t} c_{t}, \\
P_{t} g_{t}=P_{t}^{\tau} g_{t}^{\tau}+P_{t}^{n} g_{t}^{n}=\tau_{t}, \\
P_{t} g_{t}=\frac{1}{\omega} P_{t}^{\tau} g_{t}^{\tau}=\frac{1}{1-\omega} P_{t}^{n} g_{t}^{n} .
\end{gathered}
$$

The rule for allocating public consumption between tradables and non-tradables, equation (3), mimics private consumption demand.

\section{External Variables}

There are three exogenous technological processes and three variables related to the rest of the world and independent of the domestic economy:

○ the non-tradable sector's technology, $A_{t}^{n}$,

○ the tradable sector's technology, $A_{t}^{\tau}$,

○ the export sector's technology, $A_{t}^{x}$,

$\circ$ the terms of trade, $T_{t}=P_{t} / P_{t}$,

$\circ$ the foreign-currency price of imports, $P_{t}$, and

○ the foreign nominal interest rate, ${ }^{j} t$.

We assume that they evolve according to the following equations: 


$$
\begin{gathered}
\hat{A}_{t}^{n}=\log \left(A_{t}^{n} / A_{t-1}^{n}\right)=\alpha_{n}+\epsilon_{t}, \\
\hat{A}_{t}^{\tau}=\log \left(A_{t}^{\tau} / A_{t-1}^{\tau}\right)=\epsilon_{t}, \\
\hat{A}_{t}^{x}=\log \left(A_{t}^{x} / A_{t-1}^{x}\right)=\alpha_{x}+\epsilon_{t}, \\
\hat{T}_{t}=\log \left(T_{t} / T_{t-1}\right)=\epsilon_{t}, \\
\hat{P}_{t}=\log \left(P_{t} / P_{t-1}\right)=\pi, \\
\hat{v}_{t}^{f}=\log \left(1+i_{t}^{f}\right)=\bar{t}_{t}^{f},
\end{gathered}
$$

where $\epsilon_{t}, \epsilon_{t}$, and $\epsilon_{t}$ are the model's permanent shifters (a non-tradable technology shifter, a tradable technology shifter, and an export technology shifter), and the steady-state foreign interest rate, ${ }^{f}$, is given in Section V.

\section{Market Clearing}

All markets clear. We therefore impose the following conditions:

- the market for tradables:

$$
c_{j t}^{\tau}+g_{j t}^{\tau}+m_{j t}^{x}=Y_{j t}^{\tau}, \quad \forall j \in[0,1]
$$

○ the market for non-tradables:

$$
c_{t}^{n}+g_{t}^{n}+z_{t}=Y_{t}^{n}, \quad \forall j \in[0,1]
$$

○ the domestic-currency denominated asset market:

$$
b_{t}=0 \text {. }
$$

The last condition, that is, zero net supply of domestic-currency denominated assets, follows from the assumptions that (i) the assets are only traded domestically, (ii) the government follows a balanced-budget rule with no initial public debt.

\section{G. The Non-Stochastic Steady State}

The parameters that determine the model's steady state are listed in Appendix Table 1. When parameterizing the steady state we assume that the net asset position of the economy is zero, that is, $B_{t}^{f}=0$. This imposes a restriction on the steady-state foreign interest rate which cannot be parameterized freely. It is determined by the domestic economy's parameters and foreign-currency import inflation, $\pi$. 


\section{The determination of the steady state}

The growth rates and interest rates in a non-stochastic steady-state are as follows:

$$
\begin{gathered}
\hat{c}=\omega \alpha_{x}+(1-\omega) \alpha_{n}, \\
\hat{c}^{\tau}=\hat{g}^{\tau}=\hat{m}^{x}=\hat{Y}^{r}=\hat{X}=\hat{A}^{x}=\alpha_{x}, \\
\hat{c}^{n}=\hat{g}^{n}=\hat{z}=\hat{Y}^{n}=\hat{A}^{n}=\alpha_{n}, \\
\hat{P}=\pi, \\
\hat{P}^{\tau}=\pi+(1-\omega)\left(\alpha_{n}-\alpha_{x}\right), \\
\hat{P}^{n}=\pi-\omega\left(\alpha_{n}-\alpha_{x}\right), \\
\hat{\imath}=\pi+\omega \alpha_{x}+(1-\omega) \alpha_{n}-\hat{\beta}, \\
\hat{S}=\pi-\pi-(1-\omega)\left(\alpha_{n}-\alpha_{x}\right), \\
\hat{P}=\pi, \\
\hat{\imath}=\pi+\alpha_{x}-\hat{\beta}, \\
\hat{T}=0,
\end{gathered}
$$

where $\hat{c}=\log \left(c_{t} / c_{t-1}\right)$, and so forth, $\hat{\imath}=\log \left(1+i_{t}\right)$, and $\hat{\beta}=\log \beta$.

The nominal expenditure shares of GDP in a non-stochastic steady-state are: 


$$
\begin{gathered}
P C / \Sigma=1 /(1+\sigma), \\
P^{\tau} C^{r} / \Sigma=\omega /(1+\sigma), \\
P^{n} C^{m} / \Sigma=(1-\omega) /(1+\sigma), \\
P G / \Sigma=\sigma /(1+\sigma), \\
P^{\tau} G^{\tau} / \Sigma=\sigma \omega /(1+\sigma), \\
P^{n} G^{n} / \Sigma=\sigma(1-\omega) /(1+\sigma), \\
P^{m} M^{2} / \sum=P^{x} X / \Sigma=\omega /\left(\mu-\gamma_{x}\right), \\
P^{\tau} M^{x} / \sum=\gamma_{x} \omega /\left(\mu-\gamma_{x}\right), \\
P^{\tau} Y^{2} / \Sigma=\mu \omega /\left(\mu-\gamma_{x}\right), \\
P^{n} Y^{n} / \Sigma=\mu(1-\omega) /\left(\mu-\gamma_{n}\right), \\
P^{n} Z / \Sigma=\gamma_{n}(1-\omega) /\left(\mu-\gamma_{n}\right),
\end{gathered}
$$

where $\sum=P^{n}\left(C^{m}+G^{n}\right)+P^{\tau}\left(C^{\tau}+G^{\tau}\right)+P^{x} X-P^{m} M$

is domestic nominal value added.

\section{Mapping into observables}

The determination of the steady-state level of the domestic interest rate is, in principle, based on the Euler equation for the household's consumption and the inflation target. Matching the observed values of the nominal interest rate would require an unrealistic or nonsensical discount factor. This fact relates to the so-called risk-free rate puzzle, see Weil (1989) for example. We therefore loosen the model restrictions and allow for a permanent constant wedge between the model implied interest rate and its observed counterpart when estimating and simulating the model. Similarly, the foreign interest rate is determined by our assumption that the long-run net position of the economy is zero. The foreign interest rate is thus not an exogenous parameter any longer. We again allow for a permanent constant wedge between the model predictions and the observed rate.

\section{H. Real and Nominal Frictions}

We introduce deep habit in the household's consumption, costly price adjustments in the two consumption goods sectors, costly output adjustments in the export sector, and smoothing in the policy rate setting. These frictions are intended to introduce more realism into the model properties in the following dimensions: 
- $\quad$ Reduce the short-run (instantaneous) elasticity of intertemporal substitution in overall consumption, that is, the response of consumption to changes in the real interest rate (deep habit).

- $\quad$ Reduce the short-run (instantaneous) elasticity of intratemporal substitution between tradable and non-tradable consumption (deep habit).

- Introduce intrinsic persistence (auto regression) into consumption demand (deep habit).

- $\quad$ Make final prices of tradables and non-tradables sticky and reduce their responsiveness to changes in the producers' cost position (costly price adjustments).

- $\quad$ Reduce the short-run responsiveness of exports to changes in the terms of trade (costly output adjustments).

- $\quad$ Assume precaution in the central banker's behavior and distribute monetary policy reactions over time (policy rate smoothing).

Furthermore, we introduce transitory random shifters (shocks) into the specifications of preferences and technology that will be main sources of business cycle fluctuations in the model economy.

Finally, note that all the frictions are introduced in such a way that they don't affect the steady state. The steady state of the model with frictions is identical to the model without frictions.

\section{Frictions in Preferences}

\section{Households}

We redefine the household's utility index from consumption to capture a certain level of deep $^{35}$ habit in the consumption of tradables and non-tradables, and hence persistence in the household's consumption decisions:

\footnotetext{
${ }^{35}$ Deep habit relates to the quantities of individual types of goods consumed by the household as opposed to superficial habit relating to the overall level of consumption.
} 


$$
q_{t}=\frac{\left(c_{t}^{\tau}-\chi \cdot h_{t}^{\tau}\right)^{\omega}\left(c_{t}^{n}-\chi \cdot h_{t}^{n}\right)^{1-\omega}}{1-\chi}
$$

Since the consumption index cannot be interpreted as the level of overall consumption as in previous versions of the model we denote it by $G_{t}$ rather than $C_{t}$, and the overall consumption index, $c_{t}$, will be defined later. We replace $c_{t}$ with $q_{t}$ in the utility function:

$$
\mathrm{E}_{t} \sum_{k=0}^{\infty} \beta^{k} \cdot \log q_{t+k} \cdot \exp \epsilon_{t+k}^{c d}
$$

and introduce a transitory consumption demand shifter, or a shock to intertemporal preferences, $\epsilon_{t}^{c d}$.

Next, we define the laws of motion for the two habit processes. We assume that habit is external, that is, related to the aggregate levels of consumption in the economy and not to the household's own consumption, and evolve according to:

$$
\begin{aligned}
& h_{t}^{\tau}=\bar{c}_{t-1}^{\tau} \cdot \alpha_{x}, \\
& h_{t}^{n}=\bar{c}_{t-1}^{n} \cdot \alpha_{n},
\end{aligned}
$$

where $\bar{c}_{t}^{\tau}$ and $\bar{c}_{t}^{n}$ are overlined to denote that these refer to aggregate rather than individual quantities. Habit is thus externalized from the household's optimization problem. Note that $\alpha_{t}^{x}\left(\alpha_{t}^{n}\right)$ is the rate at which the consumption of tradables (non-tradables) grows so that $h_{t}^{\tau}=c_{t}^{\tau}\left(h_{t}^{n}=c_{t}^{n}\right)$ in the steady state.

The household's first-order conditions for the intratemporal choice between tradables and non-tradables are now:

$$
\begin{gathered}
P_{t}^{\tau} \frac{\left(c_{t}^{\tau}-\chi \cdot h_{t}^{\tau}\right)}{1-\chi}=\omega \cdot P_{t} c_{t} \\
P_{t}^{n} \frac{\left(c_{t}^{n}-\chi \cdot h_{t}^{n}\right)}{1-\chi}=(1-\omega) \cdot P_{t} c_{t}
\end{gathered}
$$

The household's total consumption expenditures now becomes:

$P_{t}^{\tau} c_{t}^{\tau}+P_{t}^{n} c_{t}^{n}=(1-\chi) \cdot P_{t} g_{t}+\chi \cdot\left(P_{t}^{\tau} h_{t}^{\tau}+P_{t}^{n} h_{t}^{n}\right)$ which can be substituted back into the budget constraint. 
The other first-order conditions remain unchanged except that we need to replace $C_{t}$ with Gt and take $\epsilon_{t}^{c d}$ into account:

$$
\begin{gathered}
1 / q_{t}=\lambda_{t} P_{t} \\
\beta \mathrm{E}_{t} \lambda_{t+1} \cdot \exp \left(\epsilon_{t+1}^{c d}-\epsilon_{t}^{c d}\right)=\lambda_{t} \cdot\left(1+i_{t}\right) .
\end{gathered}
$$

Note that the effect of habit disappears in the steady state or for $\chi=0$.

\section{Foreign Exchange Dealers}

There is an autonomous time-varying disparity in the first-order condition for the forex dealer (the UIP) assumed to be a stationary autoregressive process around $v$. This can arise due to various time-varying factors such as temporary changes in the riskiness of domestic assets, regional preferences of investors, capital controls, and so forth. The UIP becomes:

$$
\hat{l}_{t}-\hat{l}_{t}^{f}=\mathrm{E}_{t} \hat{s}_{t+1}+v \cdot \hat{b}+u_{t}
$$

with

$$
u_{t}=\rho_{u} u_{t-1}+\left(1-\rho_{u}\right) \hat{v}+\epsilon_{t}^{f x}
$$

where $\epsilon_{t}^{f x}$ is a transitory forex premium shifter.

\section{J. Frictions in Production}

\section{Costly price adjustments}

The price-setting behavior of monopolistically competitive firms in the tradable and nontradable sectors under flexible prices was described by a mark-up rule. In other words, firm $j$ 's profits were maximized when she posted the final price as a mark-up over her nominal marginal costs. Any deviations from this optimal rule were costly. We can approximate the firm's loss in real profits incurred by deviating from the mark-up rule up to second order as follows:

$$
-\frac{1}{2} \xi_{*} \cdot\left(\frac{p_{j t}-p_{j t}^{\star}}{P_{t}}\right)^{2} \approx-\frac{1}{2} \xi_{*} \cdot\left(\log p_{j t}-\log p_{j t}^{\star}\right)^{2}
$$

when $p_{j t}^{\star}$ denotes the flexible-price optimum given by the mark-up rule, and $\xi_{*}$ is the second derivative of profits with respect to the price, 


$$
\xi_{*}:=\frac{\mathrm{d}^{2} \mathbf{T}_{j t}}{\mathrm{~d}_{p_{j t}}{ }^{2}}
$$

To introduce price stickiness we furthermore assume that there is another source of costs for the firm, namely costs associated with the deviations of the firm's rate of price change relative to last period's aggregate inflation rate,

$$
\xi_{\Delta} \cdot\left(\Delta \log p_{j t}-\Delta \log P_{t-1}\right)^{2},
$$

where $\xi_{\Delta}$ is the weight of these costs in the firm's profits. These types of costs can be thought of as a reduced form for price optimization costs or reputation costs. The profit maximization problem becomes now intertemporal (dynamic) and can be expressed as:

$$
\min _{p_{j t}} \mathrm{E}_{t} \sum_{k=0}^{\infty} \beta^{k} \cdot\left[\xi \cdot\left(\log p_{j t+k}-\log p_{j t+k}^{\star}\right)^{2}+\left(\Delta \log p_{j t+k}-\Delta \log P_{t+k-1}\right)^{2}\right]
$$

where $\xi=\xi_{\star} / \xi_{\Delta}$. The first-order condition with respect to the current price (i.e., the Phillips curve) is:

$$
\begin{aligned}
& \Delta \log p_{j t}-\Delta \log P_{t-1}= \\
& \beta \cdot \mathrm{E}_{t}\left(\Delta \log p_{j t+1}-\Delta \log P_{t}\right)+\xi \cdot\left(\log p_{j t}^{*}-\log p_{j t}\right)+\epsilon_{t}^{p},
\end{aligned}
$$

where we have added a transitory inflation shifter $\epsilon_{t}^{t}$ to capture various types of shocks, such as shocks to marginal costs or mark-ups, expectation errors, etc. We assume these types of price adjustment costs to exist in both the tradable and non-tradable sectors, with sectorspecific parameters $\xi_{n}$ and $\xi_{\tau}$, and sector-specific shocks, $\epsilon_{t}^{p n}$ and $\epsilon_{t}^{p \tau}$.

Next, because all firms behave identically in the two sectors, $p_{j t}^{n}=P_{t}^{n}, \forall j \in[0,1]$, and $p_{j t}^{\tau}=P_{t}^{\tau}, \forall j \in[0,1]$, we can aggregate the sector-specific Phillips curves as follows:

$$
\begin{aligned}
& \Delta \log P_{t}^{n}-\Delta \log P_{t-1}^{n}= \\
& \beta \cdot \mathrm{E}_{t}\left(\Delta \log P_{t+1}^{n}-\Delta \log P_{t}^{n}\right)+\xi_{n} \cdot\left(\log P_{t}^{n *}-\log P_{t}\right)+\epsilon_{t}^{p n},
\end{aligned}
$$

and

$$
\begin{aligned}
& \Delta \log P_{t}^{\tau}-\Delta \log P_{t-1}^{\tau}= \\
& \beta \cdot \mathrm{E}_{t}\left(\Delta \log P_{t+1}^{\tau}-\Delta \log P_{t}^{\tau}\right)+\xi_{\tau} \cdot\left(\log P_{t}^{\tau \star}-\log P_{t}\right)+\epsilon_{t}^{p \tau} .
\end{aligned}
$$


Finally, the price adjustment costs only occur in consumption distribution sectors. The exporters, on the other hand, purchase their intermediate inputs from importers at a flexible price $P_{t}^{\tau \star}=\mu \cdot P_{t}^{m} / A_{t}^{\tau}$. This is taken into account in the next subsection.

\section{Costly output adjustments}

There is a similar mechanism in the export sector that makes the output, rather than price, adjustments costly. By an analogous reasoning as in the previous subsection we can derive the following first order condition of the rate of change in exports:

$$
\begin{aligned}
& \Delta \log X_{t}-\Delta \log X_{t-1}= \\
& \beta \cdot \mathrm{E}_{t}\left(\Delta \log X_{t+1}-\Delta \log X_{t}\right)+\xi_{x} \cdot\left(\log X_{t}^{\star}-\log X_{t}\right)+\epsilon_{t}^{x},
\end{aligned}
$$

where the flexible-output equilibrium, $X_{t}^{\star}$, follows from the frictionless first-order condition,

$$
X_{t}^{\star}=A_{t}^{x} \cdot\left(\gamma_{x} P_{t}^{x} / P_{t}^{\tau \star}\right)^{\gamma_{x} /\left(1-\gamma_{x}\right)}=A_{t}^{x} \cdot\left(\frac{\gamma_{x}}{\mu} A_{t}^{\tau} T_{t}\right)^{\gamma_{x} /\left(1-\gamma_{x}\right)},
$$

where $T_{t}=P_{t}^{x} / P_{t}^{m}=\mu \cdot P_{t}^{x} /\left(A_{t}^{\tau} P_{t}^{\tau \star}\right)$ is the terms of trade.

Finally, the parameter $\xi_{x}$ describes the importance of output adjustment costs relative to the costs of deviating from the flexible-output level, and $\epsilon_{t}^{x}$ is a transitory export shifter.

\section{K. Frictions in the Behavior of the Government}

First, we assume that the central banker considers, for various reasons, frequent or large policy rate movements as undesired, and prefers to smooth its trajectory to a certain extent. We therefore modify the monetary policy rule as follows:

$$
\hat{l}_{t}=\rho_{i} \hat{l}_{t-1}+\left(1-\rho_{i}\right)\left[\bar{l}+\kappa \cdot\left(\hat{P}_{t}-\pi\right)\right]+\epsilon_{t}^{m p},
$$

where $\rho_{i}$ controls the degree of policy rate smoothing, and $\epsilon_{t}^{m p}$ is a policy shock (a deviation from systematic behavior).

Second, we introduce a government consumption shifter $\epsilon_{t}^{g d}$ into the total spending rule,

$$
P_{t} g_{t}=\sigma \cdot P_{t} C_{t} \cdot \exp \epsilon_{t}^{g d} \text {. }
$$




\section{Processes for External Variables}

We allow for serial correlation in the terms of trade, foreign-currency import inflation, and the foreign interest rate, and for transitory shifters in the last two of them:

$$
\begin{gathered}
\hat{T}_{t}=\rho_{\text {tot }} \hat{T}_{t-1}+\epsilon_{t}^{\text {tot }}, \\
\hat{P}_{t}^{m f}=\rho_{p m f} \hat{P}_{t-1}^{m f}+\left(1-\rho_{p m f}\right) \pi_{m f}+\epsilon_{t}^{p m f}, \\
\hat{L}_{t}^{f}=\rho_{i f} \hat{l}_{t-1}^{f}+\left(1-\rho_{i f}\right) \bar{l}_{t}^{f}+\epsilon_{t}^{i f},
\end{gathered}
$$

Appendix Table 1: Steady-State Parameters

\begin{tabular}{clr}
\hline$\alpha_{n}$ & Non-tradable sector log-growth & 1.13 \\
$\alpha_{x}$ & Export sector log-growth & 6.11 \\
$\omega$ & Tradables share of consumption & 0.55 \\
& Intermediates share of non-tradables & 0.59 \\
$\gamma_{n}$ & production & 0.18 \\
$\gamma_{x}$ & Imports share of export production & 0.19 \\
$\sigma$ & Ratio of government to private consumption & 5.83 \\
$\pi$ & Ultimate log inflation target & 0.80 \\
$\pi_{m f}$ & Foreign-currency import price inflation & 17.06 \\
$\eta_{\mathrm{s}}$ & Systematic disparity & \\
\hline
\end{tabular}

Appendix Table 2: Behavioral Transitory Parameters

\begin{tabular}{clr}
\hline$\chi$ & Habit & 0.66 \\
$v$ & Debt elasticity of premium & 0.001 \\
$\xi_{\tau}$ & Tradable price elasticity & 0.28 \\
$\xi_{\mathrm{n}}$ & Non-tradable price elasticity & 0.10 \\
$\xi_{\mathrm{x}}$ & Export output elasticity & 0.05 \\
$\kappa_{\tau}$ & Policy reaction to tradable inflation & 0.55 \\
\multirow{2}{*}{$\kappa_{\mathrm{n}}$} & Policy reaction to non-tradable & 0.55 \\
\hline
\end{tabular}


Appendix Table 3: Autoregressive Coefficients

\begin{tabular}{llr}
\hline$\rho_{\mathrm{u}}$ & AR of forex premium & 0.66 \\
$\rho_{\mathrm{i}}$ & Policy rate smoothing & 0.31 \\
$\rho_{\text {targ }}$ & AR of inflation target & 0.993 \\
$\rho_{\text {tot }}$ & AR of terms of trade & 0.00 \\
$\rho_{\mathrm{if}}$ & AR of foreign interest rate & 0.91 \\
\multirow{2}{*}{$\rho_{\mathrm{pmf}}$} & AR of foreign-currency import & 0.06 \\
\hline
\end{tabular}

Appendix Table 4: Standard Errors of Shifters

\begin{tabular}{clr}
\hline$\varepsilon_{\mathrm{t}}^{\mathrm{cd}}$ & Consumption demand shifter & 1.10 \\
$\varepsilon_{\mathrm{t}}^{\mathrm{gd}}$ & Government consumption shifter & 7.97 \\
$\varepsilon_{\mathrm{t}}^{\mathrm{u}}$ & Forex premium shifter Tradable & 7.29 \\
$\varepsilon_{\mathrm{t}}^{a \tau}$ & technology shifter Tradable cost & 0.50 \\
$\varepsilon_{\mathrm{t}}^{\mathrm{p} \tau}$ & Shifter & 3.07 \\
$\varepsilon_{\mathrm{t}}^{a n}$ & Non-tradable technology shifter & 1.95 \\
$\varepsilon_{\mathrm{t}}^{\mathrm{pn}}$ & Non-tradable cost shifter & 0.83 \\
$\varepsilon_{\mathrm{t}}^{a x}$ & Export technology shifter & 2.00 \\
$\varepsilon_{\mathrm{t}}{ }^{x}$ & Transitory export output shifter & 5.70 \\
$\varepsilon_{\mathrm{t}}{ }^{\mathrm{m}}$ & Monetary policy shifter, PA & 11.91 \\
$\varepsilon_{t}^{\text {targ }}$ & Inflation target shifter & 6.28 \\
$\varepsilon_{t}^{\text {tot }}$ & Terms of trade shifter & 3.67 \\
$\varepsilon_{t}^{i f}$ & Foreign interest rate shifter, PA & 0.29 \\
$\varepsilon_{t}{ }^{p m f}$ & Foreign-currency import inflation & 3.94 \\
\hline
\end{tabular}

\section{Appendix Table 5: Steady-State}

Characteristics of the Model

Real consumption log-growth

Real export log-growth

6.11

Non-tradable vs. tradable inflation differential $\quad 4.98$

Government consumption to private

consumption

0.19

Exports to private consumption

0.38

Imports to private consumption

0.38

Intermediates share of model GDP

0.20

Re-exports share of model GDP

0.06 